\title{
Inequality and Economic Growth
}

\author{
A thesis submitted for the degree \\ of Doctor of Philosophy of \\ The Australian National University
}

Akihito Asano

February 2001 


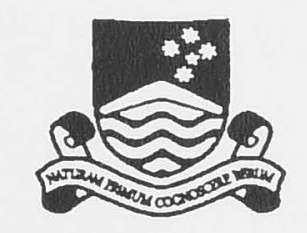

THE AUSTRALIAN

NATIONAL UNIVERSITY

This thesis is author's original work, except where due reference is made in the text.

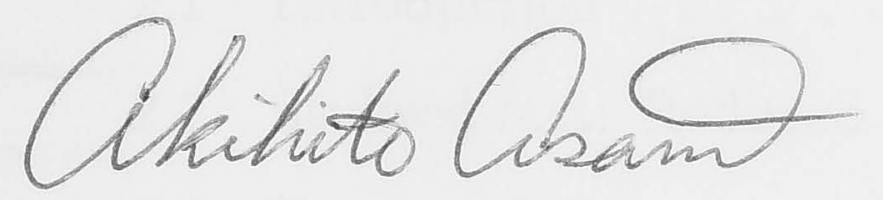

Akihito Asano

School of Economics

Faculty of Economics and Commerce

February 2001 


\section{Contents}

Abstract $\quad$ ix

Acknowledgements $\quad$ xi

1 Introduction 1

1.1 Inequality and economic growth ................ 1

1.2 Why bother? ... . . . . . . . . . . . . . 2

1.3 A brief review of the literature . . . . . . . . . . 3

1.4 How might inequality affect growth? . . . . . . . . . . . 5

1.5 The structure of the thesis . . . . . . . . . . . . 7

2 A review of the literature $\quad 9$

2.1 Introduction . . . . . . . . . . . . . . . . . 9

2.2 Stylised fact: Reduced form studies . . . . . . . . . . . . 10

2.3 Four mechanisms . . . . . . . . . . . . . . . . . . 12

2.3.1 The endogenous fiscal policy approach: Theory . . . . . 14

2.3.2 The endogenous fiscal policy approach: Evidence . . . . 16

2.3.3 The endogenous fiscal policy approach: Discussion . . . . . 18

2.3.4 The sociopolitical instability approach: Theory . . . . . 19

2.3.5 The sociopolitical instability approach: Evidence . . . . 28

2.3.6 The sociopolitical instability approach: Discussion . . . . 30

2.3.7 The human capital and borrowing constraint approach: Theory 32 
2.3.8 The human capital and borrowing constraint approach: Evidence............................ 37

2.3.9 The human capital and borrowing constraint approach: Dis-

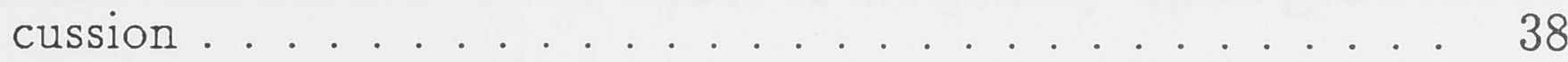

2.3.10 The endogenous fertility approach: Theory . . . . . . . 39

2.3.11 The endogenous fertility approach: Evidence . . . . . . . . 42

2.3.12 The endogenous fertility approach: Discussion . . . . . . 45

2.4 Concluding remarks: Contribution to the literature . . . . . . . 46

3 Endogenising fertility 49

3.1 Introduction . . . . . . . . . . . . . . . . . 49

3.2 The model . . . . . . . . . . . . . . . . . . . . . 49

3.3 The dynamics of disposable income distribution . . . . . . . . . 54

3.4 Growth in transition ................. 57

3.5 Concluding remarks . . . . . . . . . . . . . . . 62

4 Education, fertility, and growth: Does inequality matter? 64

4.1 Introduction . . . . . . . . . . . . . . . . 64

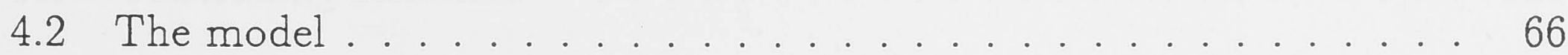

4.3 The dynamics of the economy ................ 73

4.3 .1 Case I . . . . . . . . . . . . . . . . 74

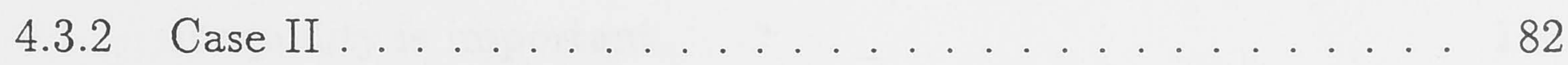

4.3.3 Demographic transition . . . . . . . . . . . . 84

4.4 Inequality: Does it matter? . . . . . . . . . . . . . . 85

4.4.1 Before the productivity take-off ... . . . . . . . 86

4.4.2 After the productivity take-off . . . . . . . . . . . . 89

4.5 Simulations: Inequality matters . . . . . . . . . . . . 91

4.5.1 Advanced economies . . . . . . . . . . . . . . 99 92

4.5.2 Middle-income economies ............... 95

4.5.3 Developing economies . . . . . . . . . . . . . 99 96 
4.5 .4 Inequality matters . . . . . . . . . . . . . 98

4.6 Concluding remarks . . . . . . . . . . . . . . . . . . . . 99

5 The non-monotonic nature of the effect of inequality upon growth 101

5.1 Introduction . . . . . . . . . . . . . . . . . . . . 101

5.2 Conjectures and the empirical model . . . . . . . . . . 103

5.3 Description of data . . . . . . . . . . . . . 107

5.3.1 Measure of inequality . . . . . . . . . . . . 108

5.3.2 Quality of this data set ............... 108

5.3.3 Characteristics of this data set ........... 109

5.3.4 Compiling the initial Gini coefficient . . . . . . . . 110

5.3 .5 Other variables ......................... 111

5.4 The estimation results . . . . . . . . . . . . . . . . 112

5.4.1 The non-monotonic effects of inequality upon growth . . . 112

5.4 .2 Is the effect of inequality significant? . . . . . . . . . 114

5.4 .3 Model testing ... . . . . . . . . . . 117

5.4.4 Sensitivity of the results . . . . . . . . . . . . 121

5.5 Concluding Remarks . . . . . . . . . . . . . . . 125

6 Conclusion $\quad 126$

6.1 Summary of our findings . . . . . . . . . . . . . 126

6.1 .1 Inequality is important . . . . . . . . . . . 126

6.1.2 Challenging the common agreement. . . . . . . 126

6.1.3 Theoretical contribution ............... 127

6.1.4 Empirical findings and contribution . . . . . . . . . . 129

6.2 Further research directions . . . . . . . . . . . . . . 130

$\begin{array}{ll}\text { Bibliography } & 133\end{array}$ 


\section{List of Figures}

2.1 Well protected property rights (Murphy et al., 1993) . . . . . . 21

2.2 Poorly protected property rights (Murphy et al., 1993) . . . . . 22

2.3 Intermediate case (Murphy et al., 1993) . . . . . . . . . . . 24

2.4 Dynamics of inheritance (Galor and Zeira, 1993) . . . . . . . . 35

2.5 Dynamics of bequest per child (Galor and Zang, 1997) . . . . . . . 41

3.1 Dynamics of disposable income . . . . . . . . . . . . . 55

4.1 Evolution of human capital: Case I . . . . . . . . . . . . 75

4.2 Growth rate of individual output . . . . . . . . . . . . 77

4.3 Number of children . . . . . . . . . . . . . . . 77

4.4 Investment in education . . . . . . . . . . . . . . . 78

4.5 Working time . . . . . . . . . . . . . . . 79

4.6 Growth rate of output per capita . . . . . . . . . . . 80

4.7 Evolution of human capital: Case II . . . . . . . . . . . 82

4.8 Extreme-poor and super-rich . . . . . . . . . . . 88

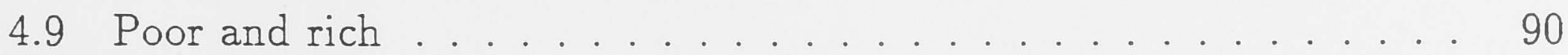

4.10 Growth rates of output per worker: Advanced economies . . . . . . 93

4.11 The coefficient of variation: Advanced economies . . . . . . . . . 94

4.12 Growth rates of output per worker: Middle-income economies . . . 95

4.13 The coefficient of variation: Middle-income economies . . . . . . . 96

4.14 Growth rates of output per worker: Developing economies . . . . 97

4.15 The coefficient of variation: Developing economies . . . . . . . . . 98 
5.1 The predicted effects of a fall in inequality upon growth for each country 


\section{List of Tables}

2.1 Reduced form regressions . . . . . . . . . . . . . . . . . 10

2.2 Persson and Tabellini (1994) . . . . . . . . . . 17

2.3 Perotti (1996): The endogenous fiscal policy approach . . . . . . 18

2.4 Alesina and Perotti (1996) . . . . . . . . . . . 29

2.5 Perotti (1996): The sociopolitical instability approach . . . . . . 30

2.6 Perotti (1996): The human capital and borrowing constraint approach 37

2.7 Galor and Zang (1997) . . . . . . . . . . . . . . 43

2.8 Perotti (1996): The endogenous fertility approach . . . . . . . . 44

5.1 Descriptive statistics for all countries ............. 111

5.2 The relevant descriptive statistics for 57 countries . . . . . . . . 112

5.3 The Gini coefficient for 57 countries . . . . . . . . . . . . . . 113

5.4 Estimation results . . . . . . . . . . . . . . . . . 114

5.5 Effects of a one standard deviation increase in GIN $I_{65}$ upon $g_{65-90}$ for different groups of economies . . . . . . . . . . . . 115

5.6 Estimation results (continued) . . . . . . . . . . 118

5.7 Estimation results (continued) . . . . . . . . . . 121

5.8 Estimation results (continued) . . . . . . . . . . 123

5.9 Effects of a one standard deviation increase in GINI $I_{65}$ upon $g_{65-90}$ for different specifications using a 57 country sample . . . . . . . 124 


\section{Abstract}

This thesis investigates the effects of initial inequality upon subsequent economic growth through human capital accumulation and endogenous fertility. The theoretical implication that inequality has a non-monotonic effect upon growth, as opposed to a seemingly common agreement that it has a negative effect upon growth, has been empirically supported.

The thesis comprises six chapters. Chapter 1 motivates the study of inequality and economic growth. Chapter 2 reviews both the theoretical and the empirical literature in this area, and discusses several channels whereby inequality might affect growth. Amongst those, accumulation of human capital will be the focus for the rest of the thesis. In addition, fertility plays an important role since it is endogenously determined with investment in human capital. As a result, this thesis deals simultaneously with inequality, human capital accumulation, endogenous fertility, and growth, whilst existing studies deal with only subsets of these.

Chapter 3 incorporates endogenous fertility into the model of the benchmark study in this area by Galor and Zeira (Review of Economic Studies, 1993), which looks at the relationship between inequality and growth via human capital accumulation. This extended model predicts a negative relationship between initial inequality and subsequent growth, but two problems arise. One is that the problematic definition of inequality in Galor and Zeira (1993) is still used, and the other is that the model consistently generates negative growth.

Chapter 4 attempts to overcome these problems. We give a different interpretation to the model by Ehrlich and Lui (Journal of Political Economy, 1991), which 
deals with endogenous fertility, human capital accumulation, and growth. Whilst they look at a country as a whole, we focus upon a number of heterogeneous individuals within a country, in order to incorporate inequality. This model predicts that growth is negatively correlated with fertility but positively correlated with the stock of human capital, which conforms to the stylised facts. The inequality effect upon growth is illustrated using numerical simulation, and it predicts that the effect may not be monotonic, i.e., it depends upon an economy's stage of development. Economies are classified into two types, one where the long run growth rate is positive, and the other where it is zero. In the former type of economy, inequality is likely to impede subsequent growth, but in the latter, inequality may not have any significant effect upon growth.

Chapter 5 presents an empirical test of this conjecture. The conjecture that the effect of inequality upon growth is non-monotonic appears to be supported. For either advanced or developing economies, inequality appears to have sizable effects upon growth, although the direction of the effect appears to be different inequality impedes growth for the former but enhances growth for the latter. In contrast, for medium-income economies, the effects appear to be trivial. 


\section{Acknowledgements}

I would like to thank Professor Steve Dowrick for his encouraging supervision throughout my $\mathrm{PhD}$. Steve's positive attitude towards my work has always saved me whenever I was stuck, especially when I was hospitalised with a perforated peptic ulcer. A number of ideas in this thesis have stemmed from constructive discussion with him. I would also like to thank my advisors, Robert Breunig and Neil Vousden. Empirical analysis in this thesis has greatly improved due to Bob's criticism. Neil's comments on theoretical chapters have been always encouraging.

Special thanks are due to two of my colleagues in our School, Guy Bruten and Takaharu Eto. Not only did Guy give me many useful comments but he also provided me with an extensive grammar check for Chapter 4. I was very lucky that he was my next door neighbour. Taka and I went through ANU's economics coursework together. Whenever I came up with new ideas about my thesis, he was the first person with whom I had discussion, which was always fruitful.

Some of the chapters of this thesis were presented in conferences (The 5th Macroeconomics Workshop at the University of Queensland and the PhD Conference at the Australian National University) and seminars (Economics Seminar at the University of Melbourne and various seminar series at the Australian National University) and I greatly benefitted from many useful comments on them. Aside from the people I have already acknowledged, I would particularly like to thank the following people in this respect: Trevor Breusch, Richard Dennis, Simon Grant, Geoffrey Kingston, Vladimir Pavlov, Ben Smith, Kam Ki Tang, Graeme Wells, and Dominic Wilson. Buly Cardak and Daiji Kawaguchi thoroughly read Chapter 4 
and gave me constructive comments.

My economic intuition has been improved greatly through my tutoring experience at the Australian National University, which made my understanding in economics much better. I would like to thank Chris Jones, Jeff Kline, and Rod Tyers, lecturers for whom I worked, fellow tutors, in particular Scott Austin and Kris Funston, and my students who survived my tutorials.

Financial support by Josuikai (Hitotsubashi University, Japan) and the Rotary Foundation is acknowledged.

Last, but not least, I would like to thank my parents and my sister for their tolerance and continuous support throughout my $\mathrm{PhD}$. 


\section{Chapter 1}

\section{Introduction}

\subsection{Inequality and economic growth}

This thesis investigates a relationship between initial income inequality and subsequent economic growth. ${ }^{1}$ We particularly focus upon investment in human capital and the rate of fertility as the economic factors through which inequality might affect growth.

This introductory chapter emphasises the importance of pursuing this question. We also briefly review the relevant debate and explain the distinguishing features of this thesis. The outline of the rest of this thesis will be provided at the end of

\footnotetext{
1 "Growth" is a little tricky economic term. Especially, we need to be careful distinguishing between growth in the short run and growth in the long run. In empirical studies, "short run" usually implies a time period around 5 years and "long run" means a time period around 20-30 years. However, when theoretical analysis is concerned, we tend to consider "short run" as time periods when an economy is on the transitional path and "long run" as where an economy is in the steady state or on the balanced growth path. In this thesis, in the empirical sense, we will focus upon investigating a relationship between initial income inequality and long run growth. However, in the theoretical respect, our focus will be on the short run, as we look at growth between two consecutive periods during transition. These are consistent as our main theoretical modelling in Chapter 4, where we employ a three-period overlapping generations (OLG) framework, growth between two consecutive periods implies growth in 25 years, which is long run growth in the empirical sense.
} 
this chapter.

\subsection{Why bother?}

Why should we bother pursuing this question? If inequality had nothing to do with growth, there would not be much point pursuing it. Even if it had anything to do with growth, if the effect of it upon growth were trivial, investigating this topic might not be that interesting.

For a number of developing countries, understanding what fosters economic growth has been a very important and serious issue. According to the World Bank's World Development Report (1997), the population of the world in 1995 was over 5.6 billion and 56 per cent of the population resided in "low-income economies," whose GNP was only about 5 per cent of the world's GNP. Over 80 per cent of the world's GNP belonged to "high-income economies," where only about 16 per cent of the world population resides. There is dispute regarding the measurement of income disparities across the countries, ${ }^{2}$ but it is beyond all dispute that the income disparities are still huge and that the disparities are increasing in the case of most Sub-Saharan economies relative to the OECD economies. ${ }^{3}$

Hence, if differences in initial inequality across economies can cause substantial differences in the subsequent growth rate of output per worker, then it would be worthwhile to investigate the relationship. This thesis confirms the findings of the

\footnotetext{
${ }^{2}$ It is noted in many papers that these figures calculated by the official exchange rates tend to underestimate GNP of "low-income economies." For example, Dowrick and Bruten (2000) report that the ratio for US/Mali GDP per capita in 1980 is 58 using the exchange rate, but is 31 using the Penn World Table estimates of PPP-adjusted GDP per capita. Various methods have been proposed to measure the true GDP (Dowrick and Quiggin, 1994, 1997, Dowrick and Bruten, 2000), and Dowrick and Bruten (2000) find that the true ratio for US/Mali GDP per capita in 1980 lies between 52 and 55.

${ }^{3}$ See, for example, Easterly and Levine (1997) regarding the miserable experience of SubSaharan African countries.
} 
existing empirical literature that the effect of inequality upon growth is non-trivial, ${ }^{4}$ but it proposes a different economic relationship that has important implications for the direction of the effect.

Reducing income inequality has been one of the important issues, especially in developing countries. Although it is controversial, ${ }^{5}$ avoiding inequality is often justified on ethical grounds. If we knew inequality would have negative impact upon growth, policies that might reduce inequality, such as an implementation of redistributive income tax, might not only be justified on ethical grounds but they might also be justified on economic grounds.

Unsurprisingly, there has been long debate on the relationship between inequality and growth. Let us briefly review the relevant literature.

\subsection{A brief review of the literature}

Conventionally, income inequality was thought to have a positive impact upon economic growth. ${ }^{6}$ This view is due to Kaldor (1961), Stiglitz (1969), and Bourguignon (1981). Kaldor (1961) postulates that the marginal propensity to save is higher for the rich than for the poor. An immediate conjecture that follows this, bearing in mind the Swan-Solow growth model, is that a more unequal economy reaches a higher steady state income level than a more equal economy does because its saving

\footnotetext{
${ }^{4}$ This is not true for all economies. We have to wait until Chapters 4 and 5 in order to further discuss this issue.

${ }^{5}$ For example, see Ray (1998) for discussion.

${ }^{6}$ The focus of this thesis will be the effect of inequality upon growth. Closely related and probably more commonly known issue to this, is the effect of economic development upon inequality, initiated by Kuznets (1955). Kuznets (1955) conjectures that economic development is necessarily accompanied by an increase in inequality since only rich people can obtain benefit from it, but then after a while inequality will decline when eventually poor people catch up. This is known as the inverted- $U$ hypothesis because a plot of income on the horizontal axis and the Gini coefficient on the vertical axis will look like an upside-down $U$. This inverted-U hypothesis has been challenged by a number of studies such as Anand and Kanbur (1993) since the mid-70s.
} 
rate tends to be higher. Stiglitz (1969) shows, using a linear saving function, that the aggregate capital accumulation behaviour, which determines the growth rate of aggregate output (in transition), is independent of the distribution of wealth. Bourguignon (1981), then, extends this analysis using a convex saving function, and predicts under this situation that the growth rate of aggregate output (in transition) is dependent upon the distribution of wealth, and that a more unequal economy will reach a higher steady state income level. If output is a linear function of capital, ${ }^{7}$ the long run growth rate will be higher for a more unequal economy.

In the 1990s, this conventional view has been challenged by a number of theoretical and empirical studies. ${ }^{8}$ On one hand, a number of empirical studies have provided evidence that inequality has a negative impact upon growth (Alesina and Rodrik, 1994, Benhabib and Spiegel, 1994, Birdsall et al., 1995 Clarke, 1995, Perotti, 1996, Persson and Tabellini, 1992a, 1992b, 1994). One the other hand, in order to account for this empirical evidence, many theoretical studies have formally shown that inequality might impede growth through various economic factors (Alesina and Rodrik, 1994, Acemoglu, 1995, Bénabou, 1996c, Benhabib and Rustichini, 1996, Bertola, 1993, Galor and Zeira, 1993, Galor and Zang, 1997, Grossman and Kim, 1996, Persson and Tabellini, 1994). "Inequality is harmful to growth" appears to have become a common agreement.

More recently, some empirical studies (Barro, 2000, Forbes, 2000, Li and Zou, 1998), using a panel data estimation technique, have found new evidence that inequality fosters subsequent growth in the short run, or that inequality affects short run growth in a non-monotonic manner. ${ }^{9}$ Deininger and Squire (1998) find that

\footnotetext{
${ }^{7}$ In this case, the economy will be approaching the balanced growth path in the long run instead of approaching the steady state.

${ }^{8} \mathrm{~A}$ more comprehensive review of the literature of this strand will be provided in the next chapter, as this study is complementary to it.

${ }^{9}$ The reason that we highlight "short run" here is because in their estimation, the dependent variable is the average annual growth rate of GDP per capita over 5 (or 10) year periods. This thesis and other empirical studies that have been mentioned look at growth in the long run, say
} 
inequality has significant effect upon long run growth only in the non-democratic countries. Alongside of these studies, this thesis questions the common agreement and emphasises the non-monotonic nature of the effect of inequality upon growth.

\subsection{How might inequality affect growth?}

We have briefly talked about both qualitative and quantitative effects of inequality upon growth so far, but let us now consider the possible mechanisms by which inequality might affect growth. A major drawback of many recent empirical studies in this area is the ad hoc nature of the econometric model. That is, most of them are estimating a typical reduced form equation, where growth is just regressed on economic factors including inequality. Although those studies have detected a negative relationship between inequality and growth, they have not been able to tell how the former might affect the latter.

Inequality per se does not have direct impact upon economic growth, but it affects growth through other economic factors. According to Temple (1999), there are three proximate sources of economic growth, namely, investment in physical capital, investment in human capital, and research and development. Inequality is included in underlying sources of economic growth, which affect economic growth directly through change in total factor productivity or indirectly through the above three sources. Aside from inequality, other underlying sources of economic growth include population growth, trade, financial development, macroeconomic stability, government size, government spending on infrastructure, and social and political factors.

This thesis particularly looks at investment in human capital as the proximate source of growth, i.e., we conjecture that inequality affects growth via its effects upon investment in human capital. Galor and Zeira (1993) is the pioneer study of this strand whose model will be reviewed in detail in the next chapter.

over 25 years (see footnote 1 ). 
What makes our study different from theirs is that, this thesis will also focus upon the rate of fertility, which is obviously strongly related to one of the other sources of economic growth, population growth. Therefore, in this thesis, we postulate that inequality might affect economic growth through both investment in education and fertility. A strong prior belief that we have behind this, is that investment in human capital and the number of children, hence fertility, are jointly determined by parents. This approach, which we refer to as the endogenous fertility approach hereafter, is originally taken by Becker (1960) and has been used in some of the recent endogenous growth literature, such as Becker et al. (1990) and Ehrlich and Lui (1991). These studies adopt a representative agent framework so there is no room for discussing inequality.

The principal theoretical contribution of this thesis to the literature is that it deals simultaneously with inequality, investment in human capital, fertility, and growth, where the existing literature deals simultaneously with only subsets of these. More specifically, our model in Chapter 3 incorporates endogenous fertility into a benchmark model by Galor and Zeira (1993), and in Chapter 4 we incorporate inequality into a model by Ehrlich and Lui (1991).

This theoretical modelling enables us to overcome the drawback of a typical reduced form regression. Our econometric model in Chapter 5, which is a system of equations, is based upon theoretical implications from Chapter 4. Whilst we cannot interpret the coefficient on inequality variable in the reduced form regression, the empirical analysis in this thesis allows us to interpret the effect of inequality upon growth more clearly. Therefore, our empirical contribution is twofold. First, we question the common agreement that inequality impedes growth in all cases, emphasising the non-monotonic nature of the effect of inequality upon growth. Second, our structural econometric model enables us to interpret the effect of inequality upon growth much more clearly than typical ad hoc estimation in existing studies. 


\subsection{The structure of the thesis}

The rest of this thesis is structured as follows. Chapter 2 reviews both the theoretical and the empirical literature. A number of empirical studies that identify negative relationship between initial inequality and growth will be introduced and we emphasise that inequality has a sizable effect upon growth. Several underlying mechanisms that could possibly back up the empirical evidence are reviewed and discussed. By the end of this chapter, it will become clearer how this thesis fits into the existing literature and what our contribution to it is.

Chapter 3 incorporates endogenous fertility into the model of the benchmark study by Galor and Zeira (1993), which looks at the relationship between inequality and growth via human capital accumulation. This extended model predicts a negative relationship between initial inequality and subsequent growth, but two problems arise. One is that the problematic definition of inequality in Galor and Zeira (1993) is still used, and the other is that the model consistently generates negative growth.

Chapter 4 attempts to overcome these problems. We give a different interpretation to the model by Ehrlich and Lui (1991), which deals with endogenous fertility, human capital accumulation, and growth. Whilst they look at a country as a whole, we focus upon a number of heterogeneous individuals within a country, in order to incorporate inequality. This model predicts that growth is negatively correlated with fertility but positively correlated with the stock of human capital, which conforms to the stylised facts. The inequality effect upon growth is illustrated using numerical simulation, and it predicts that the effect may not be monotonic, i.e., it depends upon an economy's demographic stage of development.

In the chapter, economies are classified into two types - one that has begun the demographic transition, and the other that has not. By beginning the demographic transition, we mean that individuals have become to choose to have less numbers of children, so that the growth rate of population in an economy declines and approaches zero. We will show that if an economy has begun the demographic 
transition, the growth rate of output per capita will be positive in the long run. We will also show that, in contrast, if an economy has not begun the demographic transition, it will stagnate. Our simulation predicts that, in the former type of economy, inequality is likely to impede growth, but in the latter, inequality may not have any significant effect upon growth.

Chapter 5 presents an empirical test of this conjecture. The conjecture that the effect of inequality upon growth is non-monotonic appears to be supported. For either advanced or developing economies, inequality appears to have sizable effects upon growth, although the direction of the effect appears to be different inequality impedes growth for the former but enhances growth for the latter. In contrast, for medium-income economies, the effects appear to be trivial.

This thesis is concluded by Chapter 6 where we summarise the thesis and suggest possible further research directions. 


\section{Chapter 2}

\section{A review of the literature}

\subsection{Introduction}

In this chapter, we review both the theoretical and the empirical literature that has analysed the effect of inequality upon growth. Our focus is the literature that has recently challenged the conventional view that inequality is good for growth.

The plan of this chapter is as follows. Section 2.2 reviews empirical studies that estimate a typical reduced form growth equation. We emphasise that most of these studies have found a negative relationship between inequality and growth, and that the effect of inequality upon growth is non-trivial.

As we emphasised in Chapter 1, reduced form studies cannot tell what underlies - how inequality might affect growth. Section 2.3 reviews theoretical studies that have attempted to explain it, as well as empirical studies that have attempted to support these theoretical studies.

It will become clear in Section 2.4 how this thesis fits into the existing literature and what our contribution to it is. 


\subsection{Stylised fact: Reduced form studies}

A number of empirical growth studies that include a certain measure of inequality on the RHS of a growth regression have been conducted (Alesina and Rodrik, 1994, Benhabib and Spiegel, 1994, Birdsall et al., 1995, Clarke, 1995, Deininger and Squire, 1998, Perotti, 1994, 1996, Persson and Tabellini, 1992a, 1992b, 1994).

Table 2.1 summarises the main results of these studies.

Table 2.1: Reduced form regressions

\begin{tabular}{lllcl}
\hline \hline Author(s) (year) & $\begin{array}{l}\text { LHS } \\
\text { variable }\end{array}$ & $\begin{array}{l}\text { Inequality } \\
\text { index }^{c}\end{array}$ & $\begin{array}{l}\text { Sign of the } \\
\text { coefficient }^{d}\end{array}$ & 2LHS/2SD \\
\hline Alesina and Rodrik (1994) & gdp & Gini & - & NA \\
Benhabib and Spiegel (1994) & gdp or GDP & - MID & $(-)$ & NA \\
Birdsall et al. (1995) & $g d p$ & $1-$ MID & - & 0.32 \\
Clarke (1995) & $g d p$ & various & - & 2.5 (2SLS) \\
Deininger and Squire (1998) & $g d p$ & Gini & - & 0.5 \\
Perotti (1994) & INV & - ID & - & NA \\
Perotti (1996) & $g d p$ & - MID & - & 0.6 \\
Persson and Tabellini (1992a) & $g d p$ & $-M I D D L E$ & - & at least 0.5 \\
\hline
\end{tabular}

${ }^{a} \partial \mathrm{LHS} / \partial \mathrm{SD}$ shows a percentage point increase of the LHS variable if inequality is reduced by one standard deviation. Clarke (1995) also calculates it based upon his OLS result, which is 1.3 percentage points.

${ }^{b} g d p$ : the average annual growth rate of GDP per capita over the sample period; GDP: the average annual growth rate of GDP over the sample period; INV: the average of the ratio of investment to GDP over the sample period.

${ }^{c}$ Gini: Gini Coefficient; MID: the share of the third and fourth quintiles of distribution, ID: the share of two bottom quintiles of the distribution; MIDDLE: the share of the third quintile of the distribution; various: Clarke (1995) uses various measures of inequality. Correlation amongst these measures are high, and the regression is found to be robust against the choice of the inequality measure. Gini coefficient based upon land rather than income is used in Deininger and Squire (1998).

${ }^{d} \mathrm{~A}$ sign in brackets means the estimated coefficient of the inequality measure is insignificant. Aside from Birdsall, et al. (1995), estimates are significant at at least 5 per cent level.

Most of these studies show a negative and statistically significant correlation between inequality and economic growth. The magnitude of the effect of inequality upon growth differs between one another: A one standard deviation decrease in a measure of inequality raises the annual growth rate of GDP per capita by $0.32-2.5$ 
percentage point. ${ }^{1}$

Two question have to be asked. First, is this effect significant? In other words, is the magnitude of the effect huge enough to call our attention? Second, regardless of the significance of the effect, what is the mechanism underlying it? That is, how might inequality affect growth?

A common way to analyse the effect of inequality upon growth is to see what happens if a measure of inequality changes by one standard deviation. Let us use Birdsall et al. (1995) as an example. A one standard deviation decrease in inequality leads to a 0.32 percentage point increase in the growth rate of GDP per capita. Considering that the standard deviation of the growth rate of GDP per capita is about 0.02 , we can regard that this effect is sizable. If we compare two economies that are identical but for initial income distribution by one standard deviation, GDP per capita will be 8.2 per cent higher after 25 years in an economy with the lower inequality of initial income distribution.

Having checked the importance of the effect of inequality upon growth, our interest now is to consider the underlying mechanism by which inequality affects growth. One obvious drawback of the standard growth regression using the reduced form, i.e., regressing the growth rate of GDP per capita on various economic variables including a measure of inequality, is that it is unable to tell the underlying mechanism. Given this, in the 1990s, some economists have attempted to construct theoretical models in order to back up these empirical results. In addition, some empirical studies using the structural form have been conducted to test these theoretical models.

\footnotetext{
${ }^{1}$ Recently, empirical studies by Forbes (2000) and Li and Zou (1998) have shown that inequality fosters growth. These studies use panel data and the average annual growth rate over 5 years is used for the dependent variable. Hence, they are looking at growth in the short run, whereas our focus is growth in the long run.
} 


\subsection{Four mechanisms}

Many studies that explore the mechanism by which inequality might affect growth have been conducted. Let us classify the theoretical studies we review into four approaches according to Perotti (1996). ${ }^{2}$

In the first approach, which we call the endogenous fiscal policy approach (Alesina and Rodrik, 1994, Bertola, 1993, Persson and Tabellini, 1994), income distribution affects economic growth via its effect upon government expenditure and taxation. In the models of this approach, the level of taxation and expenditure are determined by a vote. Since the level of taxation and expenditure preferred by an agent are inversely related to her income, if the crucial voter, the median voter, has less income than the mean income, government taxation will be strengthened. If we consider the ratio of the median voter's income to the mean as the measure of equality, applying the theory of endogenous policy, we can say that redistributive government expenditure and therefore distortionary taxation decrease as equality increases (political mechanism). In turn, government expenditure and taxation are negatively correlated to economic growth as agents lose their incentives to save and invest under high taxation (economic mechanism). As a result, economic growth increases as equality increases.

In the second approach (Acemoglu,1995, Benhabib and Rustichini, 1996, Grossman, 1991, 1994, Grossman and Kim, 1996, Murphy et al., 1993, Tornell and Velasco, 1992), income distribution affects economic growth via its effect upon sociopolitical instability. In more unequal societies, agents are more likely to be involved in rent seeking activities or other manifestations of sociopolitical instability, violent protests, assassinations, etc. In turn, sociopolitical instability harms growth through uncertainty and an adverse effect upon productivity due to disruption in market activities. As a consequence, economic growth increases as equality increases.

\footnotetext{
${ }^{2}$ Bénabou (1996c) is also a survey paper on this topic. But this paper does not cover the fourth approach.
} 
In the third approach (Aghion and Bolton, 1997, Banerjee and Newman, 1993, Bénabou, 1993, 1996a, 1996b, Durlauf, 1994, Fernandez and Rogerson, 1996, Galor and Zeira, 1993, Perotti, 1993, Piketty, 1997, Saint-Paul and Verdier, 1997), income distribution affects economic growth via its effect upon investment in human capital. This type of model is meaningful when agents are not able to borrow freely against future income, i.e., when market imperfections are present in the capital market. Under this situation, initial income distribution matters as it affects the number of agents who can invest in human capital. The model generally concludes that, if wealth is distributed more equally, more agents are able to invest in human capital. Since economic growth is assumed to increase as investment in human capital increases, we obtain the same conclusion as above: economic growth increases as equality increases.

The fourth approach, which we call the endogenous fertility approach, takes fertility into account (Barro and Becker, 1989, Becker and Barro, 1988, Becker et al., 1990, Galor and Zang, 1997, Kelley, 1988, Perotti, 1996). In this approach, fertility and schooling decisions are made jointly, as they are interpreted as two alternative uses of parents' human capital. That is, fertility determines the parents' quantity of immediate descendants and schooling determines their quality. This model concludes that fertility decreases and investment in human capital increases as equality increases. Since growth is assumed to be negatively related to fertility and positively related to investment in human capital, the overall conclusion is the same as above: economic growth increases as equality increases.

We review theoretical studies for each of these four approaches in turn. ${ }^{3}$ We also review some empirical studies that have attempted to support these theoretical studies.

\footnotetext{
${ }^{3}$ The first two approaches are not the focus of this thesis but it is important to be aware of every possible channel through which inequality might affect growth.
} 


\subsubsection{The endogenous fiscal policy approach: Theory}

Here, we briefly review the model by Persson and Tabellini (1994). In their overlapping generations (OLG) model, agents have same preferences but have different incomes. The $i$ th individual born in period $t-1$, indexed by $t$, maximises her utility $v_{t}^{i}$

$$
v_{t}^{i}=U\left(c_{t-1}^{i}, d_{t}^{i}\right)
$$

subject to the budget constraints:

$$
\begin{array}{r}
c_{t-1}^{i}+k_{t}^{i}=y_{t-1}^{i}, \\
d_{t}^{i}=r\left[\left(1-\theta_{t}\right) k_{t}^{i}+\theta_{t} k_{t}\right]
\end{array}
$$

where, $c$ is the consumption when young and $d$ is the consumption when old. The utility function is concave, well-behaved, and homothetic. $k$ and $k^{i}$ are the average and individual stock of an asset, respectively, and the asset yields exogenous return of $r$. $\theta$ is a redistributive policy variable. Equation (2.3) shows that the redistributive policy takes from individuals who accumulated the asset more than average and gives to those who accumulated less than average.

Next, the income when young is defined as:

$$
y_{t-1}^{i}=\left(w+e^{i}\right) k_{t-1}
$$

where $w$ is an average endowment of skills which is given exogenously, and $e$ is an individual specific endowment of skills, which is also given exogenously, with zero mean and nonpositive median.

This model assumes that there is one-period ahead commitment of policy, i.e., voters choose $\theta$ before investors choose $k$. A politico-economic equilibrium is defined as a policy and a set of private economic decisions such that: 
1. The economic decisions of all citizens are optimal, given the policy, and all markets clear (economic equilibrium).

2. The policy cannot be defeated by any alternative in a majority vote amongst the citizens who have their right to vote (political equilibrium).

The economic equilibrium is obtained by solving a utility maximisation problem. It deduces that the growth rate of income $\left(g_{t}\right)$ is a function of $\theta$ and the other variables as in Equation (2.5):

$$
g_{t}=G\left(w, r, \theta_{t}\right)=w D\left(r, \theta_{t}\right) /\left[r+D\left(r, \theta_{t}\right)\right]-1
$$

where $D\left(r, \theta_{t}\right)=d_{t}^{i} / c_{t-1}^{i}$. It can be shown that $G_{w}>0$ and $G_{\theta}<0$. This implies the higher the average skills are, the higher the growth rate is, and more importantly, the less $\theta$ is, the higher the growth rate is.

Regarding the political equilibrium, we first deduce the following equation using Equation (2.2), Equation (2.4), and the solution for $c_{t-1}^{i}$, which is obtained through solving individual's utility maximisation problem:

$$
k_{t}-k_{t}^{i}=\frac{-D(\cdot) k_{t-1}}{D(\cdot)+r\left(1-\theta_{t}\right)} e_{t-1}^{i}
$$

Equation (2.6) says that individuals who are poorer (richer) than the average accumulate the asset less (more) than the average. Therefore, the level of $\theta$ preferred by individuals is inversely related to their initial endow ments of individually specific skills $\left(e^{i}\right)$. The political equilibrium value of $\theta$ is characterised by the value of $\theta^{m}$ which is preferred by the median voter, who has the median endowment of specific skills, $e^{m}$.

Second, Equation (2.5), Equation (2.6), and the maximising condition:

$$
\frac{\partial v_{t}^{i}}{\partial \theta_{t}}=U_{d}(\cdot)\left[\left(k_{t}-k_{t}^{i}\right)+\theta_{t} \frac{\partial k_{t}}{\partial \theta_{t}}\right] r=0
$$


yields the equilibrium value of $\theta^{*}$, which is a function of $w, r$, and $e^{m}$, defined implicitly by:

$$
-\frac{D(r, \theta) e^{m}}{D(r, \theta)+r(1-\theta)}+\theta D_{\theta}(r, \theta) \frac{w r}{[r+D(r, \theta)]^{2}}=0
$$

It is easy to verify $\theta_{e}^{*}<0$. Combining Equation (2.5) and Equation (2.8), the growth rate in the politico-economic equilibrium is given as follows:

$$
g^{*}=G\left(w, r, \theta^{*}\left(w, r, e^{m}\right)\right)
$$

From Equation (2.9), using $G_{\theta}<0$ and $\theta_{e}^{*}<0$, we can derive the following implication: More equality increases growth:

$$
\frac{d g^{*}}{d e^{m}}=G_{\theta} \theta_{e}>0
$$

\subsubsection{The endogenous fiscal policy approach: Evidence}

Persson and Tabellini (1994) and Perotti (1996) are the only empirical studies that are classified into this approach. The model by Persson and Tabellini (1994) predicts that more equality leads to less distortion and thus higher investment and economic growth. The equations they have estimated are as follows:

$$
\begin{gathered}
\text { GROWTH }=\beta_{0}+\beta_{1} G D P 60+\beta_{2} P S C H O O L+\beta_{3} T R A N S F \\
\text { TRANSF }=\gamma_{0}+\gamma_{1} \text { MIDDLE }+\gamma_{2} G D P 60 .
\end{gathered}
$$

They do not treat these equations as a system, so both equations are estimated separately by OLS. GROWTH is the average annual growth rate of the real GDP per capita over 1960-85. GDP60 is the real GDP per capita in 1960 and is in the first equation to capture the possible convergence effect. PSCHOOL is percentage 
enrolled in primary school out of relevant age group in 1960, which is a proxy for the initial human capital. They measure government-induced redistribution by the average ratio of transfers (pensions, unemployment compensations, and other social expenditures other than health and education) to GDP between 1960 and 1981 (TRANSF). Inclusion of this variable reduces the number of observations to 13, which is very small. The measure of inequality is MIDDLE, which is the share of pre-tax income received by the third quintile of the population. An increase in $M I D D L E$ is regarded as more equality.

The estimation result is shown in Table 2.2. The data do not appear to support their hypothesis well. The estimate of the coefficient on MIDDLE of the second equation is negative as expected but is statistically insignificant. Also, the estimate of the coefficient on TRANSF of the first equation is negative as the model predicts but is statistically insignificant.

Table 2.2: Persson and Tabellini (1994)

\begin{tabular}{lccccc}
\hline \hline & constant & GDP60 & PSHCOOL & TRANSF & MIDDLE \\
\hline GROWTH & 4.874 & -0.00052 & 0.011 & -4.742 & \\
& $(3.414)$ & $(-3.873)$ & $(0.763)$ & $(-0.970)$ & \\
TRANSF & 0.203 & 0.000018 & & & -0.011 \\
& $(1.790)$ & $(1.756)$ & & & $(-1.286)$ \\
\hline
\end{tabular}

NB: Values in the parentheses are $t$ statistics.

Perotti (1996) estimates a system of equations by the method of two-stage least squares. The simplest specification of his system is as follows:

$$
\left\{\begin{array}{l}
\text { GROWTH }=\beta_{0}+\beta_{1} G D P 60+\beta_{2} M S E+\beta_{3} F S E+\beta_{4} P P P I+\beta_{5} M T A X \\
M T A X=\gamma_{0}+\gamma_{1} G D P 60+\gamma_{2} M I D D L E+\gamma_{3} P O P 65 .
\end{array}\right.
$$

In this system, GROWTH and MTAX are the endogenous variables. MTAX is the average marginal tax rate between 1970 and 1985 , and this variable is a proxy for the distortions caused by the redistributive policy. MSE (FSE) is average years of secondary schooling of the male (female) population in 1960, which is a proxy for 
the initial human capital, and $P P P I$ is a proxy for the market distortions for which the PPP value for the investment deflator relative to the United States in 1960 is used. As for the MTAX equation, the share of population over sixty-five years of age, average of 1970, 1975, and 1985 values (POP65) is included apart from $G D P 60$ and $M I D D L E$, in order to control for a higher distributive expenditure to those people.

The estimation result presented in Table 2.3 is not convincing in supporting the theory. The positive estimate of the coefficient on $M T A X$ in the first equation is statistically significant, but is against the prediction of the model. The negative estimate of the coefficient on $M I D$ in the second equation is anticipated but is statistically insignificant. The basic picture of the estimation result does not change if other fiscal policy variables or inequality measures are used instead.

Table 2.3: Perotti (1996): The endogenous fiscal policy approach

\begin{tabular}{lcccccc}
\hline \hline & constant & GDP60 & MSE & FSE & PPPI & MTAX \\
\hline GROWTH & 0.004 & -0.004 & 0.004 & 0.001 & -0.0005 & 0.090 \\
& $(0.47)$ & $(-2.39)$ & $(0.38)$ & $(0.10)$ & $(-0.07)$ & $(3.61)$ \\
\hline \hline \multirow{2}{*}{ MT $A X$} & constant & GDP60 & MIDDLE & POP65 & & \\
& 0.164 & -0.021 & -0.096 & 3.047 & & \\
& $(1.13)$ & $(-1.50)$ & $(-0.19)$ & $(3.78)$ & & \\
\hline
\end{tabular}

NB: Values in the parentheses are $t$ statistics.

\subsubsection{The endogenous fiscal policy approach: Discussion}

We reviewed a one sector OLG model by Persson and Tabellini (1994). Here we hastily note the fact that two sector infinite horizon models by Alesina and Rodrik (1994) and Bertola (1993) arrived at the same conclusion: Inequality will stagnate economic growth via the endogenous fiscal policy determination and the resulting distortion. It shows the robustness of this approach in the sense that two different theoretical frameworks predict the same result.

However, as we have reviewed, the empirical evidence appears to be against 
what the theory predicts. Note that the important assumption of this approach is that policies are determined endogenously by a vote. Perhaps, as a number of studies have pointed out, this approach might prevail only in democratic countries, where this assumption sounds plausible.

Perotti (1996) actually has conducted the same estimation only for the democratic country subsample, ${ }^{4}$ but the result has not improved so much to support the theory. ${ }^{5}$ In addition to this, some empirical studies that use reduced-form equation have found that little support for the endogenous fiscal policy approach. For example, Deininger and Squire (1998) find that inequality affects growth in non-democratic countries, but not in democratic ones.

In summary, we conclude that the data have not been supporting the endogenous fiscal approach so far.

\subsubsection{The sociopolitical instability approach: Theory}

Now we turn to review theoretical models of the second approach, which deals with sociopolitical instability. First, let us regard sociopolitical instability as a situation under which property rights are insecure, i.e., we assume that more inequality leads to more sociopolitical instability that leads to less secured property rights. Under this situation, rent-seeking activities will be more likely to take place than otherwise, and this may harm economic growth. Murphy et al. (1993) capture this point.

Murphy et al. (1993) show how rent-seeking is costly to economic growth. It is shown that agents tend to engage in rent-seeking activities when property rights are not protected, and the level of output is far lower than otherwise. This situation is

\footnotetext{
${ }^{4} \mathrm{~A}$ democracy index by Jodice and Taylor (1988) is used to classify economies into democratic and non-democratic countries. If an average value of it over 1960-85 is 0.5 , then a country is classified as democratic.

${ }^{5}$ Persson and Tabellini (1994) have only 13 observations for their estimation, so the similar kind of analysis is meaningless.
} 
referred to as the "bad equilibrium," and since it is stable, it is difficult to escape from that equilibrium once an economy slides into there.

Consider a farm economy where each agent can engage in one of the following three activities: production of a cash crop; production of a subsistence crop; rentseeking. A cash crop is traded in the market and the level of output per agent is $q_{1}$. But a cash crop is subject to rent-seeking. If an agent engages in rent-seeking, he can expropriate a cash crop by the maximum amount of $q_{2}$. On the contrary, a subsistence crop is not subject to rent-seeking and the level of output is $q_{3}\left(q_{3}<q_{1}\right)$. Note that agent's rent-seeking technology is subject to diminishing returns, in the sense of an upper bound on how much he can grab with limited time and abilities.

An equilibrium in this economy is an allocation of the population between cash crop production, subsistence crop production, and rent-seeking. Let us denote the ratio of people engaged in rent-seeking and cash crop production by $n$. We can find an equilibrium by considering payoffs to production and rent-seeking as a function of $n$. We first consider two extreme cases where property rights are extremely well protected and extremely poorly protected.

Case 1 . Well protected property rights $\left(q_{2}<q_{3}\right)$ : In this case, property rights are well protected because the return to rent-seeking is even lower than that to subsistence crop production. At $n=0$, the returns to cash crop production is $q_{1}$, since there is no rent-seeking. As $n$ rises, returns to cash crop production falls to $q_{1}-n q_{2}$, until it hits the critical level $q_{1}-n_{1} q_{2}$, where $q_{1}-n_{1} q_{2}=q_{3}\left(\right.$ or $\left.n_{1}=\left(q_{1}-q_{3}\right) / q_{2}\right)$. As $n$ rises above $n_{1}$, cash crop producers drop into subsistence crop production to keep their income level at $q_{3}$. As a consequence, the return to each rent-seeker will be $\left(q_{1}-q_{3}\right) / n<q_{2}$. Figure 2.1 describes the situation. The equilibrium is unique in this case. Every agent engages in cash crop production, there will be no rent-seekers or subsistence crop producers. Output per capita is $q_{1}$ which is the highest this economy can yield.

Case 2. Poorly protected property rights $\left(q_{1}<q_{2}\right)$ : In this case, rent-seekers 
are able to grab more than the amount which cash crop producers can produce, hence property rights are not well protected at all. As shown in Figure 2.2 , the ratio of population between rent-seekers and cash crop producers in the unique equilibrium, in this case, must be given by $n_{2}=\left(q_{1}-q_{3}\right) / q_{3}$, and in the equilibrium, every agent's income is equal to the subsistence level $q_{3}$, which is lower than $q_{1}$.

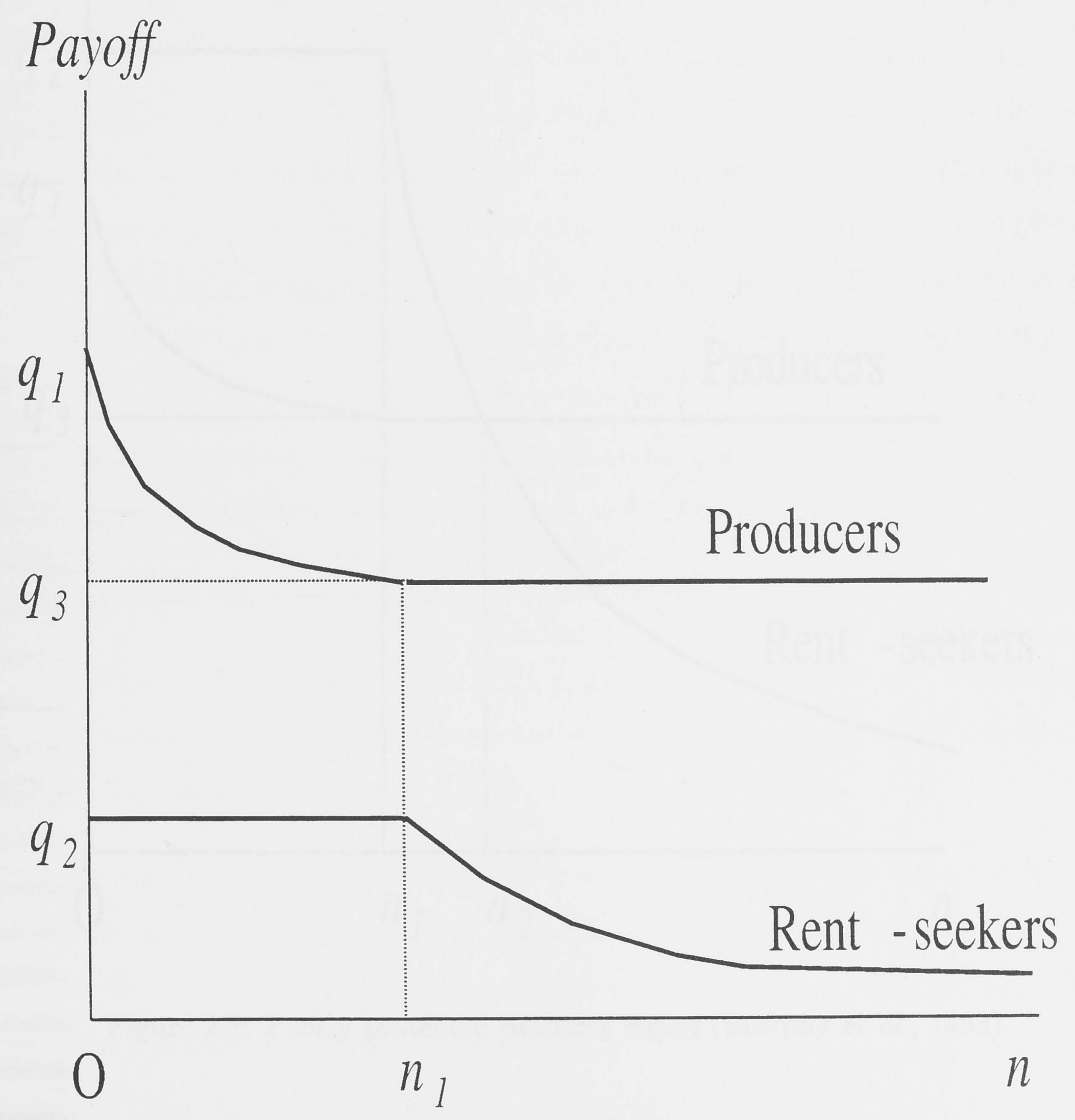

Figure 2.1: Well protected property rights (Murphy et al., 1993) 


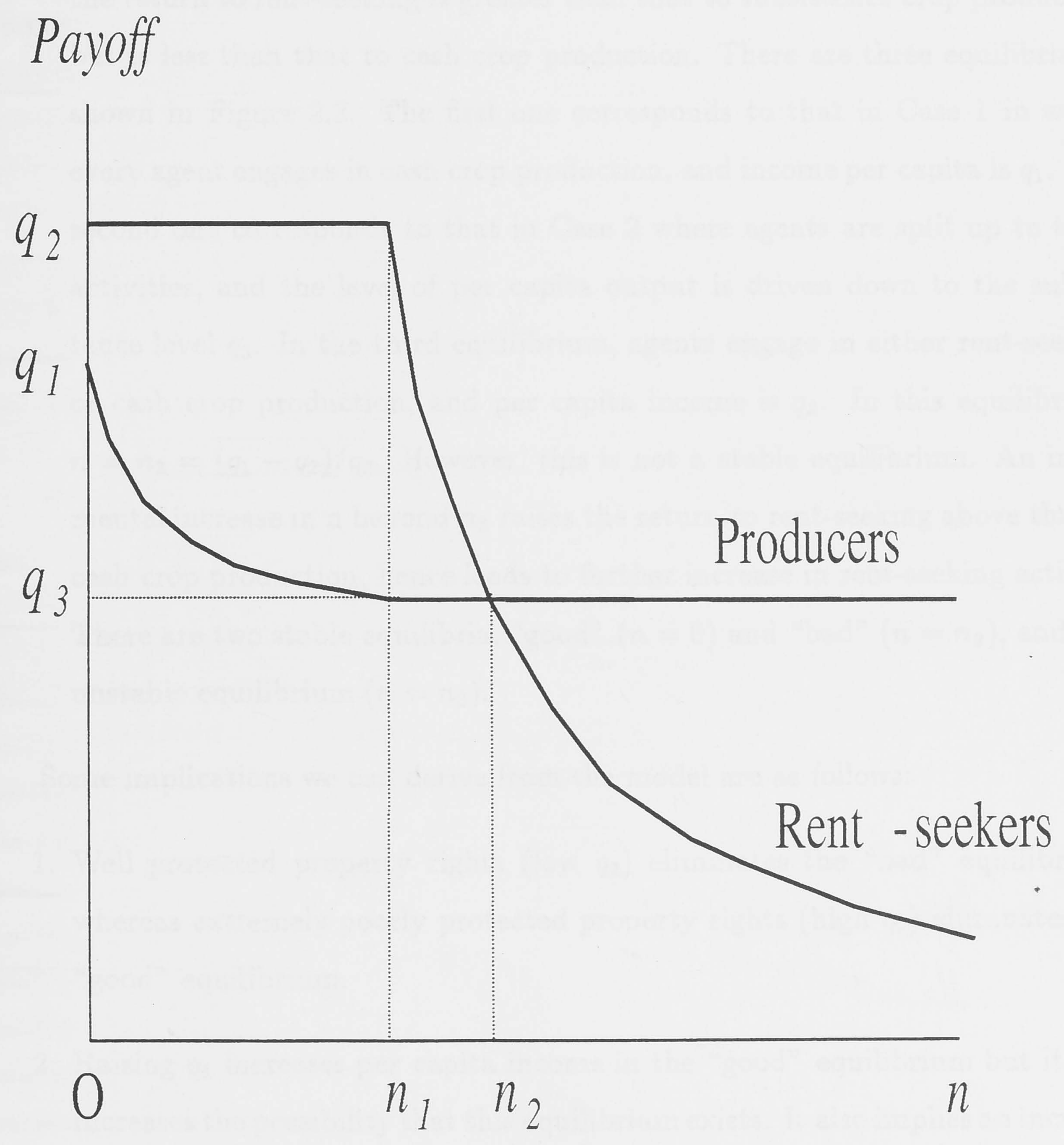

Figure 2.2: Poorly protected property rights (Murphy et al., 1993) 
Next, let us consider the intermediate case where the economy has multiple equilibria.

Case 3. Intermediate Case - Multiple equilibria $\left(q_{3}<q_{2}<q_{1}\right)$ : In this case, the return to rent-seeking is greater than that to subsistence crop production but is less than that to cash crop production. There are three equilibria, as shown in Figure 2.3. The first one corresponds to that in Case 1 in which every agent engages in cash crop production, and income per capita is $q_{1}$. The second one corresponds to that in Case 2 where agents are split up to three activities, and the level of per capita output is driven down to the subsistence level $q_{3}$. In the third equilibrium, agents engage in either rent-seeking or cash crop production, and per capita income is $q_{2}$. In this equilibrium, $n=n_{3}=\left(q_{1}-q_{2}\right) / q_{2}$. However, this is not a stable equilibrium. An incremental increase in $\mathrm{n}$ beyond $n_{3}$ raises the return to rent-seeking above that to cash crop production, hence leads to further increase in rent-seeking activity. There are two stable equilibria, "good" $(n=0)$ and "bad" $\left(n=n_{2}\right)$, and one unstable equilibrium $\left(n=n_{3}\right)$.

Some implications we can derive from the model are as follows:

1. Well protected property rights (low $q_{2}$ ) eliminates the "bad" equilibrium, whereas extremely poorly protected property rights (high $q_{2}$ ) eliminates the "good" equilibrium.

2. Raising $q_{1}$ increases per capita income in the "good" equilibrium but it also increases the possibility that this equilibrium exists. It also implies an increase in $n$ in the "bad" equilibrium since there are more rents to be disintegrated per producer before income falls down to $q_{3}$.

3. Raising $q_{3}$ increases per capita income in the "bad" equilibrium.

4. To get the best outcome, it is essential to provide enough property rights so that $q_{2}$ falls below $q_{3}$. To this end, a legal system, a rigid culture, or 


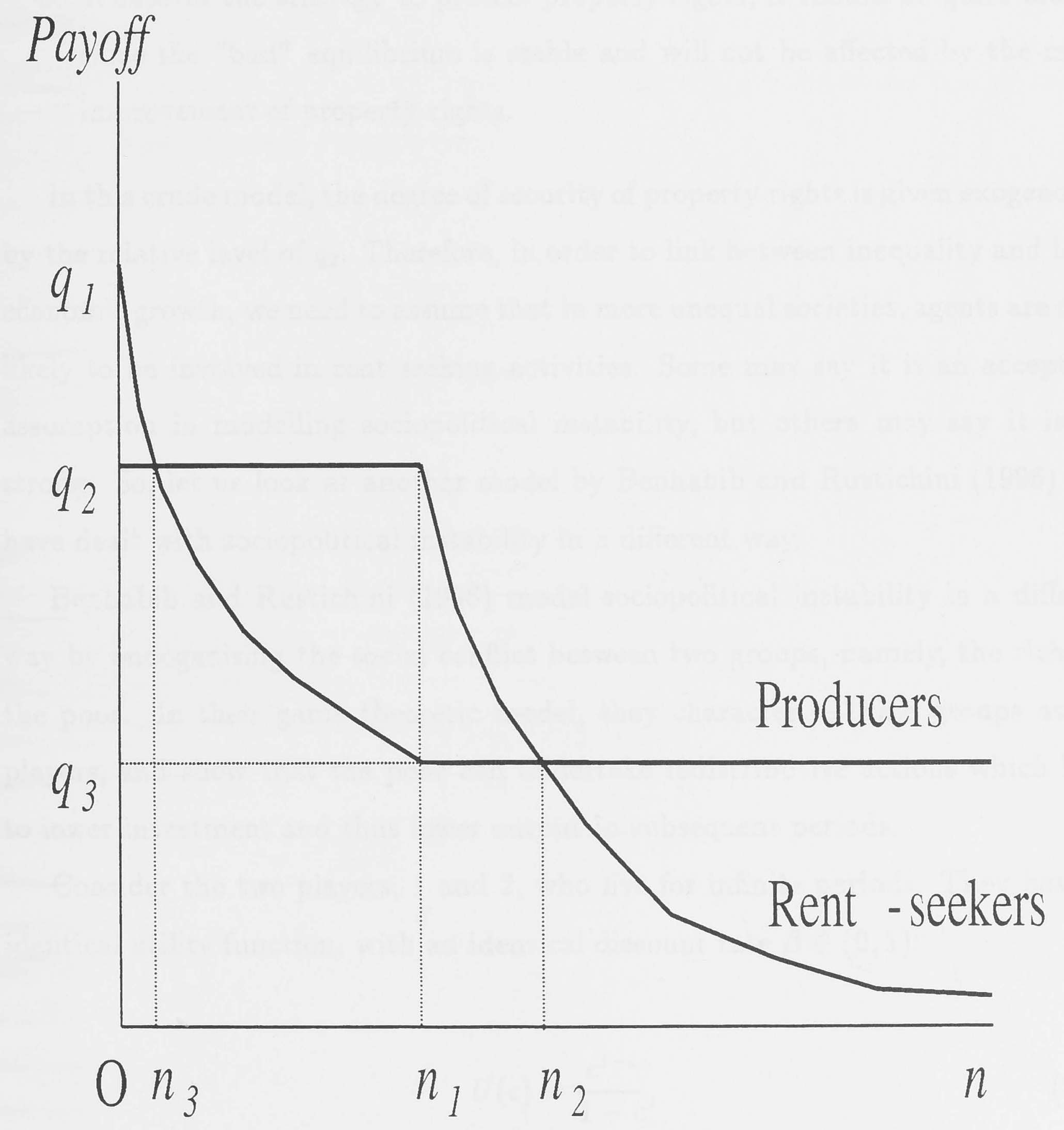

Figure 2.3: Intermediate case (Murphy et al., 1993) 
some other form of anti-rent-seeking ideology can play a role (North, 1981) to decrease $q_{2}$, or some protection of subsistence crop production, as well as raising its productivity (rise in $q_{3}$ ), also plays an important role.

5. Whatever the strategy to protect property rights, it should be quite drastic, since the "bad" equilibrium is stable and will not be affected by the minor improvement of property rights.

In this crude model, the degree of security of property rights is given exogenously by the relative level of $q_{2}$. Therefore, in order to link between inequality and lower economic growth, we need to assume that in more unequal societies, agents are more likely to be involved in rent seeking activities. Some may say it is an acceptable assumption in modelling sociopolitical instability, but others may say it is too strong. So, let us look at another model by Benhabib and Rustichini (1996) who have dealt with sociopolitical instability in a different way.

Benhabib and Rustichini (1996) model sociopolitical instability in a different way by endogenising the social conflict between two groups, namely, the rich and the poor. In their game theoretic model, they characterise these groups as two players, and show that the poor can undertake redistributive actions which leads to lower investment and thus lower output in subsequent periods.

Consider the two players, 1 and 2, who live for infinite periods. They have an identical utility function, with an identical discount rate $\beta \in(0,1)$ :

$$
U(c)=\frac{c^{1-\epsilon}}{1-\epsilon}
$$

where $0<\epsilon<1$ and $c$ is the level of consumption. The level of output $(y)$ depends only on the level of capital stock $(k)$ in each period, and the production function is given as follows:

$$
y=a k,
$$


where $a>0$. Current period's output $\left(y_{t}\right)$ is either consumed by the two players $\left(c_{t}^{1}, c_{t}^{2}\right)$ or invested to form the capital stock in the next period $\left(k_{t+1}\right)$ :

$$
y_{t}-c_{t}^{1}-c_{t}^{2} \leq k_{t+1}
$$

The total utility of each player among a first best equilibrium in derived by solving the following dynamic programme:

$$
\hat{v}=\max _{0 \leq c \leq \frac{y}{2}}\left[\frac{c^{1-\epsilon}}{1-\epsilon}+\beta \hat{v}(y-2 c)\right]
$$

It follows that the first best consumption is given as follows:

$$
\hat{c}=\hat{\lambda} y
$$

where

$$
\hat{\lambda}=\frac{1}{2}\left(1-\beta^{\frac{1}{\epsilon}} a^{\frac{1-\epsilon}{\epsilon}}\right) \geq 0 .
$$

For the first best $\hat{\lambda}$, the value function is given by:

$$
\hat{v}=s(\hat{\lambda}) y^{1-\epsilon}
$$

where

$$
s(\hat{\lambda})=\frac{\hat{\lambda}^{1-\epsilon}}{(1-\epsilon)\{1-\beta(a(1-2 \hat{\lambda}))\}} .
$$

This result shows that in a first best equilibrium, in each period, each agent will consume an equal share of output, but will not consume all output and invest the rest for the next period. 
Next, let us consider the case where a player defects against a first best play by her opponent. If a player defects, the other player will take a grim trigger strategy, i.e., all output will be consumed in equal shares by the two players after a defection. Therefore, this player must choose her consumption in the current period taking into account that a grim trigger strategy will be enacted subsequently.

Similar to the first best case, optimal defection value is given by:

$$
v^{D}=\max _{0 \leq c_{D} \leq(1-\hat{\lambda}) y}\left[\frac{c_{D}^{1-\epsilon}}{1-\epsilon}+\frac{\beta\left\{a\left((1-\hat{\lambda}) y-c_{D}\right) / 2\right\}}{1-\epsilon}\right]
$$

and the value of optimal defection from the first best $\left(v^{D}\right)$ is derived as follows:

$$
v^{D}=s_{D} y^{1-\epsilon}
$$

where

$$
s_{D}=\frac{1}{(1-\hat{\lambda})^{1-\epsilon}(1-\epsilon) M^{\epsilon}}
$$

and

$$
M=\frac{2 a}{\left(\frac{\beta a}{2}\right)^{\frac{1}{\epsilon}}+\frac{a}{2}}
$$

If $\hat{v} \geq v^{D}$ then the first best outcome prevails, but otherwise, a defection will be taken place. In the numerical example in Benhabib and Rustichini (1996), if the first best was sustained, capital stock would grow at 15 per cent. However, economy would contract by 0.0015 per cent if there was a defection. ${ }^{6}$

Inequality is characterised by the disparity of the levels of consumption between two players. Therefore, when a defection is present, i.e., $\hat{v} \leq v^{D}$, inequality is

\footnotetext{
${ }^{6}$ The following parameter values are used: $a=3.3, b=0.325, e=0.5$.
} 
present because the player who defects consumes more than the other one. The disadvantaged player will undertake a redistributive action, namely, a grim trigger strategy. In this model, this leads to a slower accumulation of capital and hence slower economic growth.

\subsubsection{The sociopolitical instability approach: Evidence}

Alesina and Perotti (1996) and Perotti (1996) are the only empirical studies that have attempted to support this approach. Alesina and Perotti (1996) test the hypothesis that inequality affects investment via destabilising the sociopolitical status. To this end, they specify a bivariate simultaneous equation model, with share of physical investment in GDP $(I N V)$ and the index of sociopolitical instability $(S P I)$ as endogenous variables. In the simplest specification, variables on the RHS of the $I N V$ equation are as follows: $S P I$, the initial level of real GDP per capita to take the convergence effect in to account, and indexes to capture domestic market price distortions (PPPI and PPPIDE: PPPI was defined previously; PPPIDE is a magnitude of the deviation of the PPP value for the investment deflator from the sample mean in 1960). On the RHS of the SPI equation, $I N V$, the initial enrolment ratio in primary school as a proxy for human capital (PRIM), and the index of equality ( $M I D C L A S S$ ) are included. In this paper, this equality index is a share of the third and fourth quintiles of the population. The higher the value of this index is, more equal is the economy. The simplest system of equations they have estimated is as follows:

$$
\left\{\begin{array}{l}
I N V=\beta_{0}+\beta_{1} G D P 60+\beta_{2} S P I+\beta_{3} P P P I+\beta_{4} P P P I D E \\
S P I=\gamma_{0}+\gamma_{1} P R I M+\gamma_{2} M I D C L A S S+\gamma_{3} I N V .
\end{array}\right.
$$

The estimation is conducted by the method of two-stage least squares, which gives efficient and consistent estimates. The result is shown in Table 2.4. The signs of all coefficients are as expected. Our interest is the estimate of the coefficient on MIDCLASS, which is negative and statistically significant. A one standard 
deviation increase in $M I D C L A S S$ decreases $S P I$ by about 5.7, which corresponds to about 48 per cent of its standard deviation. This is associated with an increase in $I N V$ about 2.85 percentage points. Provided that the standard deviation of $I N V$ is 7.49 , the effect of initial inequality upon investment appears non-trivial. This estimation result is shown to be robust against different model specifications and a different measure of SPI.

Table 2.4: Alesina and Perotti (1996)

\begin{tabular}{cccccc}
\hline \hline & constant & GDP60 & SPI & PPPI & PPPIDE \\
\hline$I N V$ & 27.36 & 0.07 & -0.50 & -0.14 & 0.04 \\
& $(9.34)$ & $(1.09)$ & $(-2.39)$ & $(-2.39)$ & $(0.62)$ \\
\hline \hline & constant & PRIM & MIDCLASS & $I N V$ & \\
\hline SPI & 37.43 & -0.23 & -1.01 & 0.72 & \\
& $(4.54)$ & $(-2.45)$ & $(-3.42)$ & $(1.30)$ & \\
\hline
\end{tabular}

NB: Values in the parentheses are $t$ statistics.

Now we turn to look at Perotti (1996) who specifies the system slightly differently. The simplest specification of the system is as follows:

$$
\left\{\begin{array}{l}
\text { GROWTH }=\beta_{0}+\beta_{1} G D P 60+\beta_{2} M S E+\beta_{3} F S E+\beta_{4} P P P I+\beta_{5} S P I \\
S P I=\gamma_{0}+\gamma_{1} M S E+\gamma_{2} F S E+\gamma_{3} M I D D L E
\end{array}\right.
$$

The definition of the variables are the same as before. The difference from Alesina and Perotti (1996) is that GROWTH instead of $I N V$ is used in the first equation of this system. Perotti (1996) does not explicitly justify why he has used the growth rate instead of the investment ratio, and this could be a potential problem, which will we come back to discuss in the next subsection.

In any case, the estimation result is shown in Table 2.5. The estimate of the coefficient on MIDDLE in the second equation is negative as anticipated and is statistically significant. In addition, the estimate of the coefficient on SPI in the first equation is negative as the model predicts and is statistically significant. This estimation predicts that a one standard deviation increase in MIDDLE decreases 
SPI by about 0.005 and, in turn, leads to an increase in GROWTH by about 0.7 percentage point.

Table 2.5: Perotti (1996): The sociopolitical instability approach

\begin{tabular}{ccccccc}
\hline \hline & constant & GDP60 & MSE & FSE & PPPI & SPI \\
\hline GROWTH & 0.034 & -0.004 & 0.028 & -0.025 & -0.014 & -1.495 \\
& $(3.46)$ & $(-1.81)$ & $(2.63)$ & $(-2.05)$ & $(-1.32)$ & $(-2.27)$ \\
\hline \hline \multirow{2}{*}{ SPI } & constant & $M S E$ & $F S E$ & $M I D D L E$ & & \\
& 0.021 & 0.006 & -0.009 & 0.090 & & \\
& $(3.26)$ & $(1.20)$ & $(-1.20)$ & $(-2.11)$ & & \\
\hline
\end{tabular}

NB: Values in the parentheses are $t$ statistics.

Inclusion of regional dummies does not change the picture much. The estimate of the coefficient on MIDDLE falls to -0.071 but is still statistically significant, which implies that the variation in SPI is explained by the continental differences, but only partly. This case, a one standard deviation increase in MIDDLE leads to an increase in GROWTH by about 0.56 percentage point. In any event, the effect of inequality upon growth appears to be sizable.

\subsubsection{The sociopolitical instability approach: Discussion}

The basic intuition behind this approach is that, in an unequal society, there is strong incentive for the different groups to engage in unproductive activities in order to deprive other groups' output, and this results in uncertainty on the final distribution of output, which induces a decrease in investment in physical capital. Therefore, the relationship between inequality and investment is derived quite rigourously from the theoretical model. The empirical study by Alesina and Perotti (1996) has tested this link and support it quite well as we have seen. Inequality has a sizable impact upon investment.

However, we are still not sure about the effect of inequality upon growth. Many of the studies have found a strongly positive and statistically significant relationship between investment and growth. However, as it is well known, Barro and Sala-i- 
Martin (1995) report the opposite evidence that investment does not have much explanatory power for growth. Therefore, we need to be a little cautious when we link investment and growth.

A possible way to get around this problem is to estimate a three-equation system. In addition to two equations of a system in Alesina and Perotti (1996), if we add a typical growth equation with the growth rate on the LHS and investment on the RHS as the third equation, we can estimate the effect of inequality upon growth, indirectly through investment.

Perotti (1996) skips this procedure and just replaces INV with GROWTH. This slight departure from the theoretical model makes the interpretation of the results very difficult. That is, from his estimation, we cannot really observe how sociopolitical instability is affecting growth.

Despite the problem raised above, Perotti (1996) provides us with an interesting finding. In his estimation, SPI is used to capture sociopolitical instability, but there is an awkward question what $S P I$ is really capturing - it might be just a proxy variable for Latin American/African countries where sociopolitical instability is often present. Interestingly, as we have seen, inclusion of regional dummies to Perotti (1996) does not change the result much. It shows that the variation in SPI is only partly explained by the regional differences. Furthermore, the estimate on the coefficient of MIDDLE remains statistically significant.

This contrasts to some reduced-form regressions such as Birdsall et al. (1995). When regional dummies are introduced to their reduced-form regression, inequality becomes statistically insignificant. Ravallion and Chen (1997) also report the similar finding. Whilst these findings suggest the relationship between inequality and growth might be spurious, Perotti (1996) presents the opposite result. 


\subsubsection{The human capital and borrowing constraint approach: Theory}

The third approach is characterised by two assumptions. One is that the credit market is imperfect and the other is that investment in human capital is indivisible, i.e., there is a decision whether or not to invest in human capital but there is no decision on how much to invest. Galor and Zeira (1993) show that under this circumstance, an economy that has a larger middle class is likely to grow faster. A brief review of their model is as follows.

We consider a small open economy. There is only one good that can be used for either consumption or investment. There are two ways to produce this good. One is to utilise both capital $\left(K_{t}\right)$ and skilled labour $\left(L_{t}^{s}\right)$, and the other is to utilise only unskilled labour $\left(L_{t}^{n}\right)$. The levels of output $Y_{t}^{s}$ and $Y_{t}^{n}$ are given as follows:

$$
\begin{array}{r}
Y_{t}^{s}=F\left(K_{t}, L_{t}^{s}\right), \\
Y_{t}^{n}=w_{n} L_{t}^{n},
\end{array}
$$

where $w_{n}$ is the competitive wage rate determined in the unskilled labour market, and $F$ is a concave CRS production function.

We consider individuals who live for two periods. In the first period, each individual decides whether to work or to invest in human capital. If she invests in human capital, she can work as a skilled labour in the second period, but if she does not invest in human capital she works as an unskilled labour in the second period. Each individual consumes only in the second period and bequeaths for her child. The utility function is given as follows:

$$
U=\alpha \log c+(1-\alpha) \log b
$$

where $c$ is consumption in the second period, $b$ is bequest, and $\alpha$ is a parameter which takes a value between 0 and 1 . 
Capital is assumed to be perfectly mobile and the constant world interest rate is given by $r>0$. It follows that:

$$
\frac{\partial F}{\partial K_{t}}=r
$$

and this equation determines the wage rate for skilled labour, $w_{s}$.

Now, we turn to the capital market. Individuals can lend any amount at the world interest rate $r$. We assume that borrowers are able to evade paying the debt by all means and lenders are trying to keep track of borrowers. If it costs $z$ to keep track of borrowers, it costs $\beta z$ to evade paying the debt, where $\beta>1$. If an individual borrows an amount of $d$ at the interest rate $i_{d}$, a zero profit condition in the competitive financial sector yields:

$$
d i_{d}=d r+z
$$

Taking into account that lenders choose $z$ high enough to make the default disadvantageous, we obtain the following result:

$$
i_{d}=i=\frac{1+\beta r}{\beta-1}>r
$$

This equation says that the borrowing interest rate, $i$, is higher than the lending interest rate, $r$. In this sense, the capital market is imperfect.

Now, let us analyse optimal decisions by individuals. Individuals are identical except that they inherit a different amount of wealth, and we can think of three types of individuals; individuals who remains unskilled; individuals who lend and invest in human capital; individuals who borrow and invest in human capital. Solving the utility maximisation problems for these three types of individuals who inherit an amount of $x$ in the first period gives the optimal amount of bequest for each type, respectively, as follows: 


$$
\begin{gathered}
b_{n}=(1-\alpha)\left[(1+r)\left(x+w_{n}\right)+w_{n}\right], \\
b_{s l}=(1-\alpha)\left[w_{s}+(x-h)(1+r)\right], \\
b_{s b}=(1-\alpha)\left[w_{s}+(x-h)(1+i)\right],
\end{gathered}
$$

where $h$ is the cost of investing in human capital. Therefore in Equation (2.30), $(x-h)$ is non-negative, but is negative in Equation (2.31). We confine our analysis to the case where lenders prefer to invest in human capital, i.e., we assume that the following relationship holds:

$$
w_{s}-h(1+r) \geq w_{n}(2+r)
$$

This relationship can be easily derived by comparing utilities of an unskilled individual and a skilled individual who lends. It can also be shown that borrowers prefer to invest in human capital as long as the resulting utility is higher than otherwise, i.e., they invest in human capital as long as the following relationship holds:

$$
x \geq f=\frac{w_{n}(2+r)+h(1+i)-w_{s}}{i-r} .
$$

The important implication here is that education is limited to individuals with high enough initial wealth (above $f$ ). This is due to a higher interest rate for borrowers.

Now we turn to analyse the dynamics of the model. The distribution of inheritances in the next period $\left(x_{t+1}\right)$ are as follows:

$$
x_{t+1}=\left\{\begin{array}{ll}
b_{n}=(1-\alpha)\left[(1+r)\left(x_{t}+w_{n}\right)+w_{n}\right] & \text { if } x_{t}<f \\
b_{s b}=(1-\alpha)\left[w_{s}+\left(x_{t}-h\right)(1+i)\right] & \text { if } f \leq x_{t}<h \\
b_{s l}=(1-\alpha)\left[w_{s}+\left(x_{t}-h\right)(1+r)\right] & \text { if } h \leq x_{t}
\end{array} .\right.
$$




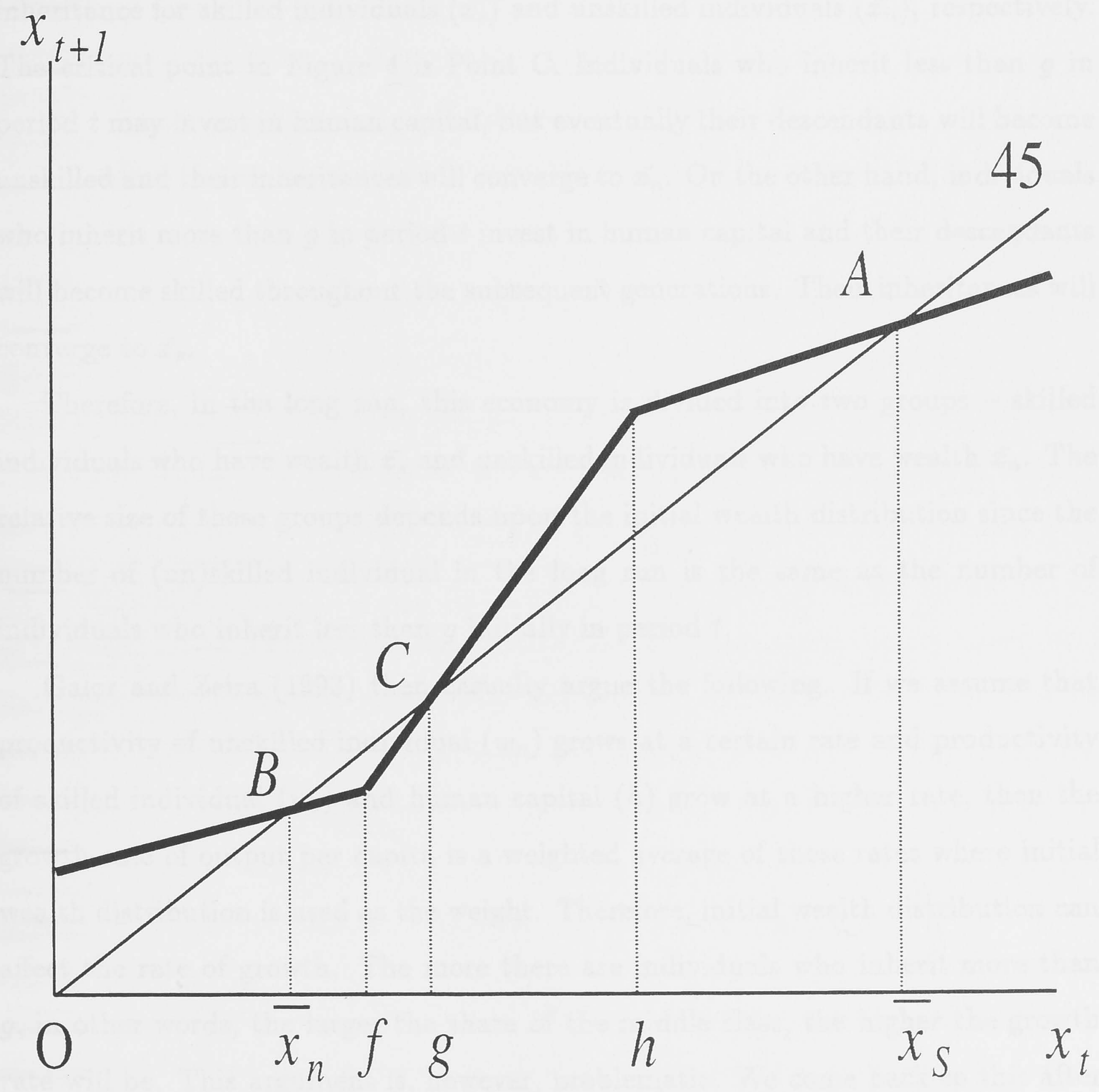

Figure 2.4: Dynamics of inheritance (Galor and Zeira, 1993) 
Figure 2.4 describes the situation. The curves in Figure 4 describe the dynamic relationships between inheritance and bequest (inheritance for the next generation) for three types of individuals.

Points $A$ and $B$ are locally stable and they correspond to the long run levels of inheritance for skilled individuals $\left(\overline{x_{s}}\right)$ and unskilled individuals $\left(\overline{x_{n}}\right)$, respectively. The critical point in Figure 4 is Point C. Individuals who inherit less than $g$ in period $t$ may invest in human capital, but eventually their descendants will become unskilled and their inheritances will converge to $\overline{x_{n}}$. On the other hand, individuals who inherit more than $g$ in period $t$ invest in human capital and their descendants will become skilled throughout the subsequent generations. Their inheritances will converge to $\overline{x_{s}}$.

Therefore, in the long run, this economy is divided into two groups - skilled individuals who have wealth $\overline{x_{s}}$ and unskilled individuals who have wealth $\overline{x_{n}}$. The relative size of these groups depends upon the initial wealth distribution since the number of (un)skilled individual in the long run is the same as the number of individuals who inherit less than $g$ initially in period $t$.

Galor and Zeira (1993) then casually argue the following. If we assume that productivity of unskilled individual $\left(w_{n}\right)$ grows at a certain rate and productivity of skilled individual $\left(w_{s}\right)$ and human capital $(h)$ grow at a higher rate, then the growth rate of output per capita is a weighted average of these rates where initial wealth distribution is used as the weight. Therefore, initial wealth distribution can affect the rate of growth. The more there are individuals who inherit more than $g$, in other words, the larger the share of the middle class, the higher the growth rate will be. This argument is, however, problematic. We come back to this after reviewing a related empirical study. 


\subsubsection{The human capital and borrowing constraint approach: Evidence}

Perotti (1996) is the only empirical study that is based upon this approach. The simplest specification of a simultaneous equation system is as follows:

$$
\left\{\begin{array}{l}
\text { GROWTH }=\beta_{0}+\beta_{1} G D P 60+\beta_{2} F S E C \\
F S E C=\gamma_{0}+\gamma_{1} G D P 60+\gamma_{2} M S E+\gamma_{3} F S E+\gamma_{4} M I D D L E .
\end{array}\right.
$$

Perotti (1996) chooses FSEC, the female secondary school enrolment ratio (average of 1965 and 1985 values), as a proxy for investment in human capital since the opportunity cost of secondly education is much likely to be higher than that of primary education. The result is basically the same if $M S E C$, the male secondary school enrolment ratio (average of 1965 and 1985 values), is used instead of FSEC.

The estimation result is shown in Table 2.6, which appears to be consistent with what the theoretical model predicts. The positive estimate of the coefficient on MIDDLE in the second equation implies that in a more equal society investment in human capital will be higher, and the positive estimate of the coefficient on $F S E C$ in the first equation implies a positive effect of investment in human capital on growth. A one standard deviation increase in MIDDLE leads to about 0.63 percentage point increase in GROWTH. Again, we emphasise that this effect is sizable. A standard deviation of GROWTH in this sample is 0.017 .

Table 2.6: Perotti (1996): The human capital and borrowing constraint approach

\begin{tabular}{lccccc}
\hline \hline \multirow{5}{*}{ constant } & GDP60 & FSEC & & \\
& 0.002 & -0.013 & 0.111 & & \\
& $(0.26)$ & $(-4.68)$ & $(5.24)$ & & \\
\hline \hline FSEC & constant & GDP60 & MSE & FSE & M IDDLE \\
& -0.212 & 0.088 & 0.235 & -0.155 & 1.078 \\
& $(-1.61)$ & $(5.86)$ & $(2.95)$ & $(-1.80)$ & $(2.51)$ \\
\hline
\end{tabular}

NB: Values in the parentheses are $t$ statistics. 
However, this estimation has nothing to do with the borrowing constraint, i.e., the imperfect capital market. In order to take this into account, a measure that can capture the degree of imperfection in the capital market is needed. Perotti (1996) reports no ideal data exist for this purpose at present.

\subsubsection{The human capital and borrowing constraint approach: Discussion}

We have reviewed a model by Galor and Zeira (1993), but it is problematic in at least two respects. One is their argument in deriving the implication for the effect of inequality upon growth in transition. In deriving the implication, they impose an assumption that both the wage rates for two types of workers and the cost for investment in human capital grow. However, the model has been solved without this assumption. The optimal behaviour of the individuals will change if this assumption is imposed, so strictly speaking, the model should be constructed and solved with this assumption imposed from the beginning.

The other problem is their definition of inequality. We have kept it a little vague what it means by inequality in their model, but they use the share of unskilled individuals in the total population $\left(l^{u}\right)$ to define inequality. They define that an economy is more unequal if this share is higher. This definition, however, is obviously different from the ordinary inequality definitions such as the Gini coefficient. If every individual is unskilled and has the same income, the Gini coefficient will be zero, showing complete equity of an economy. But according to the definition by Galor and Zeira (1993), this economy is completely unequal because the share of unskilled individuals is unity.

Let us turn to discuss a possible extension of the model - including endogenous fertility. Becker et al. (1990) point out that investment in human capital is jointly determined by individuals, as they are interpreted as two alternative uses of parents' human capital. Parents face a trade-off between investing in the number of children and investing in children's education, given their budget constraint. In fact, fertility 
has been treated as an endogenous variable in some growth models (Barro and Becker, 1989, Becker and Barro, 1988, Becker et al., 1990).

The empirical evidence also gives us a fair reason to incorporate fertility into a growth model. Brander and Dowrick (1994), using a 107 country panel data set covering 1960-85, detect strong negative fertility effects upon per capita income growth. Their study also points out the significant negative relationship between fertility and human capital. Barro (1991) also finds a strong negative relationship between fertility and investment in human capital.

This leads us to investigate the fourth approach - the endogenous fertility approach.

\subsubsection{The endogenous fertility approach: Theory}

Unfortunately, there is no formal theoretical study that can be genuinely classified into this approach. A theoretical model that captures the idea most can be found in Galor and Zang (1997) in which they incorporate exogenous fertility into a model by Galor and Zeira (1993) we previously reviewed.

In Galor and Zeira (1993), each individual has only one child as in other typical OLG models. In order to incorporate the fertility rate, Galor and Zang (1997) assume that each individual has $n$ children and the bequest from their ancestor is equally allocated to them. By virtue of this, we are able to analyse the effect of the change in $n$, although it is given exogenously.

Unlike in Galor and Zeira (1993) individuals cannot work as unskilled labour in the first period. It is assumed that in the first period individuals only make a choice whether or not they invest in human capital. In the model, imperfection of the capital market is characterised by the assumption that individuals cannot borrow at all to finance their education. Hence, if an individual inherits wealth that is less than the cost to invest in human capital, she is not able to be a skilled worker in the second period. And the model focuses on the situation where individuals who inherit more than the cost to invest in human capital are better off if they invest 
in human capital. An assumption that investment in human capital is indivisible is present in this model as well.

The dynamics of bequest per child in the model of Galor and Zang (1997) is described as follows:

$$
\frac{b_{t+1}}{n}= \begin{cases}\frac{1}{n}(1-\alpha)\left[\frac{b_{t}}{n}(1+r)+w_{n}\right] & \text { if } \frac{b_{t}}{n}<h \\ \frac{1}{n}(1-\alpha)\left[\left(\frac{b_{t}}{n}-h\right)(1+r)+w_{s}\right] & \text { if } \frac{b_{t}}{n} \geq h\end{cases}
$$

where the definition of all symbols are the same as in the previous section. Since the assumption on the capital market is stronger, we only have to consider two cases. Figure 2.5 describes the situation. As in Galor and Zeira (1993), in the long run, this economy is divided into two groups of individuals, and the relative size of these groups depends upon initial wealth distribution. .

From here they go one step further than Galor and Zeira (1993). In order to examine the effect of inequality and the family size upon growth, they derive the growth rate between two consecutive periods during transition.

After some tedious calculation from Equation (2.35), it can be shown that perfamily income $(y)$ in period $t+1$ is:

$$
y_{t+1}=\left[(1-\alpha)(1+r) \frac{y_{t}}{n}+w_{n}\right]+l_{t+1}^{s}\left[\left(w_{s}-w_{n}\right)-h(1+r)\right]
$$

where $l_{t+1}^{s}$ is the share of skilled workers in period $t+1$. The growth rate of per-family income $(g)$ is, therefore:

$$
g_{t}=\frac{y_{t+1}-y_{t}}{y_{t}}=\frac{(1-\alpha)(1+r)}{n}-1+\frac{w_{n}}{y_{t}}+\frac{l_{t+1}^{s}}{y_{t}}\left[\left(w_{s}-w_{n}\right)-h(1+r)\right] .
$$

The share of skilled workers in period $t+1, l_{t+1}^{s}$, is determined by the distribution of inheritances per-child born in period $t$, and it depends upon the per-family income $(y)$, the family size or fertility $(n)$, the income distribution $(Q)$ and the cost 


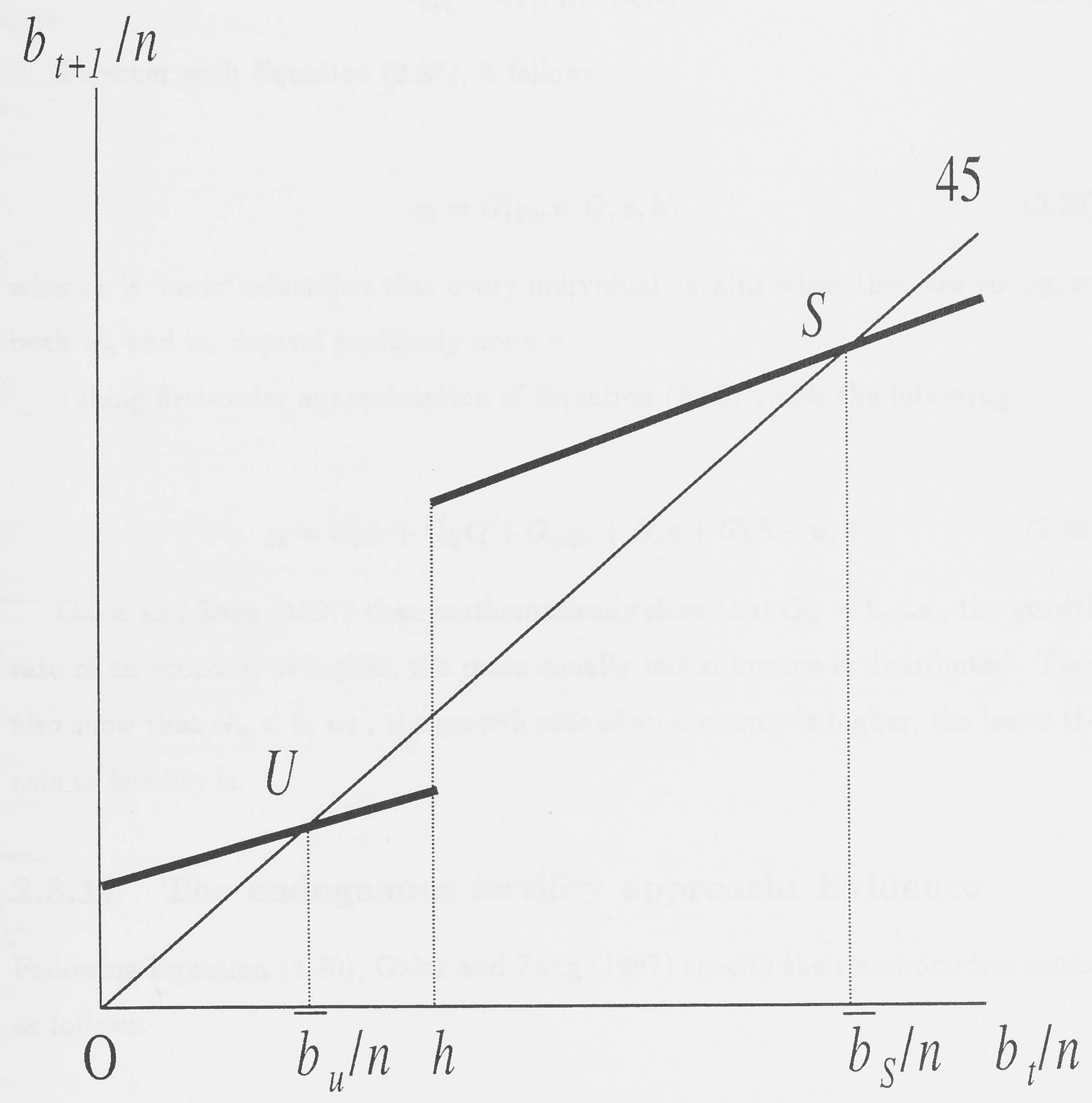

Figure 2.5: Dynamics of bequest per child (Galor and Zang, 1997) 
of human capital investment $(h) . Q$ is a measure of inequality and higher $Q$ implies greater inequality. ${ }^{7}$ Now we have the following relationship:

$$
l_{t+1}^{s}=l_{t+1}^{s}\left(y_{t}, n, Q, h\right)
$$

Together with Equation (2.37), it follows:

$$
g_{t}=G\left(y_{t}, n, Q, e, h\right)
$$

where $e$ is 'basic' education that every individual obtains when they are young, so both $w_{n}$ and $w_{s}$ depend positively upon $e$.

Taking first-order approximation of Equation (2.39) yields the following:

$$
g_{t}=G_{n} n+G_{Q} Q+G_{y_{t}} y_{t}+G_{e} e+G_{h} h+u_{t}
$$

Galor and Zang (1997) then mathematically show that $G_{Q}<0$, i.e., the growth rate of an economy is higher, the more equally initial income is distributed. They also show that $G_{n}<0$, i.e., the growth rate of an economy is higher, the lower the rate of fertility is.

\subsubsection{The endogenous fertility approach: Evidence}

Following Equation (2.40), Galor and Zang (1997) specify their econometric model as follows:

$$
\begin{array}{r}
\text { GROWTH }=\beta_{0}+\beta_{1} F E R T+\beta_{2} G I N I+\beta_{3} G D P 60 \\
+\beta_{4} P S C H O O L+\beta_{5} \text { PUBEDU }
\end{array}
$$

where GINI is the Gini coefficient and PUBEDU is the average public expenditure ratio relative to GNP for the period 1960-1983. The estimation result is presented

\footnotetext{
${ }^{7}$ This definition is problematic. We will discuss this issue shortly.
} 
in Table 2.7. It is consistent with the empirical implication of the model: given the rate of fertility, the more equal an economy is, the higher is the growth rate; given income distribution, the lower the rate of fertility is, the higher is the growth rate. Estimates of all the coefficients have anticipated signs and are statistically significant at at least 5 per cent.

Table 2.7: Galor and Zang (1997)

\begin{tabular}{ccccccc}
\hline \hline & constant & $F E R T$ & GINI & GDP60 & PSCHOOL & PUBEDU \\
\hline GROWTH & 3.2038 & -0.2547 & -3.9620 & -0.2011 & 0.0293 & 0.1785 \\
& $(3.190)$ & $(-2.182)$ & $(-2.211)$ & $(-6.056)$ & $(4.806)$ & $(1.820)$ \\
\hline
\end{tabular}

NB: Values in the parentheses are $t$ statistics.

Regarding the magnitude of effect of fertility and inequality upon growth, a reduction of the net fertility rate by a point lead to an increase in GROWTH by about 0.25 percentage point and a one standard deviation decrease in GINI leads to an increase in GROWTH by 0.32 percentage point. Again, let us emphasise that these effects are not negligible.

Their estimation shows that both fertility and inequality have significant effect upon economic growth. However, they do not deal with a system of equations as fertility is given exogenously in their model. In this sense, their result does not tell us anything about the joint decision on fertility and investment in human capital.

Perotti (1996) goes one step further in this respect, and estimates the following system of equations.

$$
\left\{\begin{array}{l}
\text { GROWTH }=\beta_{0}+\beta_{1} G D P 60+\beta_{2} P P P I+\beta_{3} F E R T \\
F E R T=\gamma_{0}+\gamma_{1} G D P 60+\gamma_{2} M S E+\gamma_{3} F S E+\gamma_{4} M I D D L E,
\end{array}\right.
$$

where FERT is the net fertility rate average of 1965 and 1985 values. $^{8}$ The estimation result (Table 2.8) appears consistent with what the theory predicts. The

\footnotetext{
${ }^{8}$ The net fertility rate is constructed as the total fertility rate multiplied by ( 1 minus infant mortality rate in the first year of life).
} 
negative estimate of the coefficient on $M I D D L E$ in the second equation is as anticipated and is statistically significant. The estimate of the coefficient on FERT in the first equation is negative and statistically significant, which implies that the growth rate will be higher, the lower the fertility rate is. A one standard deviation increase in $M I D D L E$ decreases FERT by about 0.55 , which in turn increases GROWTH by approximately 0.87 percentage point. This magnitude is about a half of its standard deviation, which is not negligible.

Table 2.8: Perotti (1996): The endogenous fertility approach

\begin{tabular}{lccccc}
\hline \hline & constant & GDP60 & PPPI & FERT & \\
\hline GROWTH & 0.101 & -0.010 & 0.011 & -0.016 & \\
& $(6.27)$ & $(-4.45)$ & $(1.29)$ & $(-5.10)$ & \\
\hline \hline FERT & constant & GDP60 & MSE & FSE & MIDDLE \\
\hline & 8.903 & -0.466 & -1.380 & 1.368 & -10.310 \\
& $(11.92)$ & $(-5.63)$ & $(-3.1-9)$ & $(2.92)$ & $(-4.24)$ \\
\hline
\end{tabular}

NB: Values in the parentheses are $t$ statistics.

Perotti (1996) then adds female secondary school enrolment ratio ( FSEC) to the second equation. When FSEC is controlled for, the estimate of the coefficient on $M I D D L E$ falls by approximately 40 per cent to -5.858 . Perotti (1996) argues that this implies the joint determination of fertility and the secondary school enrolment ratio (investment in human capital) as the model suggests, because this is showing fair part of FERT is explained by the effect of MIDDLE thorough FSEC. ${ }^{9}$

${ }^{9}$ Perotti (1996) also estimates the system where the first equation includes $F S E C$ instead of $F E R T$ and the dependent variable of the second equation is FSEC. In this case, when FERT is controlled for in the second equation, MIDDLE has no explanatory power for FSEC. We further discuss this issue in Chapter 5. 


\subsubsection{The endogenous fertility approach: Discussion}

Theoretical contribution of Galor and Zang (1997) is twofold. First, they derived the growth rate between two periods during transition, in order to observe the effect of inequality upon growth. This allows them to overcome the first problem in Galor and Zeira (1993) we previously pointed out.

Second, more importantly, Galor and Zang (1997) have attempted to incorporate fertility into the model by Galor and Zeira (1993). This has allowed them to come up with an econometric model including the fertility rate, which has enabled them to see the effect of fertility upon growth. The rate of fertility is, however, still given exogenously, in which case neither their theoretical nor econometric model capture the idea of the joint fertility and education decision.

However, Galor and Zang (1997) has not overcome the second problem in Galor and Zeira - the problem of defining inequality. They use inequality variable $Q$ in their paper and mathematically show that growth is negatively related to this variable. However, this hinges upon the assumption they impose: ${ }^{10}$

$$
\frac{\partial l_{t+1}^{s}}{\partial Q}<0
$$

In order for this to hold in general, we need to use the same definition of inequality as in Galor and Zeira (1993).

Let us turn to discuss the empirical side. Aside from Galor and Zang (1997), we have reviewed a study by Perotti (1996). He specifies a system of equations in an ad hoc manner and has attempted to support the endogenous fertility approach. However, his estimation is problematic in the following sense. In specifying his econometric model, Perotti (1996) has a strong prior belief that fertility and investment in human capital are jointly determined. However, the way he has controlled for FSEC contradicts to this prior belief, i.e., FSEC is treated exogenous to the system. If fertility and schooling decisions are made jointly, the system

\footnotetext{
${ }^{10}$ This is Equation (33) in Galor and Zang (1997)
} 
should be estimated with both FERT and FSEC being treated as endogenous variables.

Aside from this, a couple of issues regarding human capital are worth discussing. Note that female education is used in all estimations we introduced. However, it is under dispute which variable should be used as a proxy for human capital. ${ }^{11}$ In fact, Perotti (1996) also estimates the system using male education and reports that, rather surprisingly, any significant changes are observed between the estimation results.

Note also that in all the empirical studies we have reviewed, the flow of human capital, i.e., the enrolment ratio, is used in the growth equation. In other empirical studies such as Barro and Lee (1994), in contrast, the stock of human capital, i.e., the average years of schooling, is used in the growth equation. The choice of which variable to use usually has to do with the theoretical model underlying the econometric model. In Galor and Zang (1997), the flow of human capital (e) is used since they try to explain growth between two periods in transition. However, it is not clear why the flow of human capital is employed in Perotti (1996) in which the econometric model is specified in an ad hoc manner. ${ }^{12}$

\subsection{Concluding remarks: Contribution to the lit-}

\section{erature}

We have reviewed both the theoretical and the empirical literature. A number of reduced form regressions present a negative relationship between inequality and growth, which challenge the conventional view that inequality is good for growth. Four strands of theoretical approaches have been proposed to explain this negative relationship. Corresponding to these theoretical studies, some empirical studies, but not many, have been conducted in order to support them.

\footnotetext{
${ }^{11}$ This will be discussed in Chapter 5 .

${ }^{12}$ This issue will also be further discussed in Chapter 5.
} 
From reviewing theoretical and empirical studies by different approach, it appears that there is still plenty of room for further research both theoretically and empirically. Theories possess shortcomings that have to be overcome. Empirical studies that estimate a system of equations are rare. Estimation results are not particularly in favour of the theories they intend to support and some estimation appears to contain serious problems as discussed.

This thesis, from the four approaches, focuses upon the endogenous fertility approach. As we have seen, no theoretical model that deals simultaneously with inequality, endogenous fertility, investment in human capital, and growth is present. Our theoretical models in the following two chapters do deal simultaneously with these four economic factors, which is the principal theoretical contribution of this thesis to the literature.

In the next chapter, we further extend models by Galor and Zeira (1993) and Galor and Zang (1997) to incorporate endogenous fertility. As in these two previous studies, however, the way we will define inequality is still problematic in the next chapter. Furthermore, an economy in this framework turns out to be destined to exhibit negative growth, which is unrealistic. We will conclude that this is an inevitable consequence in this kind of framework where two steady states exist.

Hence, Chapter 4 attempts to deal simultaneously with the above four economic factors using a different framework. We incorporate inequality into a study by Ehrlich and Lui (1991) where they model endogenous fertility, investment in human capital, and growth. The new feature here is that we use an endogenous growth framework. Depending upon parameter values, this model produces different growth regimes with different long run growth rates, so an economy can exhibit positive growth under certain conditions. In Chapter 4, instead of using the problematic definition of inequality we have seen in this chapter, we employ the coefficient of variation of output per worker as a measure of inequality. We use numerical simulations to derive an implication for the relationship between inequality and growth. 
We also contribute to the empirical literature. In Chapter 5, we test our conjecture derived from our theoretical model. It conjectures that the effect of inequality upon growth is non-monotonic, in contrast to what the existing reduced form studies have found. We construct a structural econometric model based upon our theoretical implication from Chapter 4 so that we can interpret the estimation result clearly. Fertility and investment in human capital are both treated as endogenous variables in the system, unlike in Perotti (1996). We conduct a formal test for endogeneity and confirm that fertility and education are determined jointly. The non-monotonic nature of the effect of inequality upon growth is supported by the data, which questions the common agreement that inequality impedes growth in all cases. 


\section{Chapter 3}

\section{Endogenising fertility}

\subsection{Introduction}

This chapter incorporates endogenous fertility into models of inequality, investment in human capital, and growth, such as Galor and Zeira (1993). The chapter is structured as follows. The model is described in the following section. Section 3.3 describes the dynamics of the economy. In Section 3.4, a negative relationship between economic growth (in transition) and initial inequality is derived. Section 3.5 discusses some problems that arise from the model.

\subsection{The model}

Consider a small open economy where there is only one good, which can be used for either consumption or investment. We assume a constant returns to scale production technology. The output of the good in Period $t\left(Y_{t}\right)$ is given as follows:

$$
Y_{t}=F\left(K_{t}, \lambda N_{t}\right)=\lambda N_{t} f\left(k_{t}\right)
$$

where $K_{t}$ and $N_{t}$ are physical capital and labour utilised in Period $t, \lambda N_{t}$ is effective labour, and $k_{t}$ is physical capital per effective labour. We assume that $f$ behaves nicely, i.e. $f$ is positive, strictly concave and monotonic, and satisfying the Inada 
conditions. The productivity parameter, $\lambda$, depends upon whether an individual is educated or uneducated. We will come back to this matter later.

We assume that physical capital is perfectly mobile across countries and the constant world interest rate is given by $\bar{r}>0$. It is also assumed that both the goods and labour markets are competitive. The rate of interest $(\bar{r})$ and the wage rate per effective labour $(\bar{w})$ therefore are given as follows:

$$
\begin{aligned}
& \bar{r}=f^{\prime}\left(k_{t}\right)=f^{\prime}(\bar{k}), \\
& \bar{w}=f(\bar{k})-f^{\prime}(\bar{k}) \bar{k} .
\end{aligned}
$$

We consider individuals who live for two periods in overlapping generations. Let us consider an individual who is born in Period $t$. When she is born, her parent decides whether she receives education. From the middle of Period 1 to the middle of Period 2, she works as a skilled worker if she has received education but works as an unskilled worker if otherwise. We assume she receives her wage in advance when she starts working.

Each individual has one unit of effective labour when she is born, and if she does not receive education it remains intact. Individuals who have received education have more units of effective labour, $\theta>1$, which is assumed to be constant over time. More formally, we can write this relationship as follows:

$$
\lambda= \begin{cases}1 & \text { if not educated } \\ \theta>1 & \text { if educated }\end{cases}
$$

The wage rates of unskilled and skilled workers, therefore, are $\bar{w}$ and $\bar{w} \theta$, respectively. She cannot, however, utilise all her earnings by herself. We assume that there is a custom, which people will follow, that she gives a certain ratio $(\delta)$ of her earnings to her parent.

At the end of Period 1 , she receives bequest $\left(b_{t-1}\right)$ from her parent. Together with her earnings from work, at the beginning of Period 2, she decides whether to 
have one educated child or to have many uneducated children. To give education to her child, she has to pay $h>0$, which is assumed to be constant over time. We assume that $h$ goes to infinity from the second child, i.e., there is no incentive for a parent to have two educated children. It is also assumed that a parent does not have one educated child and other uneducated children at the same time. The cost of rearing children depends upon the number of children $\left(n_{t}\right)$, and we denote it by $g\left(n_{t}\right)$, where $g$ is positive, strictly convex, and monotonic. She saves her remaining earnings and will receive it with interest at the end of Period 2.

Since there is a custom for children to support their parent, which all children will follow, she receives support from her child(ren) in the middle of Period 2. At the end of Period 2, she decides how much to consume and how much to bequeath to her offspring. Her utility stems from her consumption and her bequest, both determined by her at the end of Period 2, and it is represented by the Cobb-Douglas utility function as follows:

$$
U=\alpha \log c+(1-\alpha) \log B
$$

where $c$ is consumption in Period 2, B is total bequest which will be equally divided amongst all children, and $\alpha$ is a parameter which takes a value between 0 and $1{ }^{1}$

Now let us analyse optimal decisions by individuals. Consider an individual who receives $b_{t-1}$ from her parent and earns $z_{t}$. Let us call $b_{t-1}+(1-\delta) z_{t}$ her disposable income and denote it by $x_{t}$. If she can afford to let her child receive education, her expected income in the middle of Period 2 will be:

$$
\left[x_{t}-(g(1)+h)\right](1+\bar{r})+\delta \bar{w} \theta
$$

and her expected utility at the end of Period 2 will be:

\footnotetext{
${ }^{1}$ It is apparent that for a parent who cannot afford her child's education having more children is preferable to having no child, since her utility explodes to minus infinity if she does not have any child $(B=0)$.
} 


$$
\log \left[\left[x_{t}-(g(1)+h)\right](1+\bar{r})+\delta \bar{w} \theta\right]+\epsilon,
$$

where $\epsilon=\alpha \log \alpha+(1-\alpha) \log (1-\alpha)$.

If she cannot afford to let her child receive education, she will choose to have more children, so that her expected income in the middle of Period 2 will be:

$$
\left[x_{t}-g\left(n_{t}\right)\right](1+\bar{r})+n_{t} \delta \bar{w}
$$

and her expected utility at the end of Period 2 will be:

$$
\log \left[\left[x_{t}-g\left(n_{t}\right)\right](1+\bar{r})+n_{t} \delta \bar{w}\right]+\epsilon
$$

Maximising Equation (3.9) with respect to $n_{t}$ gives the optimal number of children $(n)^{2}$ :

$$
n \equiv n_{t}=\left(g^{\prime}\right)^{-1}\left(\frac{\delta \bar{w}}{1+\bar{r}}\right)
$$

We assume that $n(\delta, \bar{w}, \bar{r})>1$.

Since the situation in which individuals prefer not to invest in their child's education is the least interesting, we confine our analysis to the case where individuals prefer to invest in their child's education if they can afford it, i.e., we assume that the following relationship holds:

$$
\delta \bar{w}(\theta-n)>(1+\bar{r})[(g(1)+h)-g(n)]
$$

This relationship can be easily derived by comparing utilities of a parent who has invested to her child's education and of a parent who has not. Note it also implies that $\theta>n$ holds.

\footnotetext{
${ }^{2}$ We omit integer restrictions on the number of children throughout.
} 
There will be two types of individuals in this economy. On one hand, there will be individuals whose disposable income is greater than or equal to $g(1)+h$ and they bequeath:

$$
B_{t}^{s}=(1-\alpha)\left[\left[x_{t}-(g(1)+h)\right](1+\bar{r})+\delta \bar{w} \theta\right]
$$

On the other hand, individuals whose disposable income is less than $g(1)+h$ bequeath:

$$
B_{t}^{u}=(1-\alpha)\left[\left[x_{t}-g(n)\right](1+\bar{r})+n \delta \bar{w}\right]
$$

In this economy, the working status of children (born in Period $t$ ) and bequest they receive are dependent upon the amount of disposable income their parents (born in Period $t-1$ ) have. Therefore, distribution of disposable income in Period $t-1$ is very important in determining the number of skilled and unskilled workers in Period $t$. We denote the distribution of disposable income for people who were born in Period $t-1$ by $D_{t-1}$ and the population by $N_{t-1}$. Then it follows:

$$
\int_{0}^{\infty} d D_{t-1}\left(x_{t-1}\right)=N_{t-1}
$$

This distribution determines the numbers of skilled and unskilled workers in Period $t$ that are respectively:

$$
\begin{array}{r}
N_{t}^{s}=\int_{g(1)+h}^{\infty} d D_{t-1}\left(x_{t-1}\right)=N_{t-1}^{s} \\
N_{t}^{u}=n \int_{0}^{g(1)+h} d D_{t-1}\left(x_{t-1}\right)=n N_{t-1}^{u}
\end{array}
$$

where $N_{t-1}^{s}$ and $N_{t-1}^{u}$ are the numbers of skilled and unskilled workers in Period $t-1$, respectively. 


\subsection{The dynamics of disposable income distribu- tion}

Now we turn to analyse the dynamics of the model. The distribution of disposable income in the next period $\left(x_{t+1}\right)$ is written as follows:

$x_{t+1}= \begin{cases}\frac{(1-\alpha)}{n}\left[\left[x_{t}-g(n)\right](1+\bar{r})+n \delta \bar{w}\right]+(1-\delta) \bar{w} & \text { if } x_{t}<g(1)+h \\ (1-\alpha)\left[\left[x_{t}-(g(1)+h)\right](1+\bar{r})+\delta \bar{w} \theta\right]+(1-\delta) \bar{w} \theta & \text { if } g(1)+h \leq x_{t} .\end{cases}$

Figure 3.1 describes the situation. The curves in Figure 3.1 describe the dynamic relationship between disposable income of two consecutive periods for two types of individuals.

On one hand, individuals whose disposable income is greater than or equal to $g(1)+h$ invest in their child's education so that they work as skilled workers. Their descendants in every future generation will do so as well, so that their disposable income converges to the long run level $\overline{x_{s}}$ :

$$
\bar{x}_{s}=\frac{(1-\alpha) \delta \bar{w} \theta+(1-\delta) \bar{w} \theta-(1-\alpha)(1+\bar{r})(g(1)+h)}{1-(1-\alpha)(1+\bar{r})} .
$$

On the other hand, individuals whose disposable income is less than $g(1)+h$ do not invest in education and have $n$ unskilled children. Their descendants in the all future generations will do so as well, and therefore in the long run their disposable income converges to $\overline{x_{u}}$ :

$$
\overline{x_{u}}=\frac{(1-\alpha) \delta \bar{w} n+(1-\delta) \bar{w} n-(1-\alpha)(1+\bar{r}) g(n)}{n-(1-\alpha)(1+\bar{r})} .
$$

Therefore, in the long run, individuals in this economy will be divided into two groups of individuals: skilled workers whose disposable income is $\overline{x_{s}}$ and unskilled workers whose disposable income is $\overline{x_{u}}$. 


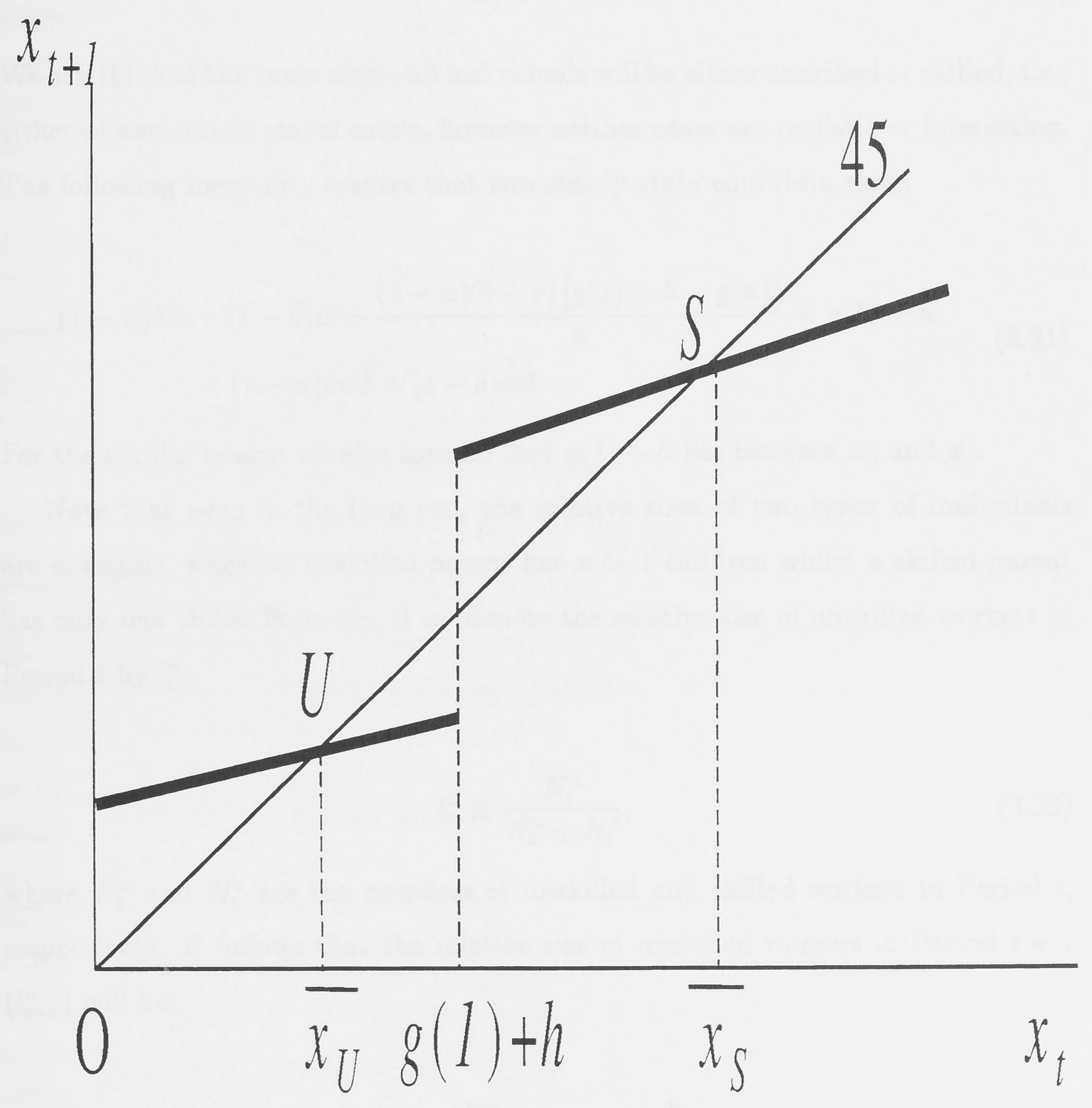

Figure 3.1: Dynamics of disposable income 
In order for Points $\mathrm{S}$ and $\mathrm{U}$ in Figure 3.1 to be locally stable, we assume the following relationships between $\alpha$ and $\bar{r}$ :

$$
(1-\alpha)(1+\bar{r})<1
$$

We can think of the cases where all individuals will be either unskilled or skilled, i.e., either of two steady states exists, however neither cases are realistic or interesting. The following inequality assures that two steady state equilibria exist:

$$
\begin{aligned}
(1-\alpha) \delta \bar{w} & +(1-\delta) \bar{w}+\frac{(1-\alpha)(1+\bar{r})[g(1)+h-g(n)]}{n}<g(1)+h \\
& <(1-\alpha) \delta \bar{w} \theta+(1-\delta) \bar{w} \theta
\end{aligned}
$$

For the similar reason we also assume that $g(1)+h$ lies between $\overline{x_{u}}$ and $\overline{x_{s}}$.

Note that even in the long run, the relative sizes of two types of individuals are changing, since an unskilled parent has $n>1$ children whilst a skilled parent has only one child. Formally, if we denote the relative size of unskilled workers in Period $t$ by $l_{t}^{u}$ :

$$
l_{t}^{u} \equiv \frac{N_{t}^{u}}{N_{t}^{u}+N_{t}^{s}}
$$

where $N_{t}^{u}$ and $N_{t}^{s}$ are the numbers of unskilled and skilled workers in Period $t$, respectively. It follows that the relative size of unskilled workers in Period $t+1$ $\left(l_{t+1}^{u}\right)$ will be:

$$
l_{t+1}^{u}=\frac{n N_{t}^{u}}{n N_{t}^{u}+N_{t}^{s}}=\frac{n l_{t}^{u}}{1+(n-1) l_{t}^{u}} .
$$

Throughout the rest of this chapter, we use $l_{t}^{u}$ as the measure of inequality in Period $t$, i.e., the larger $l_{t}^{u}$ is, the more unequal the society is ${ }^{3}$.

\footnotetext{
${ }^{3}$ This definition of inequality is used both in Galor and Zeira (1993) and Galor and Zang (1997), which turns out to be problematic. Discussion is provided in the last section of this chapter.
} 
Let us denote the average disposable income of working individuals by $\overline{x_{T}}$. Then the steady state level of the average disposable income of working individuals, $\bar{x}$, is written as follows:

$$
\bar{x}=\lim _{T \rightarrow \infty} \overline{x_{T}}=\overline{x_{s}}-\lim _{T \rightarrow \infty} l_{T}^{u}\left[\overline{x_{s}}-\overline{x_{u}}\right]
$$

From Equation (3.22), we know that $\lim _{T \rightarrow \infty} l_{T}^{u}=1$, hence:

$$
\bar{x}=\overline{x_{u}} .
$$

This is just showing that, in the long run, the economy will be dominated by the unskilled workers. This result is not surprising because whilst the number of skilled workers remains constant throughout, the number of unskilled workers increases over time. Unless there is no unskilled individual in the beginning, this long run result will be the same for all initial distribution of income. Therefore, in order to derive a more meaningful result, we will look at a relationship between initial distribution of income and growth in transition.

\subsection{Growth in transition}

In order to calculate the growth rate of disposable income per capita between two consecutive periods, let us begin with denoting aggregate disposable income and average disposable income (amongst working people) in Period $t+1$ by $X_{t+1}$ and $x_{t+1}$, respectively. Then it follows:

$$
X_{t+1}=x_{t+1} N_{t+1}=n \int_{0}^{p} x_{t+1}^{u} d D_{t}\left(x_{t}\right)+\int_{p}^{\infty} x_{t+1}^{s} d D_{t}\left(x_{t}\right)
$$

where $p \equiv g(1)+h$. Substituting Equation (3.17) into Equation (3.26) gives: 


$$
\begin{aligned}
X_{t+1}= & x_{t+1} N_{t+1}=n \int_{0}^{p}\left[\frac{(1-\alpha)}{n}\left[\left[x_{t}-g(n)\right](1+\bar{r})+n \delta \bar{w}\right]+(1-\delta) \bar{w}\right] d D_{t}\left(x_{t}\right) \\
& +\int_{p}^{\infty}\left[(1-\alpha)\left[\left[x_{t}-(g(1)+h)\right](1+\bar{r})+\delta \bar{w} \theta\right](1-\delta) \bar{w} \theta\right] d D_{t}\left(x_{t}\right) .
\end{aligned}
$$

After tedious calculation, we obtain an alternative representation of Equation $(3.27)$ :

$$
\begin{aligned}
X_{t+1} & =[(1-\alpha)[\delta \bar{w} \theta-(g(1)+h)(1+\bar{r})]+(1-\delta) \bar{w} \theta] N_{t} \\
& +[(1-\alpha)[n \delta \bar{w}-\delta \bar{w} \theta+(g(1)+h-g(n))(1+\bar{r})]+(1-\delta) \bar{w}(n-\theta)] l_{t}^{u} N_{t} \\
& +(1-\alpha)(1+\bar{r}) x_{t} N_{t} .
\end{aligned}
$$

Dividing Equation (3.28) by $N_{t+1}$ gives $x_{t+1}$ in terms of $x_{t}$ :

$$
\begin{aligned}
x_{t+1} & =A \frac{N_{t}}{N_{t+1}}+E l_{t}^{u} \frac{N_{t}}{N_{t+1}}+(1-\alpha)(1+\bar{r}) x_{t} \frac{N_{t}}{N_{t+1}} \\
& =\frac{N_{t}}{N_{t+1}}\left[A+E l_{t}^{u}+(1-\alpha)(1+\bar{r}) x_{t}\right],
\end{aligned}
$$

where,

$$
\begin{gathered}
A=(1-\alpha)[\delta \bar{w} \theta-(g(1)+h)(1+\bar{r})]+(1-\delta) \bar{w} \theta \\
E=(1-\alpha)[n \delta \bar{w}-\delta \bar{w} \theta+(g(1)+h-g(n))(1+\bar{r})]+(1-\delta) \bar{w}(n-\theta) .
\end{gathered}
$$

In the meantime, the ratio of $N_{t}$ to $N_{t+1}$ can be easily calculated as follows:

$$
\begin{aligned}
\frac{N_{t}}{N_{t+1}} & =\frac{N_{t}}{n N_{t}^{u}+N_{t}^{s}}=\frac{N_{t}}{n l_{t}^{u} N_{t}+\left(1-l_{u}^{t}\right) N_{t}} \\
& =\frac{1}{(n-1) l_{t}^{u}+1} .
\end{aligned}
$$


Substituting Equation (3.30) into Equation (3.29) and dividing both sides by $x_{t}$ yields the following:

$$
\frac{x_{t+1}}{x_{t}}=\frac{1}{(n-1) l_{t}^{u}+1}\left[\frac{A}{x_{t}}+\frac{E l_{t}^{u}}{x_{t}}+(1-\alpha)(1+\bar{r})\right] .
$$

Now what we want is the growth rate of disposable income per capita between Period $t$ and Period $t+1\left(\gamma_{t}\right)$. Let us denote disposable income per capita in Period $t$ by $q_{t}$. Then it follows:

$$
x_{t} N_{t}=q_{t}\left(N_{t}+N_{t+1}\right) .
$$

Hence we can write $q_{t}$ in terms of $x_{t}$ as follows:

$$
q_{t}=\frac{x_{t}}{2+(n-1) l_{t}^{u}}
$$

Using this equation the rate of growth of disposable income per capita can be written in terms of $x_{t}$ and $x_{t+1}$ :

$$
\gamma_{t}=\frac{q_{t+1}}{q_{t}}-1=\frac{x_{t+1}}{x_{t}} \frac{2+(n-1) l_{t}^{u}}{2+(n-1) l_{t+1}^{u}}-1
$$

Substituting Equation (3.23) into this equation gives the following:

$$
\gamma_{t}=\frac{x_{t+1}}{x_{t}} \frac{\left[2+(n-1) l_{t}^{u}\right]\left[(n-1) l_{t}^{u}+1\right]}{2+(n+2)(n-1) l_{t}^{u}}-1
$$

Finally substituting Equation (3.31) into this equation yields the following equation:

$$
\gamma_{t}=\left[\frac{A}{x_{t}}+\frac{E l_{t}^{u}}{x_{t}}+(1-\alpha)(1+\bar{r})\right] \frac{2+(n-1) l_{t}^{u}}{2+(n+2)(n-1) l_{t}^{u}}-1
$$


As we will formally state in the proof of Proposition 1 shortly, the growth rate of disposable income per capita in Period $t\left(\gamma_{t}\right)$ is negatively related to the proportion of unskilled workers in that period $\left(l_{t}^{u}\right)$. Hence, given the evolution of population in this economy, the growth rate of disposable income per capita is also negatively related to the initial proportion of unskilled workers $\left(l_{0}^{u}\right)$. We can, thus, observe two different countries achieving different growth rates of disposable income per capita due to the difference in initial inequality in disposable income.

Let us summarise the effect of income distribution upon the growth rate of disposable income per capita in the following proposition:

Proposition 1. Consider countries that are identical except for the initial distribution of income. The more unequally income is distributed, the lower the growth rate of income per capita will be.

Proof. First, let us use the following notations for simplicity:

$$
\begin{gathered}
c\left(l_{t}^{u}\right)=\frac{A}{x_{t}}+\frac{E l_{t}^{u}}{x_{t}}+(1-\alpha)(1+\bar{r}), \\
d\left(l_{t}^{u}\right)=\frac{2+(n-1) l_{t}^{u}}{2+(n+2)(n-1) l_{t}^{u}} .
\end{gathered}
$$

Calculating the first derivative of Equation (3.36) with respect to $l_{t}^{u}$ yields the following:

$$
\frac{\partial \gamma_{t}}{\partial l_{t}^{u}}=\frac{\partial c\left(l_{t}^{u}\right)}{\partial l_{t}^{u}} d\left(l_{t}^{u}\right)+\frac{\partial d\left(l_{t}^{u}\right)}{\partial l_{t}^{u}} c\left(l_{t}^{u}\right)
$$

We show this is negative. To this end, let us show the signs of $\frac{\partial c\left(l_{t}^{u}\right)}{\partial l_{t}^{u}}, d\left(l_{t}^{u}\right)$ and $\frac{\partial d\left(l_{t}^{u}\right)}{\partial l_{t}^{u}}$, and $c\left(l_{t}^{u}\right)$ in turn.

First:

$$
\frac{\partial c\left(l_{t}^{u}\right)}{\partial l_{t}^{u}}=\frac{E}{x_{t}}<0,
$$


since $x_{t}>0$, and it follows from Equation (3.12) and $n>1$ that $E>0$.

Second, it is apparent that $d\left(l_{t}^{u}\right)>0$ since $n>1$ and $0<l_{t}^{u}<1$.

Third, since $n>1$ :

$$
\frac{\partial d\left(l_{t}^{u}\right)}{\partial l_{t}^{u}}=-\frac{2\left(n^{2}-1\right)}{\left[2+(n+2)(n-1) l_{t}^{u}\right]^{2}}<0 .
$$

Finally:

$$
c\left(l_{t}^{u}\right)=\frac{A+E l_{t}^{u}+(1-\alpha)(1+\bar{r}) x_{t}}{x_{t}}
$$

It is apparent that the denominator is positive, so we check the sign of the numerator by which we denote $\nu$ :

$$
\begin{aligned}
\nu= & (1-\alpha)\left(1-l_{t}^{u}\right)[\delta \bar{w}(\theta-n)-(1+\bar{r})[(g(1)+h)-g(n)]]+(1-\delta) \bar{w} \theta\left(1-l_{t}^{u}\right) \\
& +(1-\delta) \bar{w} n l_{t}^{u}+(1-\alpha)\left[\left[x_{t}-g(n)\right](1+\bar{r})+n \delta \bar{w}\right] .
\end{aligned}
$$

The second and third terms are obviously positive, and the first and fourth terms are positive as well, from Equation (3.8) and Equation (3.12), respectively. We have shown that $c\left(l_{t}^{u}\right)>0$.

Hence:

$$
\frac{\partial \gamma_{t}}{\partial l_{t}^{u}}=\frac{\partial c\left(l_{t}^{u}\right)}{\partial l_{t}^{u}} d\left(l_{t}^{u}\right)+\frac{\partial d\left(l_{t}^{u}\right)}{\partial l_{t}^{u}} c\left(l_{t}^{u}\right)<0 .
$$

Using the Chain Rule:

$$
\frac{\partial \gamma_{t}}{\partial l_{0}^{u}}=\frac{\partial \gamma_{t}}{\partial l_{t}^{u}} \frac{\partial l_{t}^{u}}{\partial l_{0}^{u}}
$$

We know that the second term of the RHS of this equation is positive and we have already shown that the first term of the RHS of this equation is negative. Hence we have obtained the result we want:

$$
\frac{\partial \gamma_{t}}{\partial l_{0}^{u}}<0
$$




\subsection{Concluding remarks}

In this chapter, we have examined a model in which initial inequality plays an important role affecting the growth rate of income per capita in transition, through investment in human capital and fertility. This study shows that growth is affected by initial income distribution, and that different countries with the same technology could grow at different rates. More specifically, we have found that inequality hinders growth in transition, since in a more unequal country, less people invest in human capital and also population growth is higher.

However, the model we have explored has several problems. One of them is that too many rules are imposed upon the model. The model has only two optimisation problems - one by every individual when one choose how much to consume and bequeath, and the other by unskilled workers when they choose the number of children. The other decisions are given by the rules, such as, individuals always investment in human capital when it is feasible; the cost of having a second educated child is prohibitively high, etc.

Aside from this, this model has two major problems. One is that the model consistently generates negative long run growth of output per capita. This arises because of the new feature of this model, endogenous fertility. In our model, not only do individuals choose whether they educate their children but they also choose how many children they have. Due to this, the evolutions of population for two types of individuals are different. Whilst the number of high productivity people remains constant, the number of low productivity people increases at $n>1 .^{4}$ Therefore, in the long run, as low productivity people will completely dominate the economy, it is destined to exhibit negative growth. ${ }^{5}$ This unrealistic feature of the model has to be overcome.

\footnotetext{
${ }^{4}$ In models by Galor and Zeira (1993) and Galor and Zang (1997), this asymmetry in population growth is not present, so the problem of negative growth has not occurred.

${ }^{5}$ Unless initially there is no unskilled worker in the economy, in which case, economy will exhibit zero growth in the long run.
} 
The other major problem is the definition of inequality. In this paper, we define inequality as the proportion of unskilled workers to the whole population. This is problematic since there are obvious discrepancies between this definition and the "ordinary" inequality definitions. For example, in the long run, the economy is described as completely unequal using this definition because it is dominated by unskilled workers, but it is described as completely equal using some other "ordinary" inequality definitions because those unskilled workers who dominate the economy are identical in terms of their disposable income. The use of an "ordinary" measure of inequality is required. These problems will be overcome by the model we construct in the next chapter. 


\section{Chapter 4}

\section{Education, fertility, and growth: Does inequality matter?}

\subsection{Introduction}

The model we explore in this chapter not only deals simultaneously with inequality, investment in human capital, fertility, and growth, but it also overcomes two major problems raised in the previous chapter. At the same time, we deal with more complicated optimisation problems than that in the previous chapter, hence less rules are imposed upon the model.

We begin with the overlapping generations model (OLG) of Ehrlich and Lui (1991) (hereafter E\&L). In their model, a parent decides to have children in order to obtain both "companionship" and income support in their old-age. The amount of old-age support depends upon how much education they decide to provide as well as how many children they decide to have. Their prominent message is that an economy could either stagnate, having large numbers of children who are less educated, or approach the balanced growth path induced by the accumulation of human capital, where the number of children per family is driven down to its minimum level. Accordingly, they claim that changes in economic factors such as better health care that increases probability of survival could be important for an 
economy as a whole to start going through the demographic transition.

We give a different interpretation to their model. Instead of looking at an economy as a whole, we look at a number of heterogeneous individuals within an economy. First, we focus upon the evolution of these heterogeneous individuals and their descendants (dynasties henceforth). The model predicts that individual output for some dynasties could grow but for others it could stagnate. Then we sum up the dynasties and focus upon an economy as a whole. This will enable us to see if different initial distributions of human capital have different implications for the evolution of the economy.

One of the distinguishing features of the model in this chapter is that the economy could exhibit endogenous growth. No previous attempt has been made to analyse the inequality effect upon growth via human capital and fertility within the endogenous growth model framework, where long run positive growth is observed.

Unlike the model in the previous chapter that consistently generates negative growth, various types of (long run) dynamics could be considered according to the different values of parameters. We will focus upon two particular types of economies - one that has experienced the productivity take-off, and the other that has not. The latter type of economy is characterised by zero per-capita growth in the long run, whereas the former can exhibit positive long run per-capita growth. In the sense that this model can generate various long run growth dynamics, one of the drawbacks from the previous chapter, that the model consistently generates negative long run growth, has been overcome. We will also show that two types of economies, before and after the productivity take-off, have different implications for demographic dynamics - the productivity take-off is a prerequisite to the demographic transition for an economy.

We attempt to overcome the other problem raised in the previous chapter the definition of inequality. To this end, we assume that the initial distribution of human capital is lognormal and use the coefficient of variation as a measure 
of inequality. We study the relationship between initial inequality and subsequent growth conducting numerical simulations based upon two dynamic systems and the initial lognormal distribution of human capital. Considering a few economies that are identical but for the variance of initial human capital, we will compare how these economies evolve over time. In contrast to the existing empirical literature, the model predicts that inequality might have different implications for growth depending upon an economy's demographic stage of development. That is, the the effect of inequality upon growth is predicted to be non-monotonic.

The rest of the chapter is structured as follows. Section 4.2 describes the model. The dynamics of the economy, given a set of parameters, is examined numerically in Section 4.3. Section 4.4 discusses how different economies will evolve according to different initial distributions of human capital, and conjectures the impact of initial distribution on subsequent growth. Simulations are conducted in Section 4.5 in order to illustrate these conjectures. Concluding remarks are provided in Section 4.6.

\subsection{The model}

We consider a two-sector endogenous growth model without physical capital. Heterogeneous individuals live for three periods in overlapping generations. An individual is born as a child, becomes a young parent, and becomes an old parent before she dies. ${ }^{1}$

Let us consider an individual of dynasty $i$ who is born in Period $t-1$. When she is a child, she is dependent upon her parent and receives education from her parent. Let us denote the level of human capital she receives from her parent by $H_{t}^{i}$. Every individual is assumed to be endowed with the basic level of human capital $\bar{H}$. $\left(H_{t}^{i}+\bar{H}\right)$ will, therefore, be the level of human capital she possesses when she

\footnotetext{
${ }^{1}$ Some individuals will not survive for three periods, i.e., some people may die in Period One or Two.
} 
becomes a young parent at Period $t$. A child will survive to become a young parent with probability $\pi_{1}$ that is assumed to be constant over time and identical across individuals.

When she is a young parent, she is no longer dependent upon her parent and can produce a perishable consumption good $Q_{t}$, subject to the following production function:

$$
Q_{t}^{i}=\left(H_{t}^{i}+\bar{H}\right) l_{t}^{i}
$$

where $l_{t}^{i}$ denotes the time that is spent to produce this good. She produces this good since she gets utility from consuming it when she is a young parent, but she also takes her future consumption into account in making her production decision. In Period $t+1$ she will survive to become an old parent, but again with probability $\pi_{2}$ that is assumed to be constant over time and across individuals. She will be dependent upon her children at this stage of life. ${ }^{2}$ That is, she is no longer able to produce anything, but instead she can expect support from her children (if there are any). The amount of support depends upon both how much she has invested in her children's education and how many of her children survive to become a young parent. We will come back to this issue shortly.

A young parent has $T$ units of time. It is assumed that child rearing costs $v$ units of time per child. Hence, she faces the following time constraint:

$$
l_{t}^{i}=T-v n_{t}^{i}-h_{t}^{i} n_{t}^{i}
$$

\footnotetext{
${ }^{2}$ Not only are individuals unable to store a consumption good, but also they are assumed to have no access to credit markets. Therefore, in this model, children are treated as if they were financial assets. This treatment of children may be problematic especially when industrial countries are concerned, where most of people can use credit markets. However, it may be more realistic as far as developing countries are the focus, where not many people have access to credit markets. The assumption of imperfect credit markets is commonly imposed in the existing literature when developing countries are concerned.
} 
where $h_{t}^{i}$ is the time she devotes to educating each child and $n_{t}^{i}$ is the number of children.

A young parent may have an incentive to invest in education of her children as she can expect more support from them in the future. We assume that there is a custom that people will follow, in which a young parent gives her (old) parent an amount of the consumption good equivalent to a certain ratio $w$ of the education that she received, ${ }^{3}$ i.e., the level of human capital $H_{t+1} \cdot{ }^{4}$ Let us assume the following human capital production function:

$$
H_{t+1}^{i}=A\left(H_{t}^{i}+\bar{H}\right) h_{t}^{i}
$$

where $A$ is a positive productivity parameter and $H_{t+1}^{i}$ is the level of human capital that a child receives from her (young) parent.

Aside from material support, an old parent may find "companionship" by her children worthwhile. In order to specify this "companionship" function, we need the number of expected children. The number of surviving children is subject to a binomial distribution, where $n_{t}$ is the number of trials (children) and $\pi_{1}$ is the probability of success (survival). Therefore, the expected number of surviving children is $\pi_{1} n_{t}$. The "companionship" function is specified as follows:

$$
M_{t+1}^{i}=\left(\pi_{1} n_{t}^{i}\right)^{\gamma}
$$

\footnotetext{
${ }^{3}$ If $w$ is determined endogenously in the model, we get a system of nonlinear difference equations. Since the objective of this thesis is not uncovering the inter-generational transfer mechanism, the assumption of the constant compensation rate $w$ should not be important.

${ }^{4}$ This compensation scheme is the same as in E\&L. It makes sense since children compensate their parent in strict proportion to the latter's contribution to their productive capacity. The alternative scheme, which is more egalitarian, is to make children support their parent in proportion to the former's total human capital, i.e., children give their parent $w\left(H_{t+1}+\bar{H}\right)$. However, this difference is not essential. E\&L impose this assumption as well except in their simplest model.
} 
where $\gamma \in(0,1]$. This equation shows that "companionship" by children is subject to diminishing returns to the expected number of children unless $\gamma=1$. Given the expected number of surviving children, we can obtain the expected support that the surviving old parent can get and the expected support that the surviving young parent has to give, which are $\pi_{1} n_{t} w H_{t+1}$ and $\pi_{2} w H_{t}$, respectively.

Each individual gets utility from consumption when she is a young parent, and from consumption and "companionship" by her children when she is an old parent. Specifically, we assume the following CIES (constant intertemporal elasticity of substitution) utility function:

$$
u_{t}^{i}=\frac{\left(c_{1, t}^{i}\right)^{1-\theta}-1}{1-\theta}+\delta \pi_{2}\left[\frac{\left(c_{2, t+1}^{i}\right)^{1-\theta}-1}{1-\theta}+\frac{\left(M_{t+1}^{i}\right)^{1-\theta}-1}{1-\theta}\right]
$$

where $\theta>0$ is the inverse of the elasticity of intertemporal substitution, and $c_{1}^{i}$ and $c_{2}^{i}$ are consumption when she is a young parent and an old parent, respectively. ${ }^{5}$ The utility of consumption when she is old is discounted for the associated probability of survival $\pi_{2}$ and the rate of time preference $\rho$, with $\delta \equiv 1 /(1+\rho)$.

There may be a case where all children die, in which case, their parent will not get any support or "companionship" when she becomes an old parent. This will be a problem because having neither support nor "companionship" would imply that the change in her marginal utility is $-\infty$, given the CIES utility function as in Equation (4.5). Since a young parent is aware of this possibility, she will try to increase the number of children to $\infty$ in order to avoid this worst scenario. But since this is impossible from Equation (4.2), i.e., since having children incurs costs, the model becomes unsolvable. There are several ways to overcome this problem, but we follow the method as in E\&L. ${ }^{6}$ We assume that dynasty $i$ is the representative of a number

${ }^{5}-\theta$ is the elasticity of marginal utility, which is assumed to be constant. The higher $\theta$, the more rapid is the proportionate decline in $u^{\prime}(c)$ in response to increase in $c$ and, hence, the less willing individuals are to accept deviations from a uniform pattern of consumption over time. As $\theta$ approaches 0 , individuals are indifferent to the timing of consumption as long as $\delta \pi_{2}=1$.

${ }^{6}$ The alternative way is just to let an old parent work so that she can surely consume when she 
of identical dynasties with independent prospects of survival. The expected old-age support could be treated as certain, if the old-age insurance arrangement applied to this extended dynasty. Under this arrangement, all related people within the extended dynasty share in the actual responsibilities and benefits associated with old-age support and "companionship" through mutual assistance. Let us postulate that the insurance pool is large enough and administrative costs are negligible so that each intergenerational contract would be honoured on an actuarially fair basis. Then, the actual consumption flows of the representative surviving young parent and old parent can be written as follows, respectively:

$$
\begin{aligned}
c_{1, t}^{i} & =\left(H_{t}^{i}+\bar{H}\right)\left(T-v n_{t}^{i}-h_{t}^{i} n_{t}^{i}\right)-\pi_{2} w H_{t}^{i}, \\
c_{2, t+1}^{i} & =\pi_{1} n_{t}^{i} w H_{t+1}^{i},
\end{aligned}
$$

and the actual "companionship" received by an old parent can be written as in Equation (4.4).

Now let us analyse optimal decisions by the representative of dynasty $i$. Given $H_{t}^{i}$, a young parent of dynasty $i$ in Period $t$ chooses the optimal values of $n_{t}^{i} \geq 0$ and $h_{t}^{i} \geq 0$ in order to maximise her expected utility function (4.5) subject to Equations (4.4), (4.6), and (4.7). The first order conditions are as follows:

$$
\begin{aligned}
& \left(\frac{c_{2, t+1}^{i}}{c_{1, t}^{i}}\right)^{\theta} \geq \delta \pi_{2}\left(A \pi_{1} w\right)\left(\frac{h_{t}^{i}}{v+h_{t}^{i}}\right)\left[1+\gamma\left(\frac{M_{t+1}^{i}}{c_{2, t+1}^{i}}\right)^{1-\theta}\right] \equiv \delta \pi_{2} R_{t, n}^{i}, \\
& \left(\frac{c_{2, t+1}^{i}}{c_{1, t}^{i}}\right)^{\theta} \geq \delta \pi_{2}\left(A \pi_{1} w\right) \equiv \delta \pi_{2} R_{t, h}^{i},
\end{aligned}
$$

where $\delta \pi_{2} R_{n}^{i}$ and $\delta \pi_{2} R_{h}^{i}$ represent discounted expected rates of return on investment in quantity and quality of children, respectively. ${ }^{7}$

is an old parent. But this makes mathematics a lot more complicated without giving us further insight.

7If "companionship" were not assumed $(\gamma=0)$, the rate of return on investment in quality of children (education) would always exceed that on investment in quantity of children, provided that 
From these equations we can obtain the following relationship:

$$
R_{t, h}^{i} \gtreqless R_{t, n}^{i} \Longleftrightarrow \frac{v}{h} \gtreqless \gamma\left[\frac{\left(\pi_{1} n_{t}^{i}\right)^{\gamma-1}}{w H_{t+1}^{i}}\right]^{1-\theta}
$$

The following lemmas can be derived from this equation.

(E\&L) Lemma 1. The return on quantity of children $\left(R_{t, n}^{i}\right)$ cannot be greater than the return on quality of children $\left(R_{t, h}^{i}\right)$.

Proof. Suppose the return on quantity of children is greater than the return on quality of children. It follows that $h$ will approach zero and Equation (4.10) cannot hold in the way that the return on quantity of children exceeds the return on quality of children. Contradiction.

(E\&L) Lemma 2. If $H_{t}^{i}$ is sufficiently large and $\theta<1$, then the return on quality of children $\left(R_{t, h}^{i}\right)$ exceeds the return on quantity of children $\left(R_{t, n}^{i}\right)$ when $n$ has a positive lower bound. ${ }^{8}$

the compensation rate $w$ is positive. This is intuitively apparent as the equi-proportional increases in $h$ and $n$ give the same marginal utility benefits, but the marginal utility cost of $n$ is always greater than that of $h$ since the former involves the cost of both rearing and educating children whilst the latter only involves the cost of educating children. The equi-proportional increases in $h$

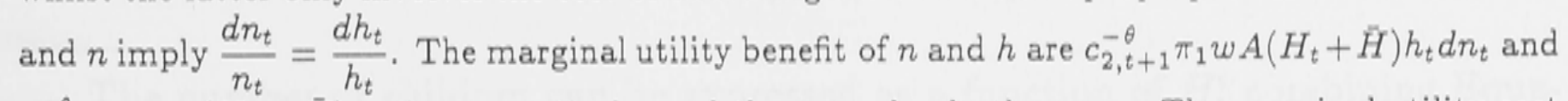
$c_{2, t+1}^{-\theta} \pi_{1} w A\left(H_{t}+\bar{H}\right) n_{t} d h_{t}$, respectively, and they are clearly the same. The marginal utility cost of $n$ is $c_{1, t}^{-\theta} d n_{t} h_{t}\left(H_{t}+\bar{H}\right)+c_{1, t}^{-\theta} d n_{t} v\left(H_{t}+\bar{H}\right)$ and the marginal utility cost of $h$ is $c_{1, t}^{-\theta} d h_{t} n_{t}\left(H_{t}+\bar{H}\right)$. The latter is the same as the first term of the marginal utility cost of $n$ given the equi-proportional increases in $h$ and $n$. Hence, the marginal utility cost of $n$ is always larger than that of $h$ by $c_{1, t}^{-\theta} d n_{t} v\left(H_{t}+\bar{H}\right)$. Under such circumstances, a young parent would want the number of children to be the smallest possible. Therefore, in order to solve the problem, we need to assume that $n$ has a lower bound. Given that $n$ has a lower bound, Equation (4.8) (with $\gamma=0$ ) will be met with strict inequality and Equation (4.9) will be met with equality.

${ }^{8}$ We will not consider the case where $\theta \geq 1$, since this is inconsistent with any economy that will be on the balanced growth path. Intuitively, if $\theta$ is high enough, then individuals want to a uniform patten of consumption over time, in which case they will not invest as much in human capital. 
Proof. The RHS of Equation (4.10) is decreasing in $H_{t}^{i}$, whereas the LHS has a lower bound. Hence, the return on quality of children must become higher than the return on quantity of children with a sufficiently high level of human capital.

Intuition behind this lemma is straightforward. As the level of human capital increases, old-age support from children increases, but "companionship" will not be affected by an increase in the level of human capital. Hence the return on quantity of children will become lower than that on quality of children, and eventually the optimal number of children will fall to its minimum level $1 .^{9}$

Let us simplify the model in order not to make mathematics unnecessarily complicated. We assume that $\gamma=1$, which implies constant marginal returns to companionship from having children. Given this, since the interior solution implies $R_{t, n}^{i}=R_{t, h}^{i}, h_{t}^{i}$ is determined by the following relationship:

$$
h_{t}^{i}=v^{\frac{1}{\theta}}\left[A w\left(H_{t}^{i}+\bar{H}\right)\right]^{\frac{1-\theta}{\theta}}
$$

Substituting this into Equation (4.3) yields:

$$
H_{t+1}^{i}=w^{\frac{1-\theta}{\theta}}\left[A v\left(H_{t}^{i}+\bar{H}\right)\right]^{\frac{1}{\theta}}
$$

The number of children can be expressed as a function of $H_{t}^{i}$ combining Equations (4.3), (4.6), (4.7), (4.9), and (4.11):

$$
n_{t}^{i}=\frac{A w\left[\left(T-\pi_{2} w\right) H_{t}^{i}+T \bar{H}\right]}{A v w\left(H_{t}^{i}+\bar{H}\right)+\left[A v w\left(H_{t}^{i}+\bar{H}\right)\right]^{\frac{1}{\theta}}\left[1+A Z^{-1}\right]}
$$

where $Z=\left[\delta \pi_{2} A \pi_{1}^{1-\theta} w^{1-\theta}\right]^{1 / \theta}$

\footnotetext{
${ }^{9}$ If "companionship" is assumed, $n$ need not have a lower bound because a young parent can lower $n$ as much as she wants in order to find an interior solution. Throughout this chapter, however, we assume that $n$ has a lower bound as do E\&L.
} 
As for the corner solution, Equation (4.9) holds as an equality but Equation (4.8) holds as a strict inequality, from (E\&L) Lemma 2. Therefore, combining Equations (4.3), (4.6), (4.7), and (4.9), and given $n=1$, we can obtain an equation for the law of motion for the human capital accumulation for this case:

$$
H_{t+1}^{i}=a H_{t}^{i}+b
$$

where,

$$
\begin{aligned}
& a=\frac{A Z\left(T-v-\pi_{2} w\right)}{A+Z} \\
& b=\frac{A Z(T-v) \bar{H}}{A+Z}
\end{aligned}
$$

Investment in education can be easily derived as follows:

$$
h_{t}^{i}=\frac{Z}{A+Z}\left[T-v-\pi_{2} w \frac{H_{t}^{i}}{H_{t}^{i}+\bar{H}}\right] .
$$

\subsection{The dynamics of the economy}

As is standard in the two-sector endogenous growth models with human capital, growth in the economy described in this chapter is driven by the accumulation of human capital. Therefore, the dynamics of the economy is determined by Equations (4.12) and (4.14).

Various types of dynamics could be considered according to the different values of parameters, but let us focus upon two particular types. One is where economies decline and stagnate in the long run (Case I, henceforth) and the other is where they exhibit long run positive growth (Case II, henceforth). ${ }^{10}$

${ }^{10}$ The former case may sound rather odd but, in fact, it conforms to the stylised fact - more than 10 per cent of the countries in the Penn World Table experienced negative growth during the period 1960-1989. 


\subsubsection{Case I}

To begin with, we choose the intertemporal elasticity of substitution to be 2, i.e., $\theta=0.5{ }^{11}$ When $n>1$, the accumulation of human capital will become subject to the following quadratic relationship:

$$
H_{t+1}^{i}=w A^{2} v^{2}\left(H_{t}^{i}+\bar{H}\right)^{2}
$$

It is easy to show that the necessary and sufficient conditions for this curve to intersect the $45^{\circ}$ degree line twice is $A^{2}<\frac{1}{4 v^{2} w \bar{H}}$. In turn, when $H_{t}^{i}$ is sufficiently high (see E\&L Lemma 2), $n=1$ and $H_{t+1}^{i}$ is a linear function of $H_{t}$ as in Equation (4.14), so whether or not $a$ is greater than unity will determine whether this curve intersects the $45^{\circ}$ degree line at the relevant region. This depends upon values of all parameters.

For Case I, other parameter values are chosen so that two positive fixed points exist. ${ }^{12}$ Putting Equations (4.14) and (4.16) together, we can draw a bold curve (phase line, hereafter) as in Figure 4.1.

Points $B$ and $S$ in the diagram represent fixed points, and $H_{B}$ and $H_{S}$ are the levels of human capital associated with these points, respectively.

\section{The evolution of human capital}

If individual $i$ happens to have exactly the same level of human capital as either of $H_{S}$ or $H_{B}$, she will pass to her children exactly the same amount of human capital as she received from her parent. There will be no growth in individual output in

\footnotetext{
${ }^{11} \mathrm{~A}$ number of studies have attempted to estimate the magnitude of the intertemporal elasticity of substitution. Estimates normally lie around or below unity, but vary substantially (see Blanchard and Fischer, 1989), and there seems to be no common agreement on this account. As in footnote 8 , we will only consider the case where $\theta<1$ hereafter.

${ }^{12}$ The values for the parameters are as follows: $A=7.4, \hat{H}=1, \delta=0.7, v=0.12, \pi_{1}=\pi_{2}=$ $0.75, w=0.26, T=1$. Two fixed points are approximately 2.47 and 0.40 .
} 


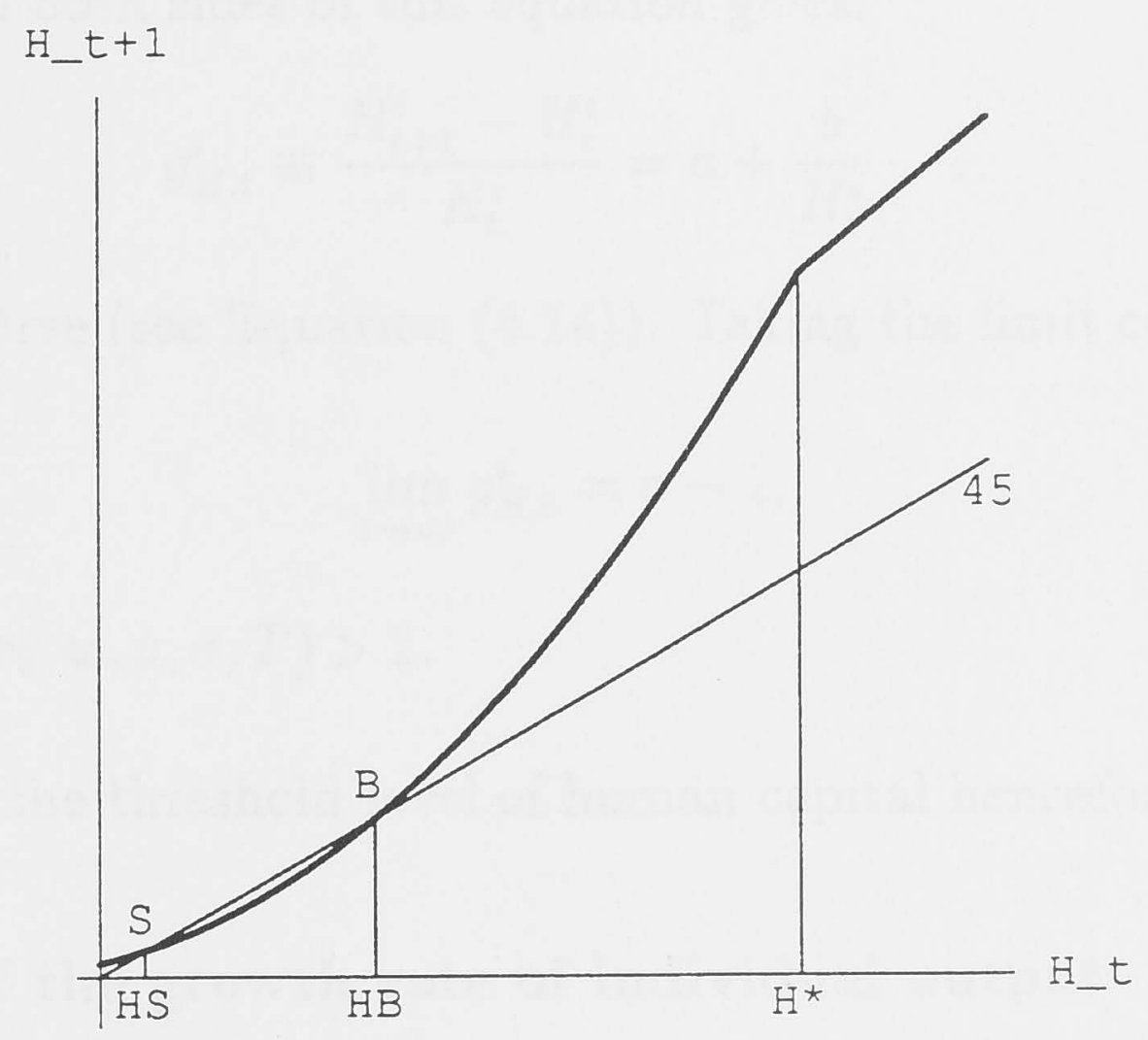

Figure 4.1: Evolution of human capital: Case I

these cases, since there is no accumulation in human capital. Note that Point $S$ is stable but Point $B$ is unstable.

Aside from these two exceptional cases, in the long run, dynasty $i$ can end up either being stagnant or growing at a constant rate. Let us examine these cases in turn. If individual $i$ in this economy happens to have less human capital than the critical level of human capital $H_{B}$, eventually human capital of her descendants will converge to Point $S$, which is the stable steady state. In contrast, if she happens to have more human capital than $H_{B}$, her descendants will eventually be on the linear segment of the phase line. That is, the growth rate of human capital will asymptotically approach a constant in the long run.

Lemma 1. The growth rate of human capital for dynasties that start with a level of human capital more than $H_{B}$ will asymptotically approach a positive constant from above if $a>1$.

Proof. Dividing both sides of Equation (4.14) by $H_{t}^{i}$ yields:

$$
\frac{H_{t+1}^{i}}{H_{t}^{i}}=a+\frac{b}{H_{t}^{i}} \text {. }
$$


Subtracting 1 from both sides of this equation gives:

$$
g_{H, t}^{i} \equiv \frac{H_{t+1}^{i}-H_{t}^{i}}{H_{t}^{i}}=a+\frac{b}{H_{t}^{i}}-1 .
$$

Note that $b$ is positive (see Equation (4.14)). Taking the limit concludes the proof:

$$
\lim _{t \rightarrow \infty} g_{H, t}^{i}=a-1
$$

where $a=a\left(A, \delta, \pi_{2}, w, v, \sigma, T\right)>1$.

Let us call $H_{B}$ the threshold level of human capital henceforth.

\section{The evolution of the growth rate of individual output}

Figure 4.2 describes the evolution of the growth rate of individual output. Five dynasties, whose initial levels of human capital are 1, 2, 3, 4, and 5, are the focus. ${ }^{13}$ If dynasty $i$ starts with a level of human capital below the threshold $\left(H_{0}=1\right.$ and $H_{0}=2$ in the figure), individuals who belong to this dynasty will experience negative growth ${ }^{14}$ and eventually will converge to the steady state where there is no growth. This corresponds to the fact that the level of human capital is approaching Point $S$. If dynasty $i$ starts with a level of human capital above the threshold ( $H_{0}=3, H_{0}=4$, and $H_{0}=5$ in the figure), people who belong to this dynasty will experience positive growth, since human capital will be accumulated forever. The growth rate of individual output will asymptotically approach a constant.

\section{The evolution of the number of children}

The evolution of the number of children is illustrated in Figure 4.3. If dynasty $i$ starts with a level of human capital below the threshold $\left(H_{0}=1\right.$ and $H_{0}=2$ in the figure), the number of children born for this dynasty will increase until it

\footnotetext{
${ }^{13} \mathrm{Here}$, we are ignoring the case where a dynasty initially has a level of human capital of either $H_{B}$ or $H_{S}$. It is clear that if this is the case, individuals who belong to this dynasty will experience zero growth forever, since there will be no accumulation of human capital.

${ }^{14}$ If the dynasty starts below $S$, it will approach the steady state from below, and hence will experience positive growth. However, let us omit this possibility for brevity.
} 


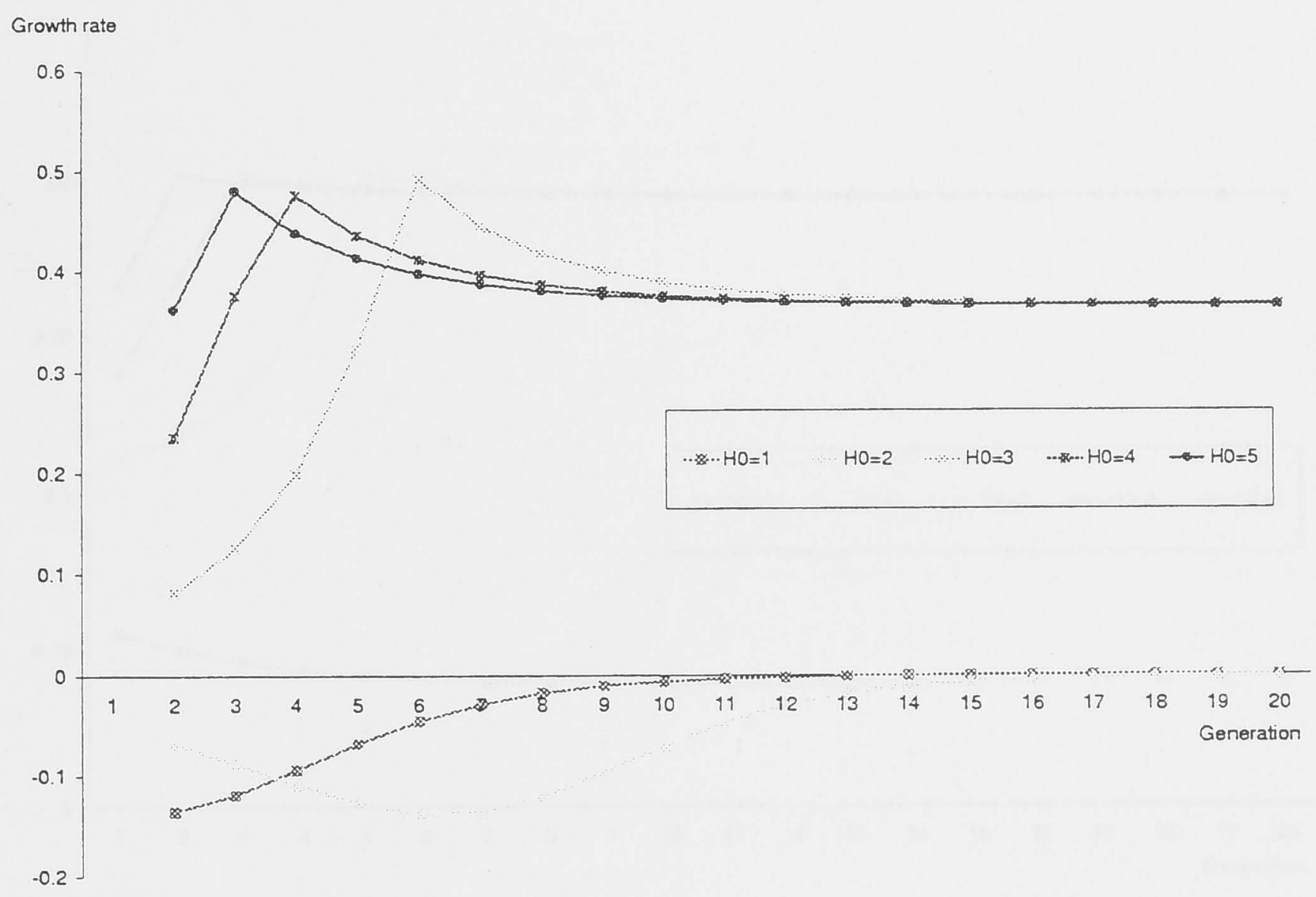

Figure 4.2: Growth rate of individual output

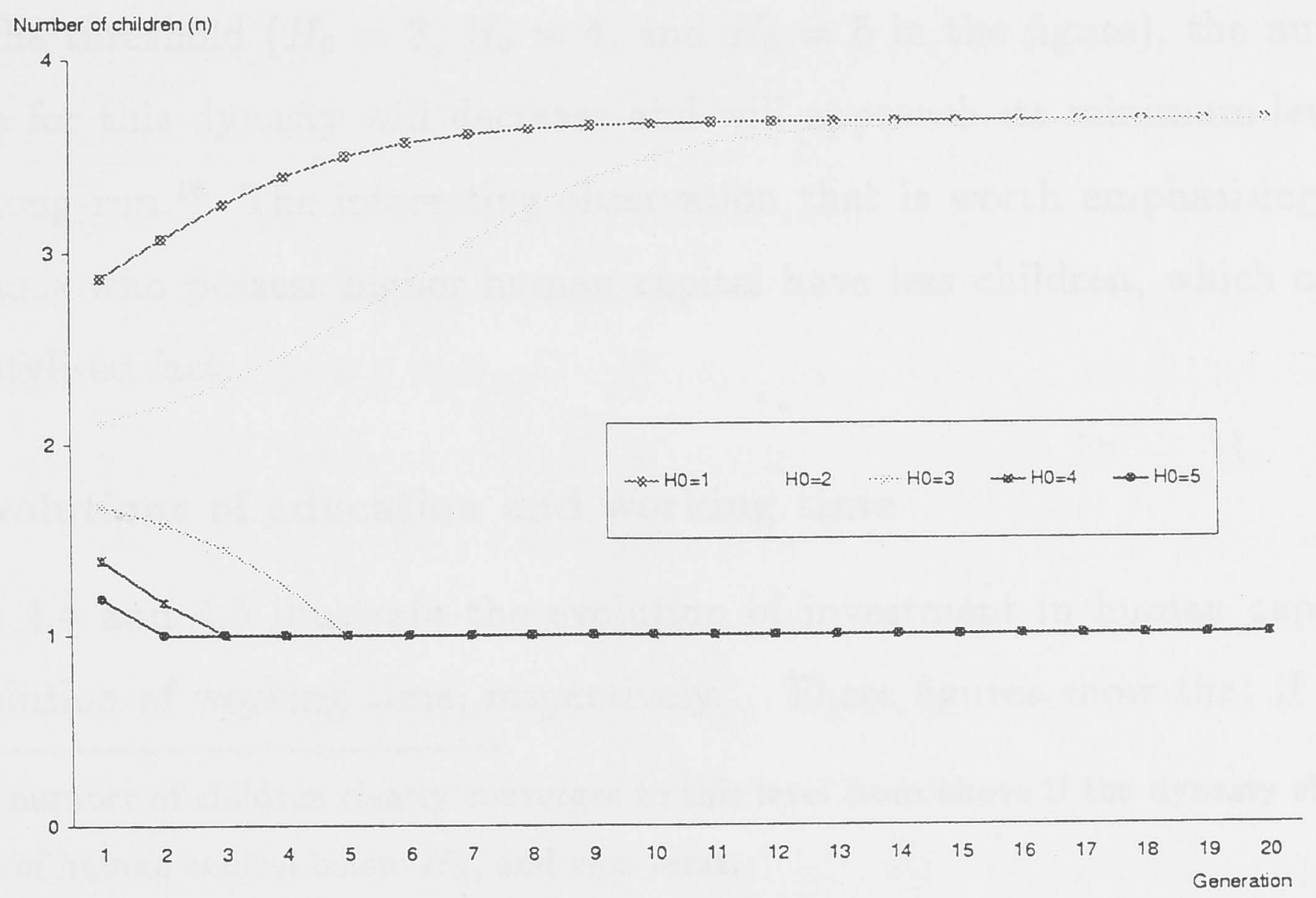

Figure 4.3: Number of children 


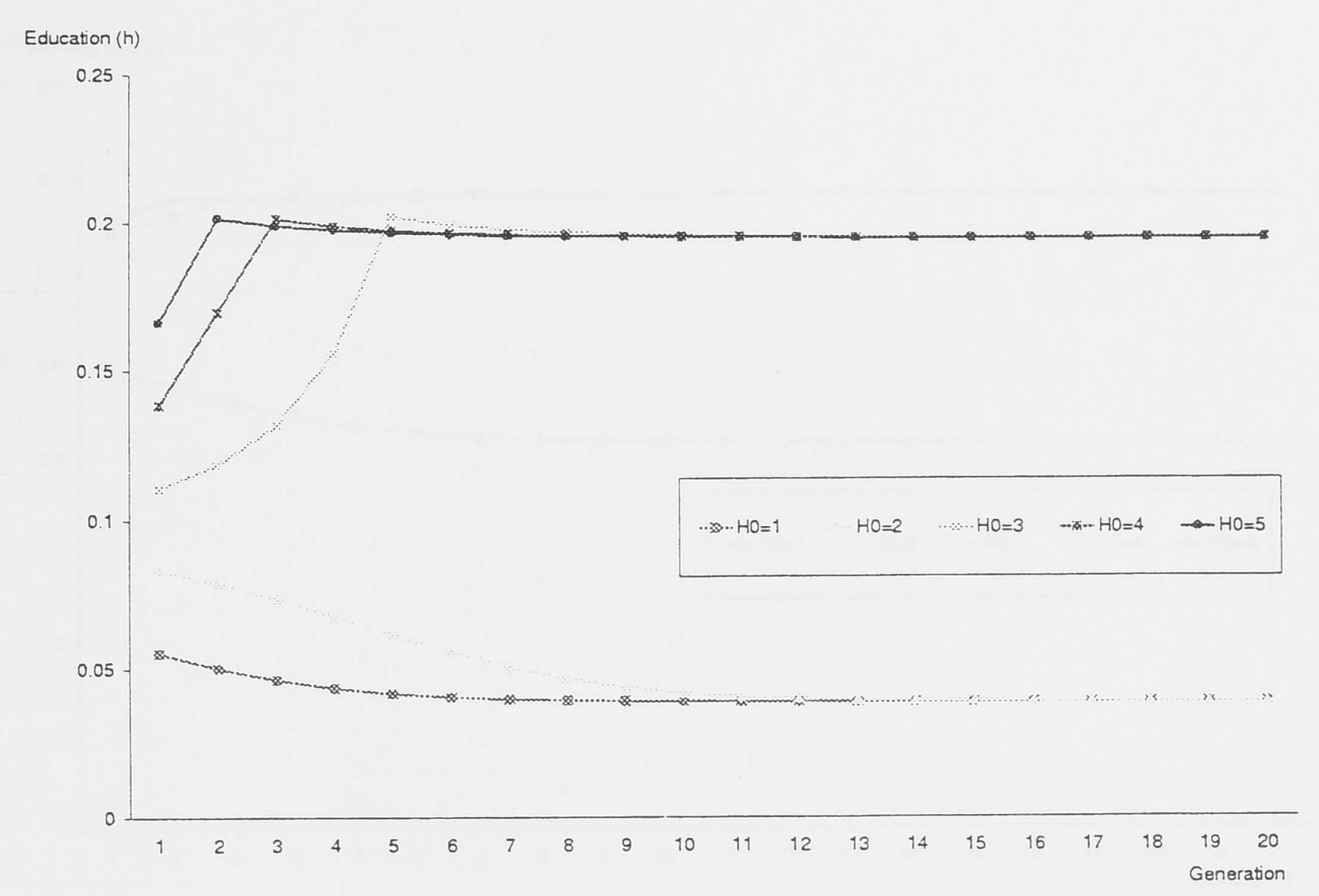

Figure 4.4: Investment in education

converges to a certain number. ${ }^{15}$ If dynasty $i$ starts with a level of human capital above the threshold ( $H_{0}=3, H_{0}=4$, and $H_{0}=5$ in the figure), the number of children for this dynasty will decrease and will approach its minimum level, one, in the long run. ${ }^{16}$ The interesting observation that is worth emphasising is that individuals who possess higher human capital have less children, which conforms to the stylised fact.

\section{The evolutions of education and working time}

Figures 4.4 and 4.5 illustrate the evolution of investment in human capital and the evolution of working time, respectively. These figures show that if dynasty

\footnotetext{
${ }^{15}$ The number of children clearly converges to this level from above if the dynasty starts with the level of human capital below $H_{S}$, and vice versa.

${ }^{16}$ If dynasty $i$ starts with the threshold level of human capital, $H_{B}$ or $H_{S}$, the number of children for this dynasty stays the same forever at the level somewhere between 1 and the number of children when a dynasty has approached the steady state.
} 


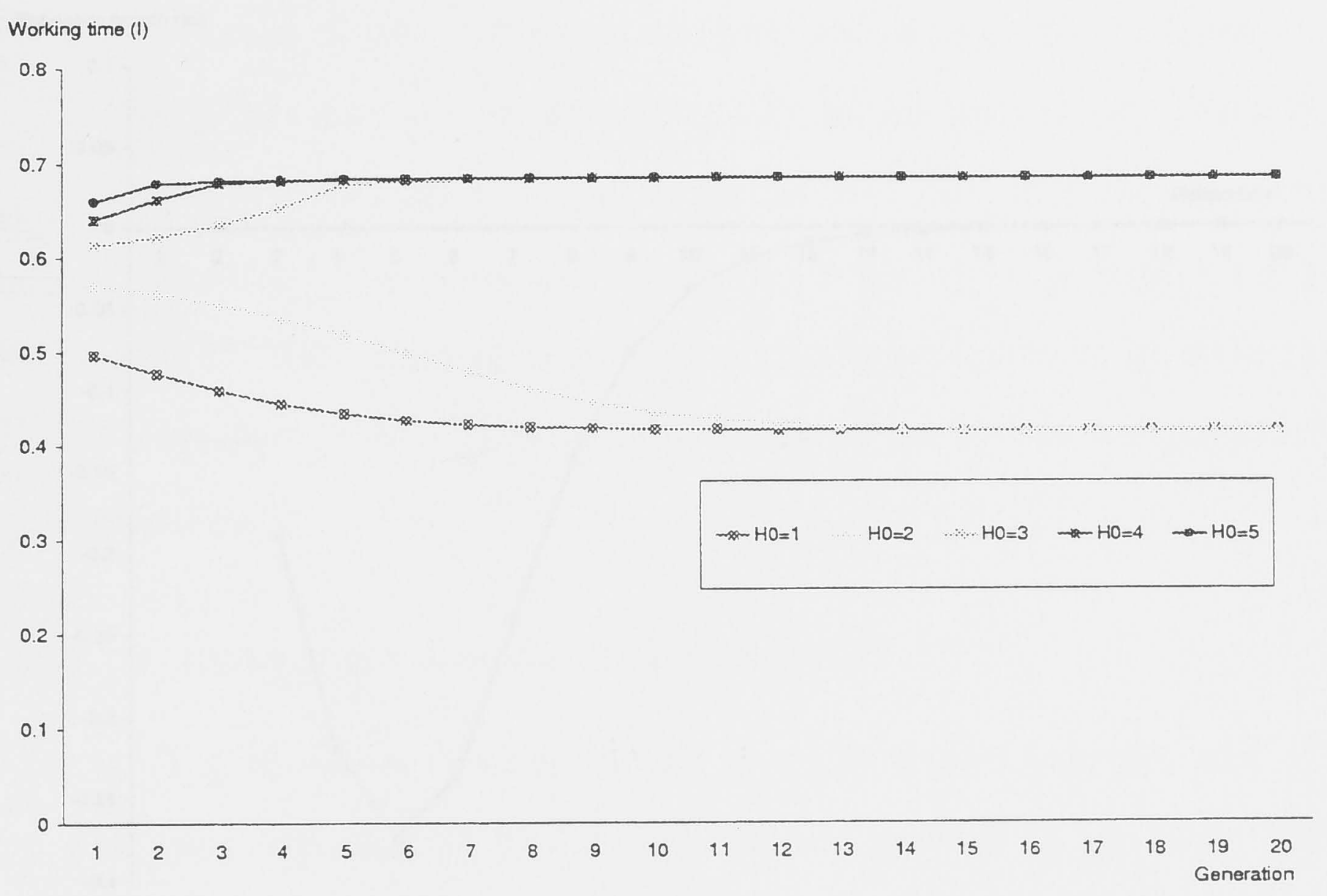

Figure 4.5: Working time

$i$ starts with a level of human capital above the threshold $\left(H_{0}=3, H_{0}=4\right.$, and $H_{0}=5$ in the figure), investment in human capital for this dynasty will increase and approach a constant, whilst working time for this dynasty will decrease and will also approach a constant. In contrast, if dynasty $i$ starts with a level of human capital below the threshold ( $H_{0}=1$ and $H_{1}=2$ in the figure), investment in human capital for this dynasty will decrease and approach a constant, whilst working time for this dynasty will decrease and will also approach a constant. In the long run, dynasties that initially possess more human capital than the threshold level will invest more in education and work harder. This happens because dynasties that initially possess less human capital than the threshold level will decide to have many more children. That is, as the number of children increases as described in Figure 4.3 , both investment in human capital and working time decrease so that the time constraint, Equation (4.2), holds. ${ }^{17}$

\footnotetext{
${ }^{17}$ One exceptional case is where dynasty $i$ starts with the threshold level of human capital. In this case, it is obvious that both investment in human capital and working time will be constant
} 


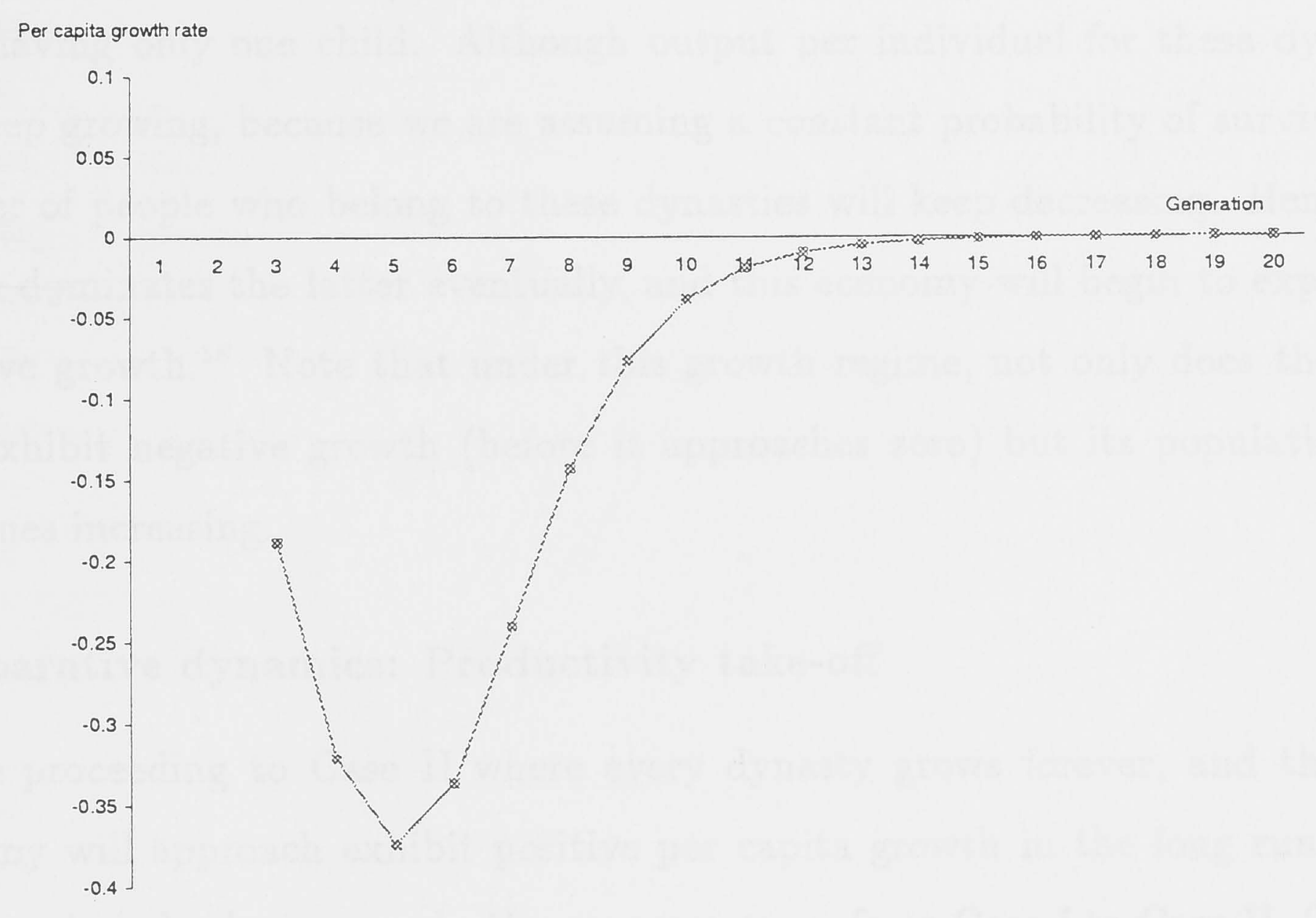

Figure 4.6: Growth rate of output per capita

\section{The growth rate of output per capita in the long run}

Let us now analyse the evolution of the output per capita growth rate in the long run. This depends greatly upon the initial distribution of human capital. If some dynasties happen to start below the threshold, the rate of growth per capita becomes negative before it converges to zero. This situation is depicted in Figure 4.6 .

The main reason that accounts for this phenomenon is an increase in population over time. In the long run, people who belong to the dynasties that have started below the threshold will converge to the steady state, $S$, where they have a constant number of children, which is greater than 1 . People who belong to these dynasties will keep increasing but their individual output will decline and approach a constant. In contrast, people who belong to the dynasties that have started above the threshold will keep accumulating their human capital but start having less children throughout. 
until having only one child. Although output per individual for these dynasties will keep growing, because we are assuming a constant probability of survival, the number of people who belong to these dynasties will keep decreasing. Hence, the former dominates the latter eventually, and this economy will begin to experience negative growth. ${ }^{18}$ Note that under this growth regime, not only does the economy exhibit negative growth (before it approaches zero) but its population also continues increasing.

\section{Comparative dynamics: Productivity take-off}

Before proceeding to Case II where every dynasty grows forever, and thus, the economy will approach exhibit positive per capita growth in the long run, let us analyse what shocks may make the economy move from Case I to Case II. One can easily infer that the threshold level of human capital $H_{B}$ will vary according to the values of parameters. It is easy to show that, for example, an increase in $A$ or $\bar{H}$ lowers the threshold level of human capital. Intuition behind this is as follows. An increase in $A$ implies a technological improvement that leads to greater output in the future. An increase in $\bar{H}$ means that individuals have greater level of basic human capital, which could be induced by improvement in work ethics. These permanent shocks make investment in human capital more attractive, hence the critical level of human capital will decrease. If these increases are large enough, the economy can move to Case II so that $A^{2}>\frac{1}{4 v^{2} w \bar{H}}$ will be satisfied. ${ }^{19}$ Let us focus upon a sufficiently large increase in $A$, and regard economies that have enjoyed this shock as those that have experienced the productivity take-off. We delve into the analysis of this type of economy in the next subsection.

\footnotetext{
${ }^{18}$ In the long run, as dynasties that started above the threshold become negligible, the growth rate of output per capita will converge to zero.

${ }^{19} \mathrm{E} \& \mathrm{~L}$ focus particularly upon an increase $\pi_{1}$ that can make the economy move from Case I to Case II. In this chapter, this is not the case because $\gamma=1$ is assumed for mathematical convenience. If it were not assumed, an increase in $\pi_{1}$ would also be one of the candidates that make the economy move to Case II.
} 


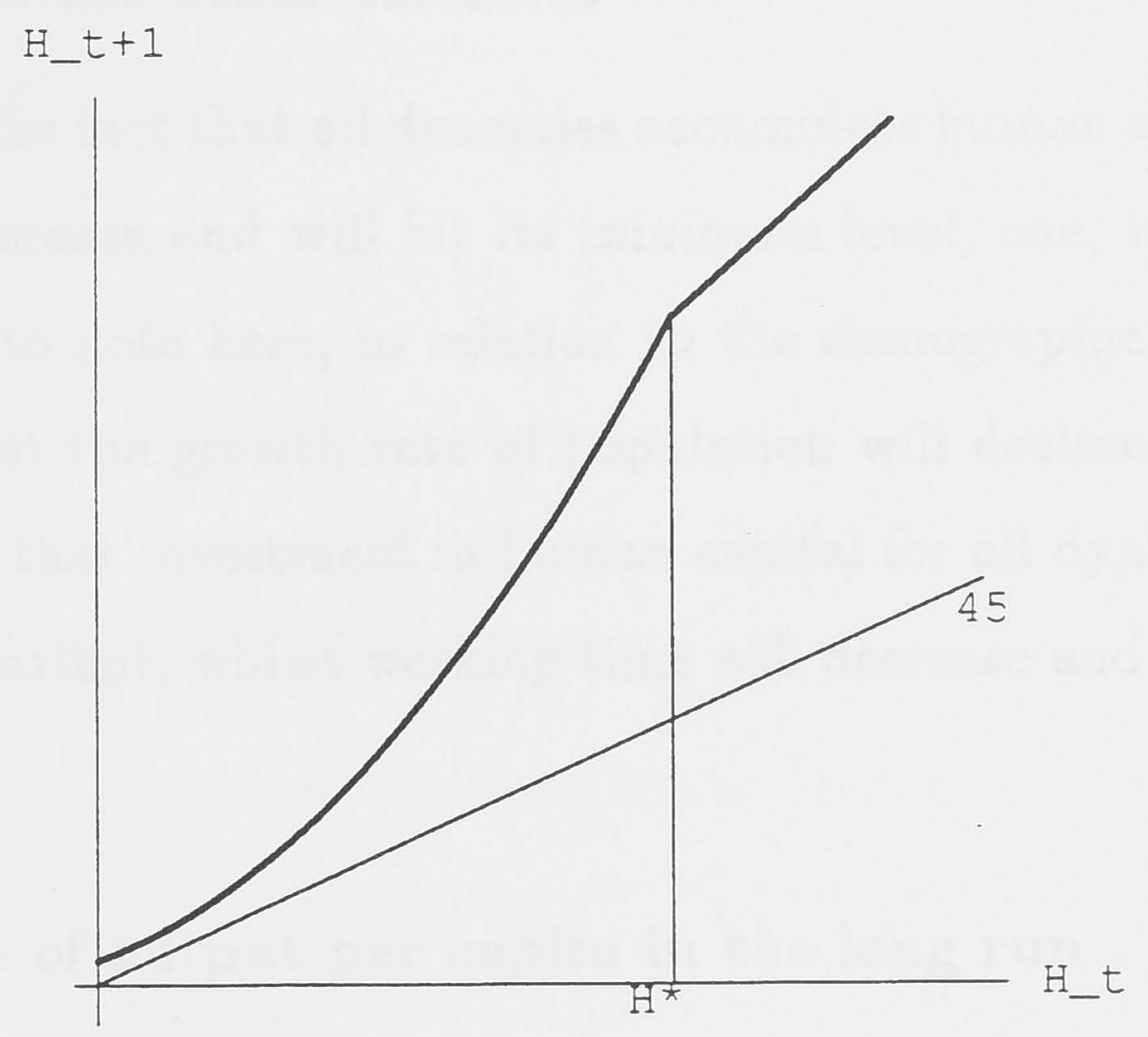

Figure 4.7: Evolution of human capital: Case II

\subsubsection{Case II}

Let us assume that the productivity take-off has taken place, i.e., $A^{2}>\frac{1}{4 v^{2} w \bar{H}}$ and $a>1 .{ }^{20}$ Now, the economy is described graphically as in Figure 4.7.

\section{The evolution of human capital}

There are no fixed points of human capital in this economy. It is apparent that all dynasties, regardless of the initial level of human capital, will accumulate human capital and the growth rate of human capital will asymptotically approach a positive constant in the long run (see Lemma 1).

\section{The evolution of the growth rate of individual output}

All dynasties will experience positive growth, since human capital will be accumulated. In the long run, the growth rate of individual output will asymptotically approach a constant.

\footnotetext{
${ }^{20}$ The values for the parameters are as follows: $A=7.5, \bar{H}=1.5, \delta=0.7, v=0.16, \pi_{1}=\pi_{2}=1$, $w=0.18, T=1$.
} 


\section{The evolutions of the other variables}

Corresponding to the fact that all dynasties accumulate human capital, the number of children will decrease and will hit its minimum level, one, in the long run. It is important here to note here, in relation to the demographic transition we will discuss shortly, that the growth rate of population will decline and become zero. It is also apparent that investment in human capital for all dynasties will increase and approach a constant, whilst working time will decrease and will also approach a constant.

\section{The growth rate of output per capita in the long run}

From Lemma 1 and Equation (4.1), we can induce that the growth rate of output per capita in the long run will approach a constant given $\pi_{1}=\pi_{2}=1$. $^{21}$

Remark 1. Regardless of initial distribution of human capital, in Case II, the growth rate of output per capita will asymptotically approach a constant given $\pi_{1}=$ $\pi_{2}=1$.

Proof. Given $\pi_{1}=\pi_{2}=1$, we know that population will become constant in the long run in Case II, so it is sufficient if we show that the growth rate of aggregate output will asymptotically approach a constant. Moreover, in the long run, the number of workers will become constant, so it is sufficient if we show that the growth rate of individual output will asymptotically approach a constant.

The growth rate of individual output, $g_{Q, t}^{i}$, can be calculated using Equation (4.1).

$$
g_{Q, t}^{i}=\frac{Q_{t+1}^{i}}{Q_{t}^{i}}-1=\frac{\frac{H_{t+1}^{i}}{H_{t}^{i}}+\frac{\bar{H}}{H_{t}^{i}}}{\frac{H_{t}^{i}}{H_{t}^{i}}+\frac{\bar{H}}{H_{t}^{i}}} \frac{l_{t+1}^{i}}{l_{t}^{i}}-1
$$

\footnotetext{
${ }^{21}$ If $\pi_{1}<1$, then population will decline in the long run. In this case, the growth rate of output per capita will increase at a constant rate in the long run.
} 
Bearing in mind that $l_{t}^{i}$ will approach a constant in the long run, we can conclude the proof by taking the limit:

$$
\lim _{t \rightarrow \infty} g_{Q, t}^{i}=\lim _{t \rightarrow \infty} \frac{H_{t+1}^{i}}{H_{t}^{i}}-1=a-1
$$

where the last equality comes from Lemma 1.

\subsubsection{Demographic transition}

The dynamics we have seen have relevance to the demographic transition. We have seen that in an economy in Case II, the growth rate of population declines before it becomes zero. In contrast, in Case I, population will continue increasing. This is due to the fact that individuals optimise the number of children given their level of human capital. Let us use Figures 4.1 and 4.7 in order to explain the difference in demographic dynamics between these two cases - before and after the productivity take-off.

Let us suppose that dynasties are distributed both above and below the threshold in an economy before the productivity take-off (Figure 4.1). Individuals who belong to dynasties below the threshold will keep having many children, whilst those who belong to dynasties above the threshold will eventually have only one child. We have seen that this economy will be dominated by the former dynasties, so it exhibits negative growth and population increases.

However, if a sufficiently large productivity shock hits this economy, the phase line will be pulled up and every individual now starts accumulating human capital and having less children (Figure 4.7). Eventually, every individual's level of human capital will become greater than $H^{*}$. At this stage, this economy has completed the demographic transition, i.e., every individual in this economy has one child.

The productivity take-off is a prerequisite for the economy to begin the demographic transition. ${ }^{22}$

\footnotetext{
${ }^{22}$ Note that this model is not explaining all aspects of what demographers call the demographic transition, which has to do with both the birth and death rates.
} 


\subsection{Inequality: Does it matter?}

Now, we can see the importance in this model of the level of initial human capital. It determines how each dynasty evolves over time, and hence, how output per capita evolves over time. Let us consider an economy in which we have a distribution of heterogeneous individuals (dynasties) with different levels of human capital. From the analysis in the last section, one can see that individuals and their descendants will accumulate human capital in different manners, according to human capital they possess. Therefore, the growth rate of output per worker is likely to be affected by initial distribution of human capital. ${ }^{23}$

Also, it is very important to note that the evolution of an economy depends greatly upon its demographic stage of development. If we consider an economy with certain distribution of human capital, the way it evolves depends upon whether or not it has begun the demographic transition. Therefore, we will investigate how initial distribution affects the evolution of the economy case by case. Before that we define inequality.

In the studies by Galor and Zeira (1993), Perotti (1996), and Galor and Zang (1997), which are similar to this study, an economy is regarded as more unequal if a greater proportion of people have a level of human capital below the critical level $H_{B}$. It is quite clear that this definition of inequality is problematic. ${ }^{24}$ Instead of

\footnotetext{
${ }^{23}$ Note that human capital and output are positively related in the model. We can see this relationship, firstly, in Equation (4.1), which shows that greater $H$ implies greater $Q$, given $l$ is constant. Secondly, the analysis in this section, especially Figure 4.5, implies that the greater $H$, the longer people work. Therefore, human capital distribution and income distribution virtually have the same qualitative implication.

${ }^{24}$ The following simple example illustrates the problem. Compare the following two economies, one in which everyone has the same level of human capital below $H_{B}$, and the other in which everyone has the same level of human capital above $H_{B}$. The former economy is less equal whereas the latter one is more equal by this definition. However, both economies should be completely equal if we use a standard measure of inequality such as the coefficient of variation or the Gini coefficient.
} 
using this problematic definition, we shall adopt the coefficient of variation as the measure of inequality. The coefficient of variation is the standard deviation divided by the mean, so only relative incomes matter.

\subsubsection{Before the productivity take-off}

Let us consider very poor economies that have not begun the demographic transition. As we have looked at in the previous section, these economies will decline and stagnate in the long run. This will be true for any initial distribution except for the one where every dynasty starts above the threshold, which is unlikely to be observed in extremely poor economies. We summarise it as follows:

Remark 2. If the economy has not begun the demographic transition, and if at least one dynasty starts below the threshold, the economy will stagnate in the long run, regardless of initial distribution.

Proof. Suppose that dynasties are indexed from 1 to $N$ according to the initial level of human capital, and that dynasties from 1 to $I$ have levels of human capital below $H_{B}$. Let us denote the growth rate of output per worker and the number of workers for dynasty $i$ in Period $t$ by $\gamma_{t}$ and $\omega_{t}^{i}$, respectively. Then:

$$
\begin{aligned}
\gamma_{t} & \equiv \ln \frac{\sum_{i=1}^{N} \omega_{t+1}^{i} Q_{t+1}^{i}}{\sum_{i=1}^{N} \omega_{t}^{i} Q_{t}^{i}}-\ln \frac{\sum_{i=1}^{N} \omega_{t+1}^{i}}{\sum_{i=1}^{N} \omega_{t}^{i}} \\
& =\ln \left[\frac{\sum_{i=1}^{I} \omega_{t+1}^{i} Q_{t+1}^{i}+\sum_{i=I+1}^{N} \omega_{t+1}^{i} Q_{t+1}^{i}}{\sum_{i=1}^{I} \omega_{t}^{i} Q_{t}^{i}+\sum_{i=I+1}^{N} \omega_{t}^{i} Q_{t}^{i}}\right]-\ln \left[\frac{\sum_{i=1}^{I} \omega_{t+1}^{i}+\sum_{i=I+1}^{N} \omega_{t+1}^{i}}{\sum_{i=1}^{I} \omega_{t}^{i}+\sum_{i=I+1}^{N} \omega_{t}^{i}}\right]
\end{aligned}
$$

When $t \rightarrow \infty, \sum_{i=I+1}^{N} \omega_{t+1}^{i} Q_{t+1}^{i}, \sum_{i=I+1}^{N} \omega_{t}^{i} Q_{t}^{i}, \sum_{i=I+1}^{N} \omega_{t+1}^{i}$, and $\sum_{i=I+1}^{N} \omega_{t}^{i}$ all approach zero. This implies that the second term of the right hand side of Equation (4.17) approaches $\ln n_{S}$. Also, for all $i$ from 1 to $I$ :

$$
\lim _{t \rightarrow \infty} Q_{t}^{i}=\left(H_{S}+\bar{H}\right) l_{S}
$$


where $l_{S}$ is working time in the steady state $S$. This implies that the first term of the right hand side of Equation (4.17) approaches $\ln n_{S}$ when $t \rightarrow \infty$. Therefore:

$$
\lim _{t \rightarrow \infty} \gamma_{t}=\ln n_{S}-\ln n_{S}=0
$$

Since this long run story is uninteresting, we shall look at what happens in the short run. ${ }^{25}$ Let us consider two very poor countries, in terms of human capital, where almost all dynasties decline towards the steady state. For brevity, we shall call the more unequal country, Country I, and the other one Country E. How different will the evolution of these two economies be in the short run?

Let us introduce Figure 4.8 in order to conjecture how Country I will evolve compared to Country E. The bold probability density function in the figure shows initial human capital distribution of Country I. There are two important differences in distributions that lead to different evolutions of economies. First, initially in Country I, there are more extremely-poor dynasties that choose to have a relatively large number of children (shaded area $\mathrm{A}$ in Figure 4.8). They will contribute to lower both output per capita and output per worker more than in Country E. Let me call this difference in distributions the difference in extreme-poor for brevity. Second, initially in Country I, there are more super-rich dynasties that produce much more output than others do (shaded area B in Figure 4.8). These dynasties choose to have a relatively small number of children (one child after their human capital hits a certain level), and will contribute to raise both output per capita and output per worker more than in Country E. We shall call this difference in distributions the difference in super-rich henceforth.

These two differences have critically important effects in determining the difference in the growth rate of output per worker, but it is easy to see that both differences are diminishing over time. The difference in super-rich will disappear in

\footnotetext{
${ }^{25}$ Note that one period in this model is a generation, which is 25 years.
} 


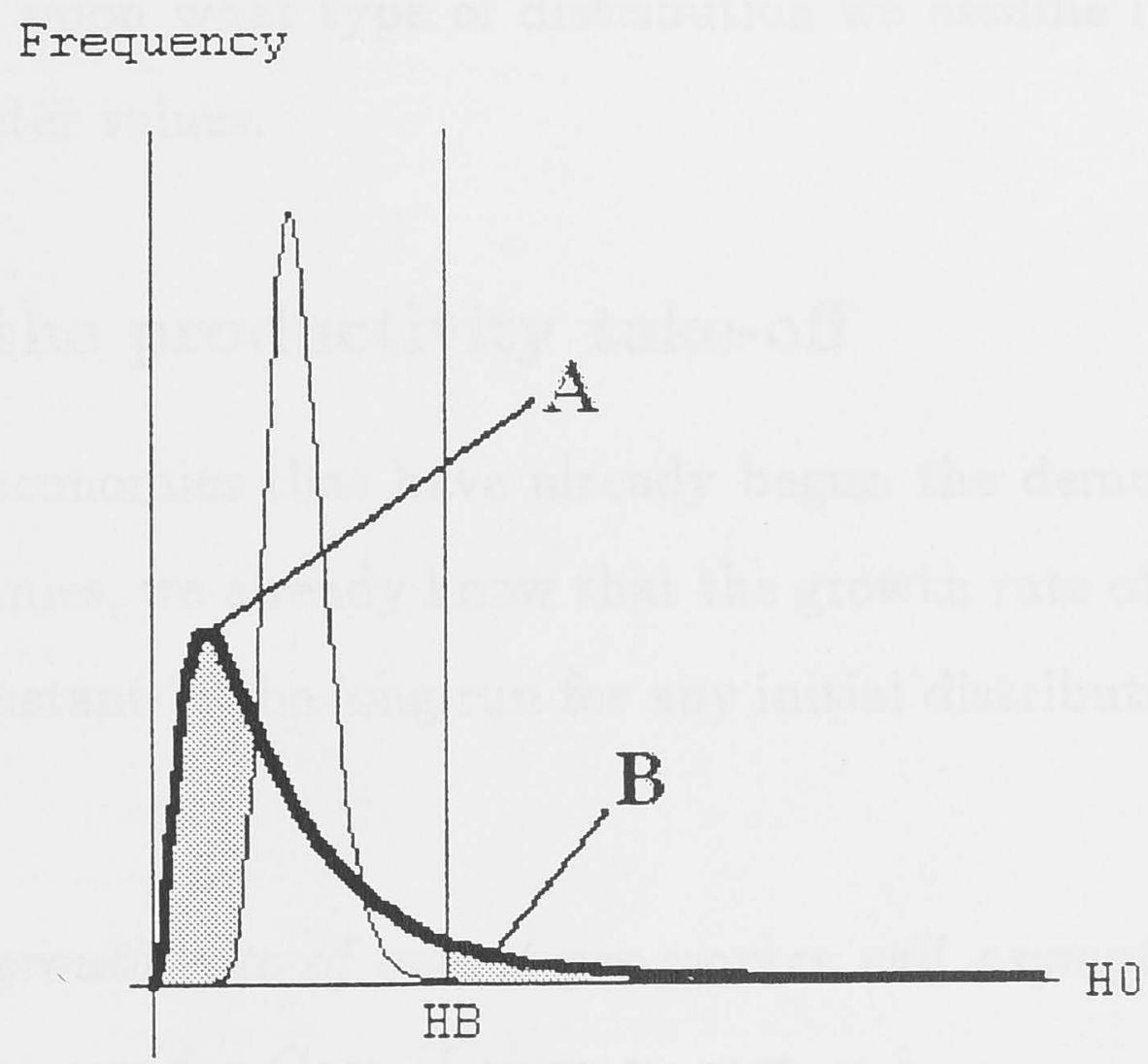

Figure 4.8: Extreme-poor and super-rich

due course because the population of super-rich dynasties diminish over time, given that probability of survival is less than one. In contrast, the difference in extremepoor will be diminishing over time since every dynasty below the critical threshold will eventually have the same number of children and output at the steady state. ${ }^{26}$

The difference in the growth rates of output per worker between two countries will largely depend upon these differences in distributions. However, it is ambiguous which one of these differences will influence the growth rate more in the short run. For example, if the difference in extreme-poor is huge but the difference in superrich is negligible, then the growth rate will be much higher in Country $\mathrm{E}$ than in Country I. But if the difference in super-rich diminishes much slower than the difference in extreme-poor does, then the growth rate in Country I may become higher than in Country E, because whilst most of declining dynasties are already around the steady state, i.e., the population growth rates are the same for the both countries, there still exists the difference in distributions in super-rich. These

\footnotetext{
${ }^{26} \mathrm{As}$ we have seen in Remark 2 , in the long run where both of these effects are zero, both economies will grow at the same rate, which is zero.
} 
things will depend upon what type of distribution we assume in the first place as well as the parameter values.

\subsubsection{After the productivity take-off}

Now we consider economies that have already begun the demographic transition. As for these economies, we already know that the growth rate of output per worker will approach a constant in the long run for any initial distribution. We summarise it as follows:

Remark 3. The growth rate of output per worker will asymptotically approach a constant in the long run for Case II given $\pi_{1}=\pi_{2}=1$.

Proof. From Remark 1, we know that the growth rate of output per capita will asymptotically approach a constant in the long run. We also know that, in the long run, the number of workers will become a third of population. Therefore, the growth rates of output per worker and output per capita will approaches the same positive constant.

How does the growth rate of output per worker evolve in the short run? We will look at two types of economies. One is middle-income economies where the mean of initial human capital is still low, and the other is advanced economies where the mean of initial human capital is high. The definitions of Country I and Country $\mathrm{E}$ are the same as they are in the previous subsection. We define differences in distributions of poor and rich as shaded areas C and D, respectively, in Figure 4.9.

\section{The short run dynamics: Middle-income economies}

The growth rate of output per-worker must be positive in the short run. It should be fair to guess that Country $\mathrm{E}$ will grow faster than Country I for the following reason. Given that both Country I and Country E are still in their development stage, the difference in aggregate output due to the difference in rich is still not that large, but the difference in population growth rates is large due to the difference in 


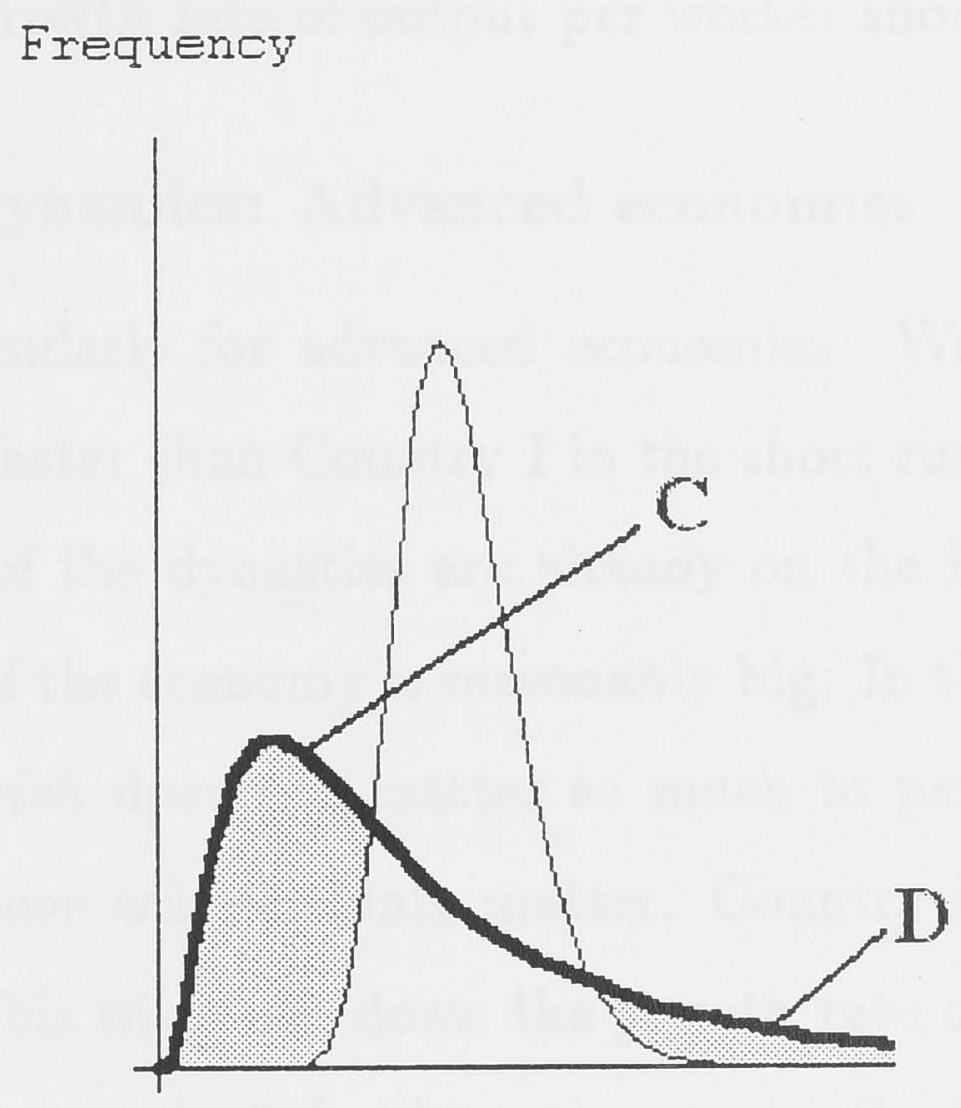

Figure 4.9: Poor and rich

poor. The population growth rate will be significantly higher in Country I than in Country $\mathrm{E}$ due to that difference, and since the difference in rich is not large enough to offset it, i.e., the growth rate of the output is not large enough in Country I, the growth rate of output per worker will be higher in Country $\mathrm{E}$.

Regarding middle-income economies, for the first few generations, the growth rate of output per worker should be increasing. However, as every dynasty is about to reach the point where $n=1$, it could become decreasing. This happens because of the following. By that stage, almost all the dynasties are on the linear segment of the phase line and they are approaching to grow at a constant rate (from above: see Lemma 1). Only a small proportion of the whole dynasties have $n>1$ but their output grows faster. When this proportion of dynasties reaches the linear segment of the phase line, they have $n=1$ (the worker growth rate will decrease) and output grows a little slower than before. ${ }^{27}$ Therefore, if a decrease in the population growth rate is relatively small compared with a decrease in the growth rate of aggregate

\footnotetext{
${ }^{27}$ This story depends upon parameter values. More specifically, we need to assume that the derivative of Equation 4.16 with respect to $H_{t}$ evaluated at $H^{*}$ is greater than $a$.
} 
output, then the growth rate of output per worker should become lower.

\section{The short run dynamics: Advanced economies}

The story goes similarly for advanced economies. We should again expect that Country E grows faster than Country I in the short run but for a different reason. Recall that most of the dynasties are already on the linear segment of the phase line, and the size of the economy is reasonably big. In this case, we can expect that the difference in rich does not matter so much to per-worker output. However, the difference in poor will certainly matter. Country I has the higher population growth rate, and this will push down the growth rate of output per worker.

In passing, since most of the dynasties are on the linear segment of the phase line already, the growth rate of output per worker could be decreasing throughout as we have just seen before.

In the next section, we will conduct simulations in order to see how economies will evolve given different initial human capital distributions.

\subsection{Simulations: Inequality matters}

Let us assume that initial human capital is lognormally distributed, that is, logarithm of initial human capital is normally distributed, i.e., $\log H \sim N\left(\mu_{H}, \sigma_{H}^{2}\right)$, where $\mu_{H}$ and $\sigma_{H}^{2}$ are the mean and the variance of $H$, respectively. This distribution is often used since it is skewed to the right and takes only positive values.

The moments of $H$ are as follows:

$$
\begin{aligned}
E[H] & =e^{\mu_{H}+\left(\sigma_{H}^{2} / 2\right)}, \\
\operatorname{Var}[H] & =e^{2\left(\mu_{H}+\sigma_{H}^{2}\right)}-e^{2 \mu_{H}+\sigma_{H}^{2}} .
\end{aligned}
$$




\subsubsection{Advanced economies}

First, we consider a group of three advanced economies. $E[H]$ of these three economies are the same, ${ }^{28}$ but $\operatorname{Var}[H]$ are different. We use three values for $\sigma_{H}$, $0.2,0.5$, and 0.8 and change $\mu_{H}$ in order to keep $E[H]=e^{1.8} \approx 6.04965$ intact for all three simulations. These economies consist of 1000 dynasties indexed by $i=1 \ldots 1000$ and are identical except for the initial human capital distribution. ${ }^{29}$ The evolution of the growth rate of output per worker and the coefficient of variation of output per worker are the particular focus. ${ }^{30}$ As we have seen in the last section, the coefficient of variation in Period $t\left(C_{t}\right)$ defined below is used to describe the evolution of inequality:

$$
C_{t}=\frac{1}{\mu_{Q, t} \sum_{i=1}^{1000} \omega_{t}^{i}} \sqrt{\sum_{i=1}^{1000} \omega_{t}^{i}\left(Q_{t}^{i}-\mu_{Q, t}\right)^{2}}
$$

where $\mu_{Q, t}$ is the mean of income in Period $t, \omega_{t}^{i}$ is the number of workers of dynasty $i$ in Period $t$ and $\omega_{1}^{i}=1$ for all $i$ so that $\sum_{i=1}^{1000} \omega_{1}^{i}=1000$.

Simulation procedures are straightforward. First, given the initial distribution of human capital, the number of children is determined by Equation (4.13) and by the fact that we have constrained $n$ to have a positive lower bound. That is, if Equation (4.13) implies $n<1$, we replace this with $n=1$. Second, the evolution of human capital can be derived, using Equation (4.12) when $n>1$, or we use Equation (4.14) when $n=1$. Third, investment in education $h$ can be derived using Equation (4.11) or Equation (4.15) depending upon the value of $n$, and working time $l$ and output $Q$ can be calculated using Equations (4.2) and (4.1),

\footnotetext{
${ }^{28}$ The Barro and Lee (1993) dataset has 101 observations for average schooling years in total population over age 25 in 1960 . For the bottom 34 countries, the average is 0.93997 . For the top 34 countries, the average is 6.16544 . $E[H]$ for developing countries and advanced countries are set close to these values, respectively.

${ }^{29}$ Mathematica is used to generate 1000 random numbers of initial $H$.

${ }^{30}$ We define workers as young parents who engage in production of the goods.
} 


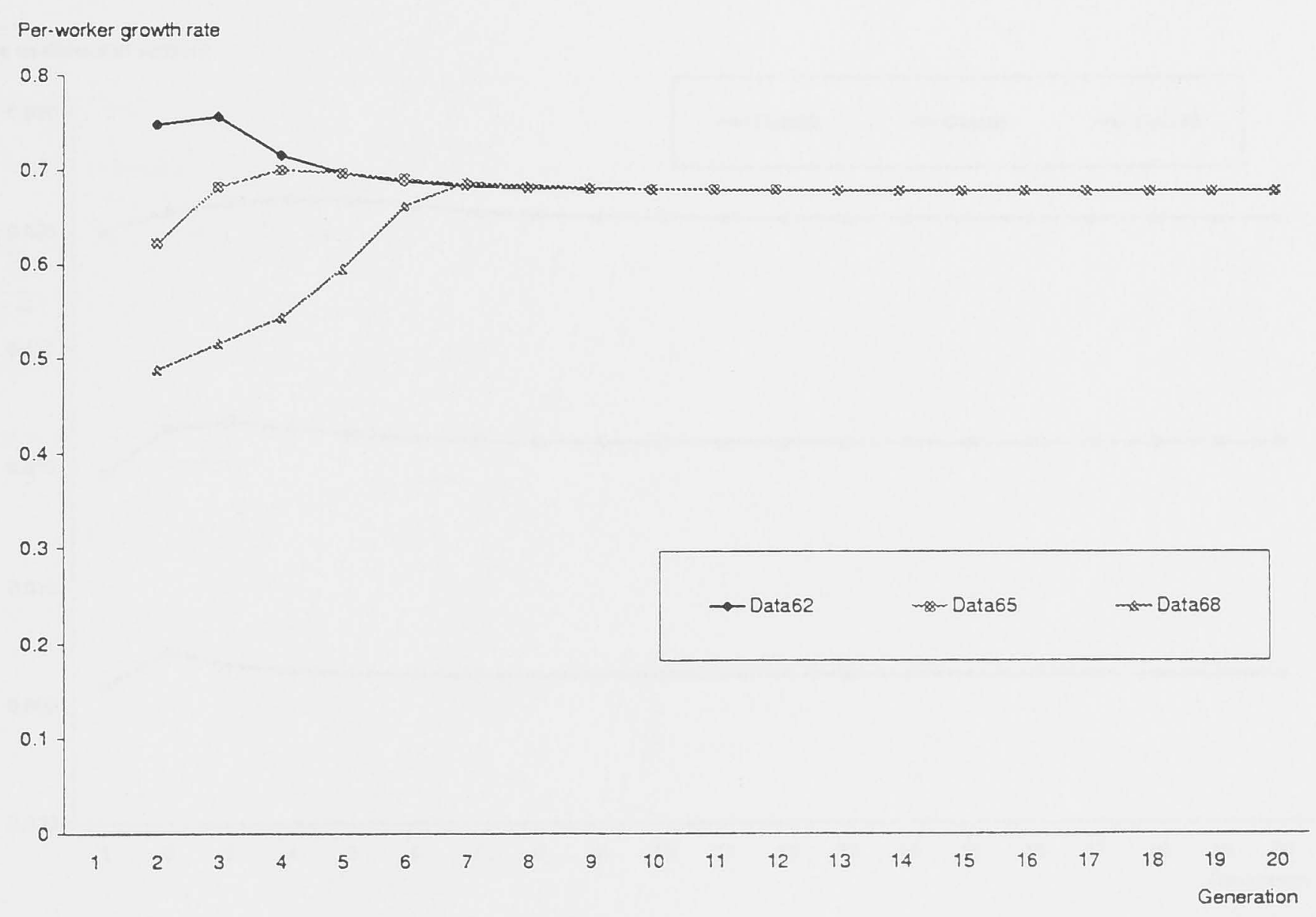

Figure 4.10: Growth rates of output per worker: Advanced economies

respectively. Finally, the growth rate of output per worker and the coefficient of variation can be calculated as we can calculate the change in the number of workers over time using the information on $n, \pi_{1}$, and $\pi_{2}$.

The simulation results are described graphically in Figures 4.10 and $4.11 .^{31}$ Figure 4.10 shows that three economies will evolve differently in the short run but will asymptotically approach the same per-worker growth rate in the long run. Note that these are growth rates over a generation, which is about 25 years.

As we have conjectured, the more equal an economy is, the faster it grows, and the difference of growth rates appears quite significant especially in the beginning. The intuition behind this is as explained in the last section. Whilst the difference in the change in the aggregate output of these economies is relatively small, the difference in the change in workers is significant, i.e., more equal economies have lower growth of the work force. This makes the growth rate of the more equal economy higher than that of the more unequal economy.

${ }^{31}$ Data62 is the most equal economy and Data68 is the least equal economy. 


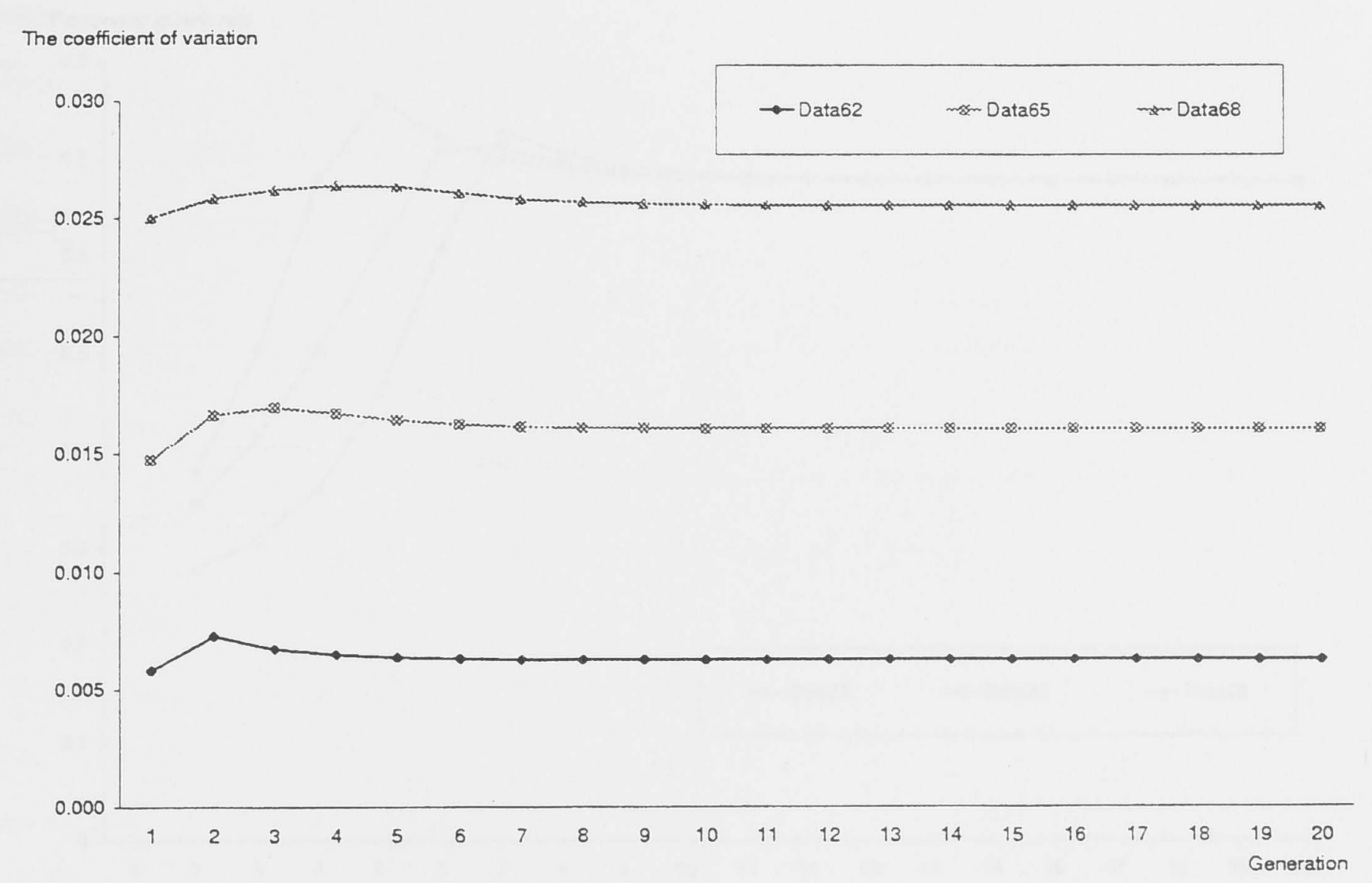

Figure 4.11: The coefficient of variation: Advanced economies

In turn, let us look at the coefficient of variation in shown Figure 4.11. It is apparent that all countries will approach their long run levels of inequality eventually.

Remark 4. The coefficient of variation of output per worker will asymptotically approach a constant.

Proof. From Remarks 2 and 3, the growth rate of output per worker will asymptotically approach a constant. Since the coefficient of variation is invariant to scale, the coefficient of variation of output per worker will asymptotically approach a constant.

It is also clear that there is no change in the inequality ranking, i.e., a country that is more equal than the other one in the beginning will not become more unequal. 


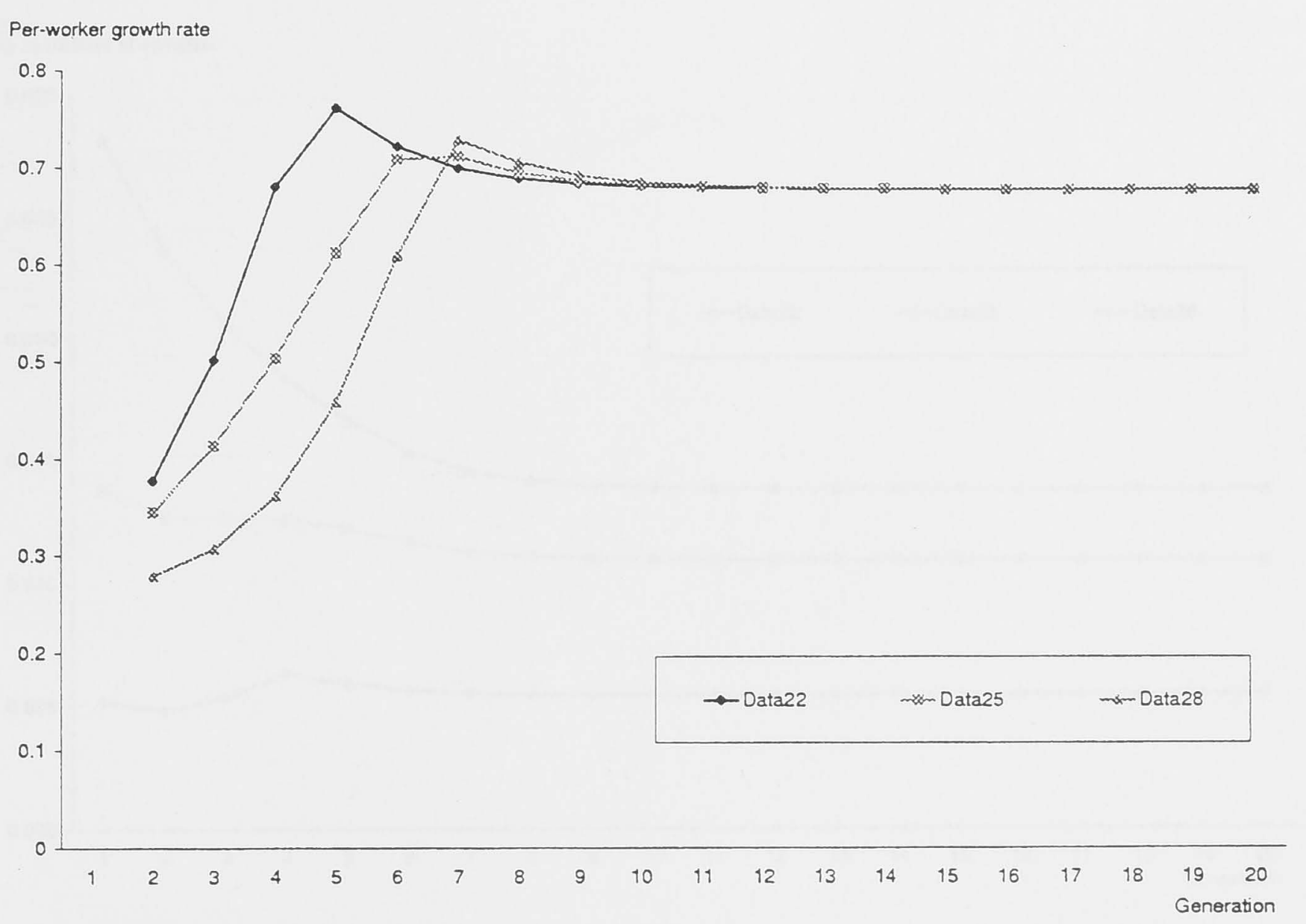

Figure 4.12: Growth rates of output per worker: Middle-income economies

\subsubsection{Middle-income economies}

Now we turn to examine a group of three middle-income economies. The initial $E[H]$ of these countries are the same and now they are set to approximately 2.01 . I again use the same values of $\sigma_{H}$, and change $\mu_{H}$ in order to keep $E[H]=e^{0.7} \approx 2.01$ intact for all simulations. All simulation procedures are the same as in the previous subsection. The simulation results are described graphically in Figures 4.12 and $4.13 .^{32}$

As we have conjectured, we observe at first a more equal country growing faster than a less equal country. The intuition behind this is the dominance of the difference in the change in workers. The worker growth rate in a more unequal country is much higher than that in a more equal country. Although there are more dynasties that produce a lot in the more unequal country, their contribution will be more than offset by this increase in workers.

${ }^{32}$ Data22 is the most equal economy and Data28 is the least equal economy. 


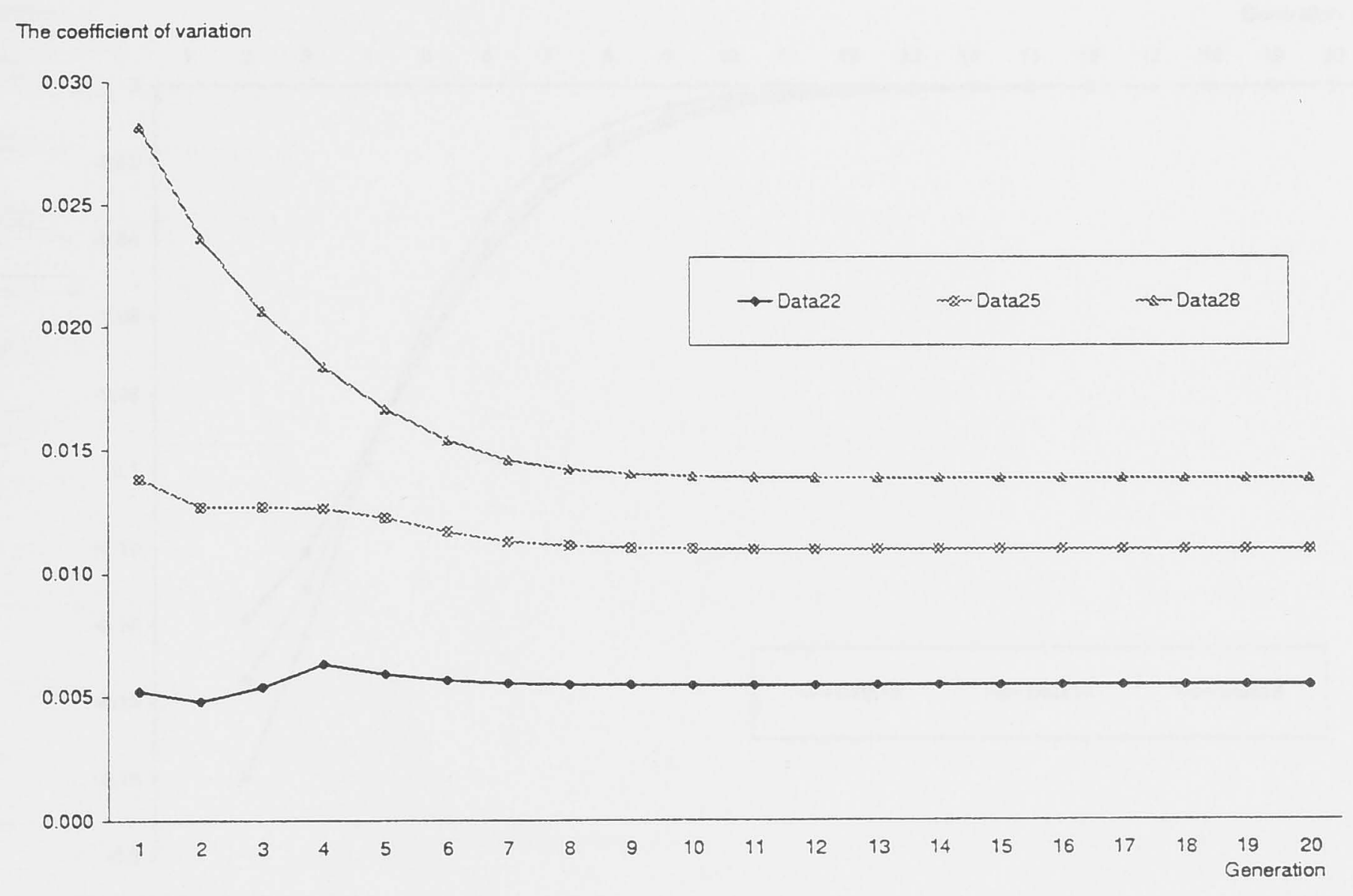

Figure 4.13: The coefficient of variation: Middle-income economies

The difference in the coefficients of variation for three economies is shown in Figure 4.13. As in the previous case, one can observe no changes in the inequality ranking, i.e., a country that is initially more unequal will end up being more unequal. However, if we look at the evolution of the coefficient of variation of the most unequal economy, we can see that this economy is becoming at first less equal, then more equal over time until it converges to the long run level of inequality. The latter result arises mainly from the fact that there are many more dynasties that are catching up (growing faster than) other dynasties that are already on the linear segment of the phase line. The decrease in inequality will asymptotically approach zero for the same reason as in the previous subsection (see Remark 4).

\subsubsection{Developing economies}

Finally, we consider a group of three developing economies that have not begun the demographic transition, where $E[H] \ll H_{B}$. The initial $E[H]$ of these countries are the same but now they are far below $H_{B}$. We again use the same three values of 


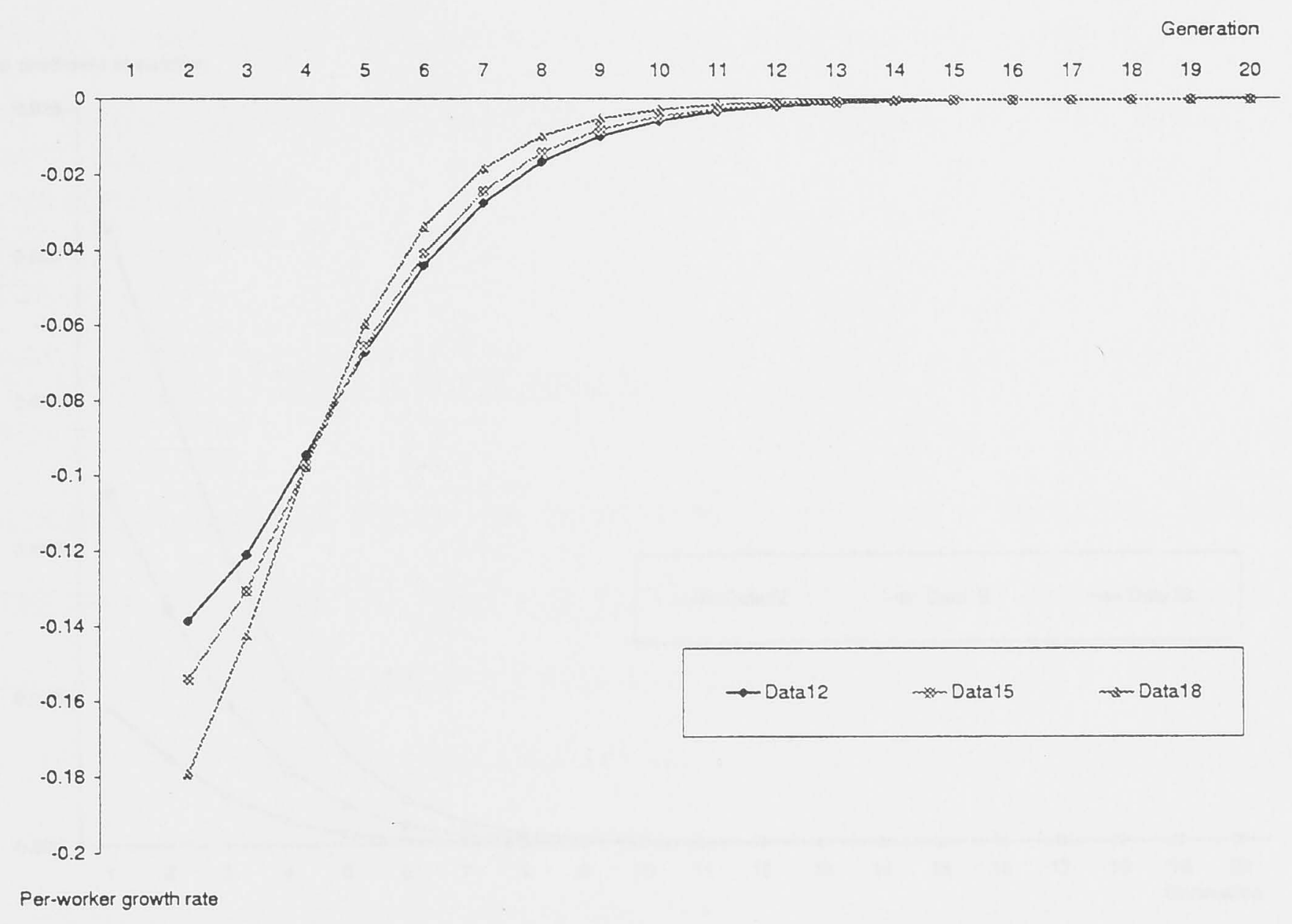

Figure 4.14: Growth rates of output per worker: Developing economies

$\sigma_{H}$, and change $\mu_{H}$ in order to keep $E[H]=e^{0}=1$ intact for all simulations. After going through the same simulation procedures as in the previous subsections, we get the following simulation results that are described graphically in Figures 4.14 and $4.15 .^{33}$

The figure shows that a more equal country will grow faster (decline slower) in the beginning but the relationship will be reversed after a while. This situation is the one given as an example in the last paragraph of Subsection 4.4.1. However, the results are most likely to differ according to the different parameter values. An important thing to note here is that the difference in growth rates of output per worker is rather small compared to the cases for advanced and middle-income economies. The parameter values appear to affect the qualitative implication of inequality for subsequent growth, but the quantitative implication appears to be rather insignificant.

The difference in the evolution of the coefficients of variation is shown in Fig-

${ }^{33}$ Data12 is the most equal economy and Data18 is the least equal economy. 


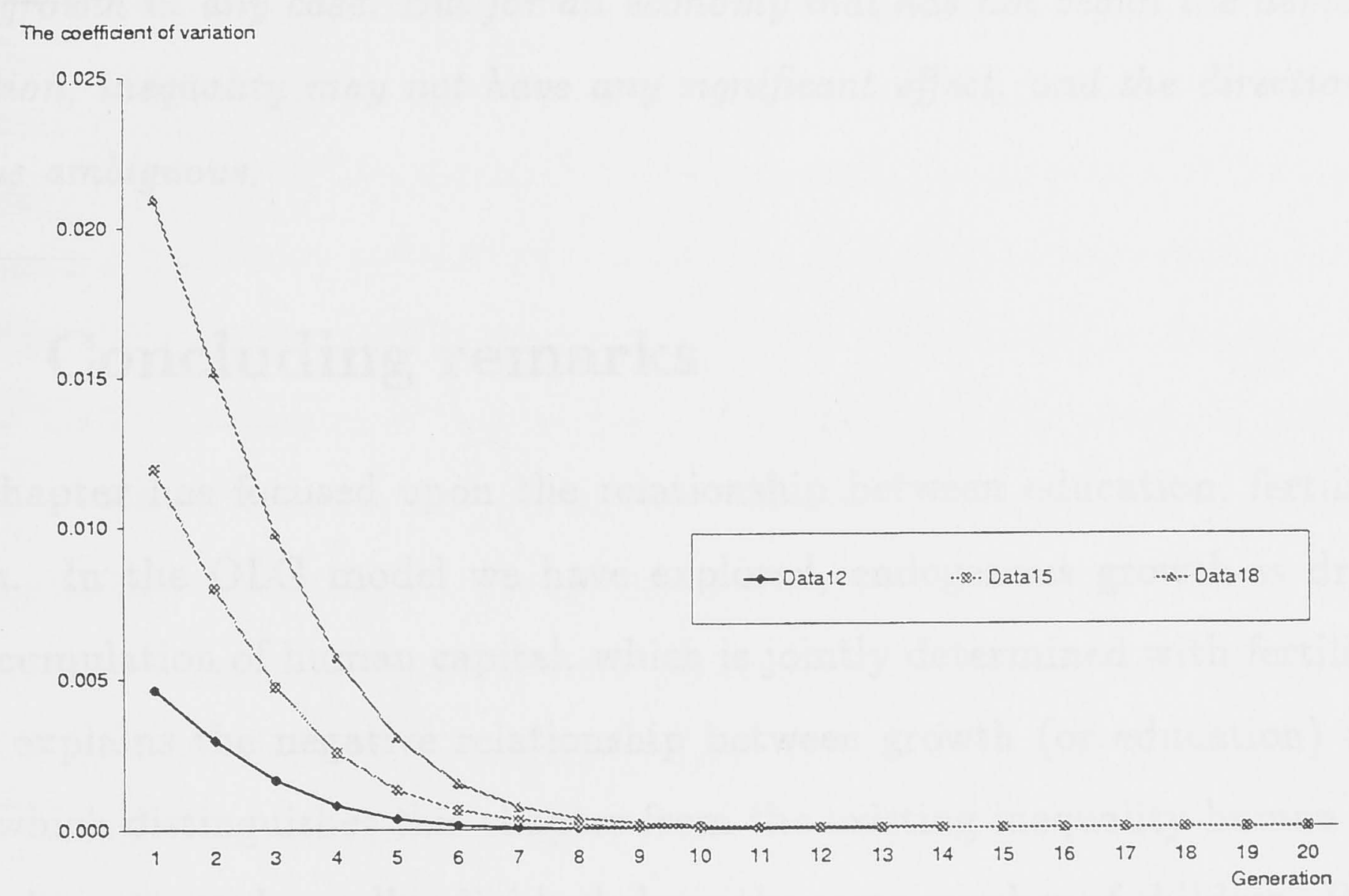

Figure 4.15: The coefficient of variation: Developing economies

ure 4.15. This figure shows that these economies will approach the state where every dynasty is completely equal, whatever the initial distributions are. This happens because all growing dynasties (in terms of output) will be disappearing in the long run because of a constant survival probability whereas all declining dynasties (in terms of output) will be approaching the steady state.

\subsubsection{Inequality matters}

It appears that inequality matters especially when middle-income and advanced economies are concerned. Regarding developing countries, the implication is not that obvious. The following conjecture, which could be tested against the real data, concludes this section.

Conjecture 1. The implication of inequality for the per-worker growth rate depends upon an economy's demographic stage of development. For an economy that has already begun the demographic transition, inequality is likely to impede subse- 
quent growth in any case. But for an economy that has not begun the demographic transition, inequality may not have any significant effect, and the direction of the effect is ambiguous.

\subsection{Concluding remarks}

This chapter has focused upon the relationship between education, fertility, and growth. In the OLG model we have explored, endogenous growth is driven by the accumulation of human capital, which is jointly determined with fertility. The model explains the negative relationship between growth (or education) and fertility, which distinguishes this chapter from the existing inequality-human capitalgrowth literature where all individuals have the same number of children. Becker et al. (1990) have also explained this negative relationship between education and fertility using a representative agent model framework. This chapter differs from their study because we have allowed individuals to be heterogeneous. This has enabled us to see if initial human capital distribution have any implication for subsequent economic growth, and if any, how the former affects the latter.

In line with the existing literature, this chapter has shown that initial human capital distribution might have implications for subsequent economic growth. Whilst much of the existing empirical literature has identified a negative relationship between inequality and growth, this chapter, in contrast, conjectures that the relationship might be dependent upon an economy's demographic stage of development. Simulations in this chapter predicts that the relationship is negative as for middle-income and advanced economies that have begun the demographic transition, but that the relationship is ambiguous for developing countries that have not begun the demographic transition.

We need to be aware that the model in this chapter focuses upon only one particular mechanism - the accumulation of human capital and fertility - by which inequality affects economic growth. As a number of empirical studies have shown, the overall inequality effect upon growth may be negative. In fact, many theoretical 
studies, which focus upon mechanisms aside from what we have looked at, have also suggested that inequality should impede growth. Nevertheless, this chapter has shown that, as long as this mechanism is concerned, the direction of the inequality effect upon growth may not always be negative, in contrast to the recent theoretical literature. This is the most interesting issue that is raised in the chapter.

One major limitation of this model is that there is no interaction between the dynasties. Since there is no interaction between individuals, in the model, an economy is not well defined - it is just a set of dynasties we arbitrarily define. Furthermore, interaction between the dynasties, or individuals, may have important implication for the effect of inequality upon growth. Further research should be directed to incorporate interactions between individuals into the model. ${ }^{34}$

In the next chapter, we test our conjecture that has been derived from the model in this chapter - the non-monotonic nature of the effect of inequality upon growth. Testing the conjectures against real data is very important because the most of the analysis in this chapter is conducted numerically. The predictions of this chapter hinge heavily upon values of the parameters as well as the type of distribution assumed for the initial level of human capital.

\footnotetext{
${ }^{34} \mathrm{We}$ will discuss this issue in the concluding chapter.
} 


\section{Chapter 5}

\section{The non-monotonic nature of the effect of inequality upon growth}

\subsection{Introduction}

The previous chapter has suggested an important economic conjecture on the relationship between initial inequality and subsequent growth - the non-monotonic nature of the effect of inequality upon growth. This chapter attempts to test this interesting conjecture by utilising the newly compiled inequality data by Deininger and Squire (1996).

This is considered to be a challenging attempt. As we have seen in Chapter 2, a number of empirical studies have found a negative and statistically significant relationship between inequality and growth. Recently, some studies (Forbes, 2000 and $\mathrm{Li}$ and Zou, 1998) have found a positive relationship between inequality and growth, but they focus upon the relationship in the short run ( 5 years) utilising panel data. A common agreement that a relationship between inequality and growth is negative in the long run appears to stand firmly.

The conjecture is based upon the theoretical model from the previous chapter, in which inequality impacts growth through both human capital accumulation and fertility. Perotti (1996) is the only empirical study that has genuinely attempted 
to uncover the effect of inequality upon growth through both human capital accumulation and fertility. He has claimed that this decision is jointly made, and that the relationship between inequality and growth is negative.

This study is similar to Perotti (1996) but is different in the following three points. First, Perotti's (1996) empirical specification is ad hoc and is not derived from a theoretical model, so a number of different interpretation of the results could be possible. In contrast, the theoretical model in the previous section enables us to give us a unique interpretation to the estimation results in this study. The specification of the empirical model is based upon that in Perotti (1996) but we modify his econometric specification in order for it to be consistent with our theoretical model. Second, related to this first point, since our model tells us that the effect of inequality depends upon an economy's demographic stage of development, we attempt to specify the system so that we can identify the effects of inequality upon different types of economies. Some empirical studies such as Barro (2000) and Deininger and Squire (1998) also conjecture the non-monotonic effects of inequality upon growth (for different reasons from ours). They separate their samples into two according to some criteria, such as an income level or a degree of democracy. ${ }^{1}$ In this chapter, however, we use a different method in order to identify the development-stage-dependent effects. Finally, we utilise an inequality data set compiled by Deininger and Squire (1996), which was not available when Perotti (1996) conducted his study. This data set could be called industry standard by now as all the recent empirical studies on inequality (Forbes, 2000, Barro, 2000, Deininger and Squire, 1998, and Li and Zou, 1998) use it. The use of this data set

\footnotetext{
${ }^{1}$ The results of these studies are not of interest here. Barro (2000) looks at the short-run effects of inequality on growth and also has a problem in his estimation technique. The random effect panel estimation is used on panel data, but since the data are actually dynamic that include initial income, the random effect estimation produces an inconsistent estimator; see Arellano and Bond (1991). Deininger and Squire (1998) look at the long run story, but separate sample according to whether a country is democratic or not. Their study finds that the effect of inequality does not exist in democratic societies.
} 
alleviates the estimation bias from the possible measurement error. We will have a close look at this data set in Section 5.3.

The data appear to support a part of the conjecture from the previous chapter, i.e., the effect of inequality upon growth appears to be non-monotonic. However, the data do not appear to support the claim that inequality does not have any significant effect for economies that have not begun the demographic transition. It does appear to have a significant and positive effect for these economies. The rest of the chapter is structured as follows. Section 5.2 recaps the conjectures from the previous chapter and specifies the empirical model. Section 5.3 describes the data set we use, paying special attention to the inequality data set compiled by Deininger and Squire (1996). Section 5.4 conducts estimations and analyses the results. Section 5.5 concludes.

\subsection{Conjectures and the empirical model}

First, we split the conjecture from the previous chapter into two for convenience:

Conjecture 2. The implication of inequality for the per-worker growth rate depends upon an economy's demographic stage of development.

Conjecture 3. For an economy that has already begun the demographic transition, inequality is likely to impede subsequent growth. But for an economy that has not begun the demographic transition, inequality may not have any significant effect, and the direction of the effect is ambiguous.

The objective of chapter is two verify if these conjectures are true. The procedure is very simple. To begin with, we specify the empirical model as follows:

$$
\begin{cases}g_{65-90} & =f\left(\ln _{65}, P P P I_{65}, F E D U_{65-90}\right) \\ F E D U_{65-90} & =g\left(F E R T_{65-90}, G I N I_{65}, F H C_{65}\right) \\ F E R T_{65-90} & =h\left(F E D U_{60}, F E R T_{60}, F H C_{60}, P O P_{65}\right)\end{cases}
$$


where $g_{65-90}$ is the average annual growth rate of real GDP per worker 1965-1990, $\ln _{65}$ is a logarithm of real GDP per worker in 1965 that captures convergence, $P P P I_{65}$ is the PPP value of the investment deflator as an indication of price distortion, relative to that of the United States in 1965, FERT $65-90$ is the net fertility rate, ${ }^{2}$ average of 1960 and 1990 values, GINI $I_{65}$ is the Gini coefficient in or around $1965,{ }^{3} F E D U_{65-90}$ is the female gross enrolment ratio for secondary education, average of 1960 and 1990 values, and $F H C_{65}$ is average years of secondary schooling in the female population over age 25 in $1965 .{ }^{4} F E D U_{60}, F E R T_{60}$, and $F H C_{60}$ are the 1960 values of $F E D U_{65-90}, F E R T_{65-90}$, and $F H C_{65-90}$, respectively, and $P_{65}$ is total population in 1965.

System (5.1) consists of three equations. The first is a growth equation where the growth rate of real GDP per worker is explained by the initial level of real GDP per worker, the degree of price distortion in the economy, and investment in education. ${ }^{5}$ In turn, the second equation shows that investment in education depends upon various variables including the net fertility rate, which is jointly determined with investment in education. This equation is derived from the results of the previous chapter, a point we will come back to shortly. In order to complete the system, we need an equation that explains cross-country variations in fertility. There appear to be many factors that explain differences in the fertility rate across countries, such as the difference in child rearing costs, the differences in religious and social norms, the difference in knowledge of contraception, etc, and estimating this equation per se will be worth a paper. Since our main objective is to uncover the effect of inequality upon growth, we will not attempt to estimate the whole system. Instead, we postulate in the third equation in System (5.1) that fertility

\footnotetext{
${ }^{2}$ Net fertility rate is defined as total fertility rate times (1 - infant mortality rate in the first year of life).

${ }^{3}$ Details on how we compile the Gini coefficient will be discussed in Section 5.3.

${ }^{4}$ See Section 5.3 for the data sources of these variables.

${ }^{5}$ We also include regional dummies in this equation but will omit them until Section 5.4 for brevity.
} 
is explained by the initial population and lagged fertility and education variables, i.e., we will instrument fertility by these variables. Issues regarding the choice of instruments will be discussed in Section 5.4, where we conduct estimation and sensitivity analysis.

Two other issues regarding this system of equations should be discussed. ${ }^{6}$ First, most of the empirical studies that relate education to growth use both male and female education variables or the aggregated one, whereas in this chapter, we use only female education variable. A rationale for doing this is that the female education appears more relevant in relation to the model in the previous chapter. The crucial aspect of the model is that individuals make a joint decision over fertility and investment in human capital. Evolutions of population and stock of human capital, which are crucial in determining the growth rate of output per worker, rely upon that decision by individuals. In the model, there is no gender, but in reality, it is much more likely to be the female that faces the decision.

In fact, the issue about coefficients on male and female education variables has been controversial. Barro and Lee (1994), using cross-country estimation, find that male education contributes positively to growth but female education retards growth, therefore stress the importance of male education. In contrast, Caselli et al. (1996), using the dynamic panel GMM estimation, find the exact opposite - female education contributes to growth but male education has negative effects upon growth. Some studies such as Mankiw et al. (1992) use the average enrolment ratio for all working-age population and find the contribution to growth positive and significant. We will stick to our interpretation of the model and use female education, but given this unrobustness of the estimates, we will check the sensitivity of the result using the education variables for the entire working-age population.

Second, if we look at a growth equation in System (5.1) it is the flow of education that influences growth. In some studies, however, it is the stock of education that counts for growth. It depends upon the theoretical model as to which of these two

\footnotetext{
${ }^{6}$ Recall that we have briefly discussed these issues in Subsection 2.3 .12 in Chapter 2 .
} 
variables is used. If endogenous growth is postulated, it is a level of human capital stock that matters to growth in the long run, so the initial stock of education enters the growth equation (Barro and Lee, 1994). On the other hand, if the Swan-Solow growth model is behind the empirical model, it is investment in human capital that matters during transition (since long-run growth is given exogenously), so the flow of education is employed (Mankiw et al., 1992).

Our system has both of these flavours. As we have seen, growth is directly dependent upon the flow of human capital in our specification. This comes from the fact we are looking at growth between two consecutive periods in the short run (although it is 25 years). Note, however, that in turn, the flow of human capital is dependent upon the stock of human capital, and that our system can be reduced as follows:

$$
g_{65-90}=f\left(\ln y_{65}, P P P I_{65}, g\left(F E R T_{65-90}, G I N I_{65}, F H C_{65}\right)\right) .
$$

Therefore, indirectly the level of human capital stock is important in determining growth, which is consistent with the theoretical framework underlying this empirical system, which is an endogenous growth model.

Now, given that fertility is instrumented by the predetermined variables, we try to estimate the following econometric model similar to Perotti (1996):

$$
\begin{cases}g_{65-90} & =\alpha_{1}+\alpha_{2} \ln _{65}+\alpha_{3} P_{P P I_{65}}+\alpha_{4} F E D U_{65-90}+\epsilon_{1}, \\ F E D U_{65-90} & =\beta_{1}+\beta_{2} G I N I_{65}+\beta_{3} F H C_{65} \\ & +\beta_{4} F E R T_{65-90}+\beta_{5} F E R T_{65-90} \text { GINI }_{65}+\epsilon_{2} .\end{cases}
$$

What are the expected signs of the coefficients? Regarding a growth equation, we expect $\alpha_{2}<0$ if there is a convergence effect, $\alpha_{3}<0$ as price distortion in the market is considered to retard economic performance, and $\alpha_{4}>0$ because investment in education contributes to economic growth. As for the second equation, note that we can rewrite it as follows:

$F E D U_{65-90}=\beta_{1}+\beta_{3} F H C_{65}+\beta_{4} F E R T_{65-90}+\left(\beta_{2}+\beta_{5} F E R T_{65-90}\right) G I N I_{65}+\epsilon_{2}$. 
Due to the analysis in the previous chapter, we can expect that $\beta_{3}>0$ and $\beta_{4}>0$. In an economy with higher stock of human capital, the return on investment in human capital is higher, given any distribution of human capital, and therefore the investment in education is higher. Fertility is endogenously determined with investment in human capital and the relationship is postulated negative, which is emphasised more than enough in the previous chapter. The focus of this chapter is more upon the coefficient on GINI $I_{65}$. As we can see, the coefficient on GINI 65 is sum of $\beta_{2}$ and $\beta_{5} F E R T_{65-90}$. Therefore, the effect of inequality upon investment in education depends upon these two things. We expect that the whole effect is expected to be negative according to the existing empirical work - more inequality will lead to less investment in education, and that leads to lower economic growth. If this is expected, we can expect that $\beta_{2}$ is negative, which shows the common negative effect of inequality upon growth. Also, we can expect $\beta_{5}$ is positive. Our conjecture implies that in economies that have not begun the demographic transition, the rate of fertility is likely to be higher. In these economies, negative effect of inequality represented by the first term may be offset by positive $\beta_{5}$ together with high $F E R T_{65-90}$ to some extent so that the overall effect is insignificant. We shall come back to further interpretation of this coefficient in Section 5.4 where we actually conduct the estimation. Before carrying out this interesting estimation, however, let us have a look at the data set we use.

\subsection{Description of data}

We use an inequality data set compiled by Deininger and Squire (1996) as in the most of the recent empirical literature. Some of the important characteristics of this data set are summarised, whilst more detailed explanation can be found in their original article. 


\subsubsection{Measure of inequality}

The Gini coefficient is chosen as a measure of inequality for the empirical analysis. Given from the previous studies that aggregate results are similar for different measures of inequality, ${ }^{7}$ it should be best to utilise it since it is most widely reported in official sources that are based upon primary data.

\subsubsection{Quality of this data set}

Deininger and Squire (1996) select 682 "high quality" inequality data out of more than 2600 data sources according to three selection criteria. First, they require that inequality data should be based upon actual observation of individual units drawn from household surveys. Therefore, data sets based upon synthetic estimates of inequality using national accounts and some sort of assumed functional form of income distribution will be excluded from this data set.

Second, they require that inequality data should cover all the population. It is well known that differences between Gini coefficients based upon a subset of the population and those based upon a nationally representative sample can be substantial.

Third, comprehensive coverage of different income sources are required. Exclusion of non-monetary income as well as non-wage earnings might have significant effect upon Gini coefficients.

One important thing to note here is the following. Data sets that have been used in the existing literature may be of doubtful quality if we apply these three criteria. Persson and Tabellini (1994) have detected a negative relationship between inequality and growth using their 55 country data set (gathered from various sources). But only 18 out of 55 data are in high quality, and Deininger and Squire (1996) claim that use of this reduced data undermines their finding.

\footnotetext{
${ }^{7}$ See Anand and Kanbur (1993) for example.
} 


\subsubsection{Characteristics of this data set}

This data set has many more observations and covers more economies over longer periods than any other inequality data sets. However, Deininger and Squire (1996) note that we need to be careful when we want to compare one observation with another, because the definition of the coefficient differs across countries and over time. Three important differences are the focus.

First, the inequality measure based upon individuals differs from that based upon households when there are systematic differences in size between rich and poor households. Household-based data give slightly lower inequality than individualbased data, but the difference is not too large (the mean difference of the coefficient is 1.67 percentage points).

Second, use of before-tax income should give a higher inequality measure than use of after-tax income. The quantitative importance of the redistributive tax's effect depends upon the progressivity and effectiveness of the tax system. The data show some difference (the mean difference of about 3 percentage points) for the OECD economies, but this difference might be irrelevant for developing economies where the role of redistributive taxation is smaller.

Finally, inequality in expenditure is usually smaller than inequality in income since it is much easier for individuals to smooth expenditure than to smooth income. The data shows the systematic and significant difference between incomebased and expenditure-based inequality measures (the mean difference is 6.6 percentage points). It is most preferable that we confine our analysis to measures that are defined consistently, i.e, use either income-based or expenditure-based measure. However, this will reduce the number of observation. In order to avoid this, Deininger and Squire (1996) suggest that we should correct the difference by adding the mean difference to expenditure-based observations. Of course, they also note the importance of checking the robustness of results to this correction.

This comprehensive data set even allows us to conduct panel estimation, and in fact, some studies have already conducted it (Li and Zou, 1998, Barro, 2000, Forbes, 
2000). As Forbes emphasises, panel estimation is preferred to cross-sectional estimation for various reasons. Panel estimation can capture time-invariant systematic differences between countries that independent variables cannot capture, so the estimation is not as prone to omitted variable problem as in cross-sectional estimation. It also provides us with effects of the independent variables upon dependent variables within a country, whereas cross-sectional estimation provides a relationship across countries. Bearing in mind these superiority in panel estimation, however, this study does not fully utilise the time dimension of this data set, i.e., we only use data for the Gini coefficient in 1965 (or the year around 1965). This is due to the fact that our theoretical implication is related to the long run where one generation implies around 25 years.

\subsubsection{Compiling the initial Gini coefficient}

The following outlines the way the Gini coefficient data in 1965 used in this chapter is compiled. The (high quality) Gini coefficients in 1965 are available for only 56 countries. In addition to this. we allow to include the nearest high-quality observation prior to 1965 , if there is no observation for 1965. If we cannot find observations prior to 1965, we use the nearest observation after 1965 but no later than 1975 . We also follow Barro (2000) in order to increase the number of the observations. Namely, we add observations that are excluded from the high-quality data set because their source was unidentified. The source being unidentified implies that these observations may not satisfy the second criteria - the data should cover all the population - but Barro (2000) argues these observations appear to be based upon representative national coverage. Again we look for the observations for 1965 first. If we cannot find them, we look for nearest observations prior to 1965, and then after 1965 but no later than 1975. If there are multiple observations in the same year, we use the average value of them. 
Table 5.1: Descriptive statistics for all countries

\begin{tabular}{rrrrrr}
\hline \hline Variable & Obs & Mean & Std. Dev. & Min & Max \\
\hline$g_{65-90}$ & 105 & .0166417 & .0175463 & -.025103 & .0662873 \\
GINI $_{65}$ & 85 & 42.23183 & 9.970333 & 22.23 & 61.88 \\
PPPI $_{65}$ & 118 & .9265627 & .467477 & .194 & 3.3549 \\
$\operatorname{lny}_{65}$ & 125 & 8.372516 & 1.019235 & 6.419995 & 10.24178 \\
$F H C_{65}$ & 107 & .4969626 & .6127281 & 0 & 3.253 \\
$F E D U_{65-90}$ & 99 & .3742273 & .2752068 & .015 & .935 \\
$F E R T_{65-90}$ & 113 & 4.469705 & 1.479164 & 1.766405 & 7.164125 \\
\hline
\end{tabular}

\subsubsection{Other variables}

Data sources for other variables used in this chapter are as follows. The average annual growth rate of real GDP per worker 1965-1990 and real GDP per worker in 1965 are taken from the Penn World Table 5.6a (Summers and Heston, 1995). All the schooling variables, the net fertility rate, a price distortion variable, ${ }^{8}$ total population, and regional dummies are taken from Barro and Lee (1993) data set. For the flow variables, it is common to use the average of initial and terminal periods, but the data for schooling variable (enrolment ratio) for 1990 is unavailable in Barro and Lee (1993), so we use 1985 instead and take the average of that and 1965. We do the same for the net fertility rate. The descriptive statistics for the all observations are shown in Table 5.1.

As it turns out in the next section, only 57 observations are available to estimate System (5.3) using the method of two-stage least squares. The descriptive statistics for that subset are shown in Table 5.2. Table 5.3 shows the detailed information on the Gini coefficient data for these 57 observations. Following the suggestion by Deininger and Squire (1996), we have added 6.6 to the Gini coefficient if the data source is expenditure-based, in running all the regressions throughout this chapter. ${ }^{9}$

\footnotetext{
${ }^{8}$ Following Perotti (1996), we use the PPP value of the investment deflator as an indication of price distortion, relative to that of the United States in 1965.

${ }^{9}$ The Gini coefficient values in Table 5.3 are after-adjustment values.
} 
Table 5.2: The relevant descriptive statistics for 57 countries

\begin{tabular}{rrrrrr}
\hline \hline Variable & Obs & Mean & Std. Dev. & Min & Max \\
\hline$g_{65-90}$ & 57 & .0182755 & .0171273 & -.0165344 & .0662873 \\
GINI $_{65}$ & 57 & 42.97968 & 9.107882 & 24.3 & 61.88 \\
$P P P I_{65}$ & 57 & .7538105 & .2979437 & .194 & 2.1101 \\
$\ln _{65}$ & 57 & 8.732098 & .9049669 & 6.74052 & 10.24178 \\
$F H C_{65}$ & 57 & .6433684 & .7145447 & .003 & 3.253 \\
$F E D U_{65-90}$ & 57 & .4411403 & .2719671 & .015 & .935 \\
$F E R T_{65-90}$ & 57 & 3.961862 & 1.494163 & 1.852062 & 7.164125 \\
\hline
\end{tabular}

\subsection{The estimation results}

We estimate System (5.3) using the method of two-stage least squares (2SLS). $g_{65-90}$ $F E D U_{65-90}, F E R T_{65-90}$, and $F E R T_{65-90} G I N I_{65}$ are the three endogenous variables to the system, and exogenous variables are $\ln _{65}, P P P I_{65}, G I N I_{65}, F H C_{65}$, and the regional dummies, ASIAE, LAAM, and SAFRICA. ${ }^{10}$ As we have discussed in Section 5.2, we use 1960 values of $F E D U_{65-90}, F E R T_{65-90}$, and $F H C_{65}$ as well as $P O P_{65}$, as instruments.

The estimation results for various specifications including System (5.3) are presented in Tables 5.4, 5.6, 5.7, and 5.8. The Breusch-Pagan $L M$ test is employed for every equation in order to check heteroskedasticity of the error term. Throughout the analysis, heteroskedasticity-robust $t$ statistics will be reported if we reject the null hypothesis of homoskedasticity of the error term at 5 per cent.

\subsubsection{The non-monotonic effects of inequality upon growth}

Column (1) in Table 5.4 presents the estimation results for System (5.3). First, let us look at a growth equation in Column (1). The estimate of coefficients on $\ln y_{65}$ is statistically significant at 1 per cent and the estimate of coefficient on $F E D U_{65-90}$ is statistically significant at 5 per cent. We observe the anticipated signs on coefficients, i.e., a negative coefficient on $\ln y_{65}$ that captures the conver-

\footnotetext{
${ }^{10}$ These dummies are taken from Barro and Lee Data Set (1993) as well.
} 
Table 5.3: The Gini coefficient for 57 countries

\begin{tabular}{|c|c|c|c|c|c|c|c|}
\hline Economy & Source & $G I N I_{65}$ & Quality & Economy & Source & $G I N I_{65}$ & Quality \\
\hline Argentina & Income & 42.00 & ps & Mexico & Income & 55.50 & accept \\
\hline Australia & Income & 32.02 & accept & Netherlands & Income & 28.60 & accept \\
\hline Bangladesh & Income & 37.31 & accept & New Zealand & Income & 30.05 & accept \\
\hline Benin & Income & 42.12 & ps & Norway & Income & 37.52 & accept \\
\hline Bolivia & Income & 49.60 & ps & Pakistan & Expenditure & 37.16 & accept \\
\hline Brazil & Income & 53.00 & accept & Panama & Income & 57.00 & accept \\
\hline Canada & Income & 31.61 & accept & Peru & Income & 55.00 & accept \\
\hline Chile & Income & 45.64 & accept & Philippines & Income & 51.32 & accept \\
\hline Colombia & Income & 52.02 & accept & Portugal & Income & 40.58 & accept \\
\hline Costa Rica & Income & 50.00 & accept & Senegal & Income & 57.37 & ps \\
\hline Denmark & Income & 38.00 & ps & Sierra Leone & Income & 60.79 & accept \\
\hline Ecuador & Income & 35.00 & ps & Singapore & Income & 41.00 & accept \\
\hline El Salvador & Income & 53.00 & ps & South Korea & Income & 34.34 & accept \\
\hline Fiji & Income & 46.00 & ps & Spain & Income & 31.99 & accept \\
\hline Finland & Income & 31.80 & accept & Sri Lanka & Income & 47.00 & accept \\
\hline France & Income & 47.00 & accept & Sweden & Income & 33.41 & accept \\
\hline Germany & Income & 28.13 & accept & Thailand & Income & 41.28 & accept \\
\hline Greece & Expenditure & 41.71 & accept & Togo & Income & 33.80 & ps \\
\hline Honduras & Income & 61.88 & accept & Trinidad and Tobago & Income & 46.02 & accept \\
\hline Hong Kong & Income & 40.90 & accept & Tunisia & Expenditure & 48.90 & accept \\
\hline India & Expenditure & 37.74 & accept & Turkey & Income & 56.00 & accept \\
\hline Indonesia & Expenditure & 39.90 & accept & Uganda & Income & 40.07 & ps \\
\hline Ireland & Income & 38.69 & accept & United Kingdom & Income & 24.30 & accept \\
\hline Italy & Income & 41.00 & accept & United States & Income & 34.64 & accept \\
\hline Jamaica & Income & 54.31 & accept & Venezuela & Income & 47.65 & accept \\
\hline Japan & Income & 34.80 & accept & Yugoslavia & Income & 31.18 & accept \\
\hline Kenya & Income & 48.80 & ps & Zambia & Income & 51.32 & ps \\
\hline Malawi & Income & 46.08 & ps & Zimbabwe & Income & 46.00 & ps \\
\hline Malaysia & Income & 50.00 & accept & & & & \\
\hline
\end{tabular}

gence effects, a negative coefficient on $P P P I_{65}$, albeit statistically insignificant, showing that price distortion in an economy is harmful to growth, and a positive coefficient on $F E D U_{65-90}$ implying that investment in education fosters economic growth. Regional dummies are also statistically significant at 1 per cent, Asian economies being estimated to have higher growth than Latin American and SubSaharan African economies.

In turn, let us look at the other equation in Column (1). All variables are estimated statistically significant at at least 5 per cent. Coefficients on $F H C_{65}$ and FERT $T_{65-90}$ are in expected signs as we have discussed in Section 5.2. Most interestingly and strikingly, the coefficient on $G I N I_{65}$ is negative and that on FERT $T_{65-90} G I N I_{65}$ is positive as we have anticipated.

These results show that the effect of inequality upon growth through human cap- 
ital accumulation is statistically significant, and that the effect is non-monotonic. That is, Conjecture 2 appears to be supported by the data. Furthermore, the effect of inequality appears to be larger if a country has lower fertility. Let us check next if the effect is, at all, significant in terms of economics, ${ }^{11}$ and try to interpret the results in line with the implication from the previous chapter.

Table 5.4: Estimation results

\begin{tabular}{|c|c|c|c|c|c|c|}
\hline \multirow[b]{3}{*}{ Dependent variable } & \multicolumn{2}{|c|}{ Our specification } & \multicolumn{2}{|c|}{ Reduced form } & \multicolumn{2}{|c|}{ Including direct effects } \\
\hline & & (1) & (2) & (3) & & (4) \\
\hline & $965-90$ & $F E D U_{65-90}$ & $965-90$ & $965-90$ & $965-90$ & $F E D U_{65-90}$ \\
\hline \multirow[t]{2}{*}{$\ln y_{65}$} & -0.012 & & -0.014 & -0.015 & -0.012 & \\
\hline & $(-3.263)$ & & $(-4.250)$ & $(-4.224)$ & $(-3.242)$ & \\
\hline \multirow{2}{*}{$P P P I_{65}$} & -0.005 & & -0.002 & -0.010 & -0.003 & \\
\hline & $(-0.846)$ & & $(-0.485)$ & $(-1.749)$ & $(-0.584)$ & \\
\hline \multirow[t]{2}{*}{$F E D U_{65-90}$} & 0.025 & & 0.029 & 0.053 & 0.022 & \\
\hline & $(2.018)$ & & $(2.454)$ & $(3.930)$ & $(1.729)$ & \\
\hline$F E R T_{65-90}$ & & $\begin{array}{c}-0.443 \\
(-3.135)\end{array}$ & & & & $\begin{array}{c}-0.443 \\
(-3.135)\end{array}$ \\
\hline$F H C_{65}$ & & $\begin{array}{c}0.094 \\
(3.334)\end{array}$ & & & & $\begin{array}{c}0.094 \\
(3.334)\end{array}$ \\
\hline$G I N I_{65}$ & & $\begin{array}{c}-0.030 \\
(-2.080)\end{array}$ & $\begin{array}{l}-0.0002 \\
(-0.850)\end{array}$ & $\begin{array}{c}-0.0003 \\
(-1.060)\end{array}$ & $\begin{array}{l}-0.0001 \\
(-0.554)\end{array}$ & $\begin{array}{c}-0.030 \\
(-2.080)\end{array}$ \\
\hline$F E R T_{65-90} G I N I_{65}$ & & $\begin{array}{c}0.007 \\
(2.163)\end{array}$ & & & & $\begin{array}{c}0.007 \\
(2.163)\end{array}$ \\
\hline$A S I A E$ & $\begin{array}{c}0.012 \\
(2.568)\end{array}$ & & $\begin{array}{c}0.014 \\
(2.499)\end{array}$ & & $\begin{array}{c}0.013 \\
(2.605)\end{array}$ & \\
\hline$L A A M$ & $\begin{array}{c}-0.013 \\
(-3.296)\end{array}$ & & $\begin{array}{c}-0.009 \\
(-2.272)\end{array}$ & & $\begin{array}{c}-0.012 \\
(-2.540)\end{array}$ & \\
\hline$S A F R I C A$ & $\begin{array}{l}-0.027 \\
(-4.326)\end{array}$ & & $\begin{array}{c}-0.027 \\
(-5.766)\end{array}$ & & $\begin{array}{l}-0.028 \\
(-4.310)\end{array}$ & \\
\hline constant & $\begin{array}{c}0.121 \\
(4.422)\end{array}$ & $\begin{array}{c}2.108 \\
(3.684)\end{array}$ & $\begin{array}{c}0.142 \\
(5.830)\end{array}$ & $\begin{array}{c}0.149 \\
(5.283)\end{array}$ & $\begin{array}{c}0.126 \\
(4.312)\end{array}$ & $\begin{array}{c}2.108 \\
(3.684)\end{array}$ \\
\hline Number of observations & 57 & 57 & 60 & 60 & 57 & 57 \\
\hline$R^{2}$ & 0.6751 & 0.8231 & 0.6977 & 0.3735 & 0.6763 & 0.8231 \\
\hline
\end{tabular}

NB: Values in the parentheses are $t$ statistics, but for those in the second equation of Column (2), which are heteroskedasticity-robust $t$ statistics.

\subsubsection{Is the effect of inequality significant?}

Since the effect of inequality depends upon the level of $F E R T_{65-90}$, we need to refer to the descriptive statistics in order to obtain a single magnitude. Results are summarised in Table 5.5

When we evaluate the effect at the 57 country sample mean, the coefficient on

${ }^{11}$ We want to compare the magnitude of the inequality effect with that of the existing empirical studies. 
Table 5.5: Effects of a one standard deviation increase in GINI $I_{65}$ upon $g_{65-90}$ for different groups of economies

\begin{tabular}{lcc}
\hline \hline Group of countries & Change in FEDU $65-90$ & Change in $g_{65-90}$ \\
\hline All 57 countries & -0.007 & -0.0002 \\
OECD & -0.117 & -0.0028 \\
Latin America & 0.032 & 0.0008 \\
Developing countries $\left(G D P_{65}<\$ 2000\right)$ & 0.110 & 0.0027 \\
Sub-Saharan Africa & 0.134 & 0.0033 \\
\hline
\end{tabular}

NB: $G D P_{65}$ is the real GDP per worker in 1965. Values are evaluated at mean of sample or subsample.

GINI $I_{65}$ in Equation (5.4) is negative, i.e., more inequality will have a negative effect on investment in human capital, and that will lead to lower growth. A one standard deviation increase in the Gini coefficient will lower investment of human capital (the female secondary school enrolment ratio) by about 0.007 . This implies a decrease in the growth rate of GDP per worker by around 0.02 percentage points. The effect of inequality upon growth appears significantly small compared with what the existing literature has found. ${ }^{12}$

When we evaluate the effect using the OECD country subsample mean, the coefficient on GINI 65 in Equation (5.4) is negative as well, i.e., inequality will have a negative impact upon investment in human capital, which will impede growth. However, the magnitude of the effect appears much more significant. A one standard deviation decrease in the Gini coefficient will lower investment in human capital by about 0.12 , and this implies a decrease in the growth rate of GDP per worker by 0.28 percentage points. This magnitude is very similar to what Birdsall et al. (1995) has found, which is 0.32 percentage points. The effect of inequality upon growth appears to be sizable, considering that the standard deviation of the annual growth rate of real GDP per worker of our whole sample is around 1.8 per cent.

\footnotetext{
${ }^{12}$ The effect ranges between 0.32 and 2.5 in the existing literature. See a review of the literature on Chapter 2.
} 
In turn, if we look at a subsample of Latin American countries, the story looks a little different. For this sub-sample, a one standard deviation increase in the Gini coefficient will foster growth. However, the magnitude of this effect is only 0.08 percentage points, which appears to be relatively small. This comparison between the OECD and Latin America appears to support our Conjecture 3 if we regard the latter as a region that has not begun the demographic transition.

However, if we focus upon another developing country subsample, where we define developing countries as those whose real GDP per worker in 1965 is less than 2000 US Dollars, we find stronger and seemingly non-negligible inequality effects. For this sample, a one standard deviation increase in the Gini coefficient will increase investment in human capital by around 0.11 , which increases the growth rate of GDP per worker by 0.27 percentage points. The magnitude is almost the same as that for the OECD but the direction is different.

Recalling that inequality effects rest upon interaction between evolutions of super-rich and extreme-poor dynasties (or the relative strength of the contributions of these two classes), we should interpret the results that in developing countries, super-rich effects have had much more than offset extreme-poor effects. This result appears to undermine the latter part of our Conjecture 3, however, it is not surprising to observe it. Recall that our conjectures are derived using numerical simulations and the results have appeared to be sensitive to the choice of parameter values. The simulation in the previous chapter has illustrated the case in which these two effects roughly offset each other in developing countries, but this empirical result suggests that it is not necessarily the case.

Figure 5.1 plots the initial income levels against the predicted changes in the growth rate of real GDP per worker for each of countries in our 57 country sample, when the Gini coefficient decreases by one standard deviation, i.e., when an economy becomes more equal. The picture appears to convey the following facts. For either advanced or developing countries, inequality appears to have sizable effects upon growth, although the direction of the effect appears to be different - inequal- 


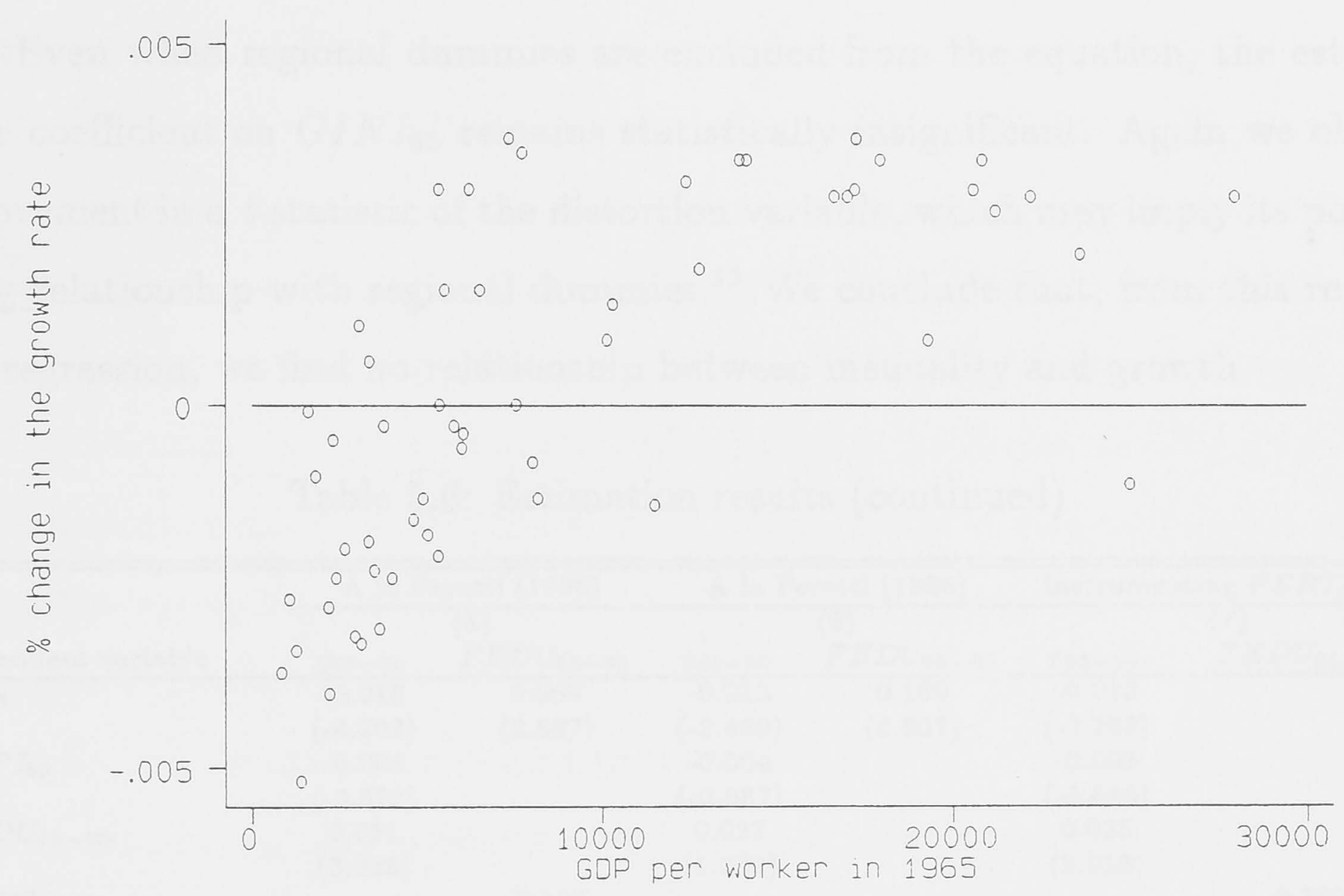

Figure 5.1: The predicted effects of a fall in inequality upon growth for each country

ity impedes growth for the former but enhances growth for the latter. In contrast, for medium-income economies, the effects appear to be trivial.

\subsubsection{Model testing}

It is very important to check whether our specification is preferable to ones in the existing empirical studies. A number of empirical studies estimate the reduced form, i.e., they regress the growth rate of GDP per worker on various economic variables including a measure of inequality. Column (2) in Table 5.4 presents estimation results of a typical growth regression using our data set. The problem about this kind of estimation is that the interpretation of the coefficient on GINI 65 , i.e., we do not know how inequality is affecting the growth rate of output. In any case, the coefficient on GINI $I_{65}$ is estimated to be negative but statistically insignificant. Some studies have found that it happens when regional dummies are included in the equation, implicating possible high correlation between inequality and the regional dummies. However, the results in Column (3) shows that this is not the 
case. Even when regional dummies are excluded from the equation, the estimate of the coefficient on $G I N I_{65}$ remains statistically insignificant. Again we observe improvement in a $t$ statistic of the distortion variable, which may imply its possible strong relationship with regional dummies. ${ }^{13}$ We conclude that, from this reduced form regression, we find no relationship between inequality and growth.

Table 5.6: Estimation results (continued)

\begin{tabular}{|c|c|c|c|c|c|c|}
\hline \multirow[b]{3}{*}{ Dependent variable } & \multicolumn{2}{|c|}{ Á la Perotti (1996) } & \multicolumn{2}{|c|}{ Á la Perotti (1996) } & \multicolumn{2}{|c|}{ Instrumenting $F E R T_{65-90}$} \\
\hline & & (5) & & (6) & & \\
\hline & $g_{65-90}$ & $F E D U_{65-90}$ & $g_{65}-90$ & $F E D U_{65-90}$ & $g 65-90$ & $F E D U_{65-90}$ \\
\hline \multirow[t]{2}{*}{$\ln y_{65}$} & -0.018 & 0.069 & -0.013 & 0.169 & -0.012 & \\
\hline & $(-4.202)$ & $(2.687)$ & $(-2.480)$ & $(6.507)$ & $(-3.263)$ & \\
\hline \multirow[t]{2}{*}{$P P P I_{65}$} & -0.004 & & -0.004 & & $=0.005$ & \\
\hline & $(-0.672)$ & & $(-0.687)$ & & $(-0.846)$ & \\
\hline$F E D U_{65-90}$ & $\begin{array}{c}0.051 \\
(3.338)\end{array}$ & & $\begin{array}{c}0.027 \\
(1.339)\end{array}$ & & $\begin{array}{c}0.025 \\
(2.018)\end{array}$ & \\
\hline$F E R T_{65-90}$ & & $\begin{array}{l}-0.107 \\
(-6.670)\end{array}$ & & & & $\begin{array}{c}-0.139 \\
(-10.27)\end{array}$ \\
\hline$F H C_{65}$ & & $\begin{array}{c}0.081 \\
(3.212)\end{array}$ & & $\begin{array}{c}0.094 \\
(2.792)\end{array}$ & & $\begin{array}{c}0.108 \\
(4.458)\end{array}$ \\
\hline$G I N I_{65}$ & & $\begin{array}{l}-0.001 \\
(-0.377)\end{array}$ & & $\begin{array}{c}-0.007 \\
(-3.518)\end{array}$ & & $\begin{array}{c}0.001 \\
(0.444)\end{array}$ \\
\hline \multicolumn{7}{|l|}{$F E R T_{65-90} G I N I_{65}$} \\
\hline$A S I A E$ & $\begin{array}{c}0.011 \\
(2.329)\end{array}$ & & $\begin{array}{c}0.014 \\
(3.043)\end{array}$ & & $\begin{array}{c}0.012 \\
(2.568)\end{array}$ & \\
\hline \multirow{2}{*}{$L A A M$} & -0.009 & & -0.012 & & -0.013 & \\
\hline & $(-1.999)$ & & $(-2.681)$ & & $(-3.296)$ & \\
\hline \multirow[t]{2}{*}{$S A F R I C A$} & -0.024 & & -0.027 & & -0.027 & \\
\hline & $(-3.594)$ & & $(-4.024)$ & & $(-4.326)$ & \\
\hline \multirow[t]{2}{*}{ constant } & 0.161 & 0.242 & 0.124 & -0.776 & 0.121 & 0.887 \\
\hline & $(5.128)$ & $(0.969)$ & $(3.457)$ & $(-3.163)$ & $(4.422)$ & $(10.81)$ \\
\hline Number of observations & 57 & 57 & 59 & 59 & 57 & 57 \\
\hline$R^{2}$ & 0.6420 & 0.8780 & 0.6902 & 0.7629 & 0.6751 & 0.8607 \\
\hline
\end{tabular}

One up-side of estimating the reduced form is that we could regard it as if GIN $I_{65}$ is capturing every effect of inequality upon growth. That is, although our specification allows us to tell how inequality affects growth - through human capital accumulation and the rate of fertility, there might be some other channels through which inequality could affect growth. ${ }^{14}$ One way to capture this possible effects of inequality is to introduce $G I N I_{65}$ in to the first equation of System (5.3). Column

${ }^{13}$ We come back to this issue in Subsection 5.4.4.

${ }^{14}$ See a review of the literature in Chapter 2. 
(4) presents the results of this estimation. The estimates for the second equation do not change as we did not introduce new instruments. As for the first equation, in comparison with our specification, note that the magnitude of the coefficient on $F E D U_{65-90}$ does not change much. This implies that the effect of inequality upon growth through human capital accumulation and fertility does not change much, either, even when the direct inequality effect is taken into account. The estimates of the coefficient on $G I N I_{65}$, which captures direct effects of inequality upon growth, is negative as we have expected, but is statistically insignificant. It appears the direct effect does not exist.

Finally, we compare our results with Perotti (1996). Column (5) in Table 5.6 presents estimation results based upon a model specification à la Perotti (1996). The important thing to note here is that Perotti (1996) does not treat FERT $65-90$ as an endogenous variable, although he follows the endogenous fertility approach. Therefore, in estimating Column (5), we do not use instruments to control for FERT $T_{65-90}$. Perotti (1996) also includes $\ln y_{65}$ (he uses $G D P_{65}$ ) but does not include the interaction term, FERT $T_{65-90} G I N I_{65}$, which is crucial to the non-monotonic nature of the effect of inequality upon growth. ${ }^{15}$ The estimates of coefficients on FERT $T_{65-90}$ and $F H_{65}$ are quite close to those in Perotti (1996), confirming that our data are similar to what he has used.

The estimate of the coefficient on $G I N I_{65}$ is negative but statistically insignificant, which is identical to what Perotti (1996) has found. ${ }^{16}$ Perotti (1996) argues that this is due to the inclusion of $F E R T_{65-90}$. That is, Perotti (1996) finds a negative and statistically significant coefficient on $G I N I_{65}$ if $F E R T_{65-90}$ is not included in the equation. He argues that, since in an endogenous fertility approach, investment in education is mainly dependent upon fertility, income distribution largely affects investment in education through its effects upon the rate of fertility. There-

\footnotetext{
${ }^{15}$ Another difference is that Perotti (1996) uses regional dummies in the second equation instead of using them in the first one. All regional dummies turn out to be insignificant for this specification.
}

${ }^{16}$ Recall our discussion in Subsections 2.3.11 and 2.3.12 in Chapter 2. 
fore, once $F E R T_{65-90}$ is controlled for, it is not surprising to see that inequality has no explanatory power. In fact, when we estimate the identical system without $F E R T_{65-90}$, we find a negative and significant (at 1 per cent) estimate of the coeffcient on GINI $I_{65}$. The results are presented in Column (6). However, the estimate of the coefficient on FEDU $65-90$ is statistically insignificant, and so is the effect of inequality through investment in human capital.

In any event, Perotti's (1996) argument sounds a little odd, as on one hand he claims that investment in human capital and fertility are jointly determined, whilst on the other hand he treats the former as endogenous and the latter as exogenous to the system. ${ }^{17}$ So in Column (7), we present estimation results when we instrument fertility (FERT $\left.T_{65-90}\right)$ in Column (5). ${ }^{18}$ This specification is the same as ours (See Column (1) in Table 5.4) except that it does not include the interaction term, FERT $T_{65-90} G I N I_{65}$, which captures the non-monotonic nature of the effects of inequality upon growth we have conjectured.

The estimate of the coefficient on $G I N I_{65}$ is positive, against our prediction, but is statistically insignificant. When we include the interaction term as in Column (1) in Table 5.4, estimates of coefficients on both $G I N I_{65}$ and $F E R T_{65-90} G I N I_{65}$ become statistically significant (at 5 per cent), and are in anticipated signs. The fact that inequality is not statistically significant just by itself, but is statistically significant with the interaction term, could be regarded as an indication that inequality has a non-monotonic impact upon growth. Having said so, however, there is no strong evidence that our specification is superior to other specifications on other statistical grounds.

In summary, our three-equation system, which is based upon the theoretical model and the conjecture from the previous chapter, gives us much clearer interpretation of the estimated coefficients. However, the question whether our specification is statistically preferred to other ones remains unsolved for future research.

\footnotetext{
${ }^{17}$ In fact, Perotti (1996) does not state which of these specifications is preferable.

${ }^{18} \ln _{65}$ is excluded from the second equation in order to make it similar to our specification.
} 


\subsubsection{Sensitivity of the results}

In concluding the empirical analysis, we check the sensitivity of these results. The results appear to be fairly robust to changes in specification we have discussed in Section 5.2 as well as to changes in the correction of the Gini coefficient data.

Table 5.7: Estimation results (continued)

\begin{tabular}{|c|c|c|c|c|c|c|}
\hline \multirow[b]{3}{*}{ Dependent variable } & \multicolumn{2}{|c|}{ No regional dummies } & \multicolumn{2}{|c|}{ No GINI adjustment } & \multicolumn{2}{|c|}{ No instruments } \\
\hline & & & & & & \\
\hline & $g_{65-90}$ & $F E D U_{65-90}$ & $965-90$ & $F E D U_{65-90}$ & $965-90$ & $F E D U_{65}-90$ \\
\hline \multirow[t]{2}{*}{$\ln y_{65}$} & -0.011 & & -0.012 & & -0.009 & \\
\hline & $(-2,472)$ & & $(-3.266)$ & & $(-1.517)$ & \\
\hline \multirow{2}{*}{$P P P I_{65}$} & -0.017 & & -0.005 & & -0.005 & \\
\hline & $(-2.608)$ & & $(-0.846)$ & & $(-1.046)$ & \\
\hline \multirow{2}{*}{$F E D U_{65-90}$} & 0.040 & & 0.025 & & 0.011 & \\
\hline & $(2.706)$ & & $(2.022)$ & & $(0.494)$ & \\
\hline \multirow[t]{2}{*}{$F E R T_{65-90}$} & & -0.533 & & -0.398 & & -0.145 \\
\hline & & $\begin{array}{c}(-2.301) \\
0.094\end{array}$ & & $\begin{array}{c}(-3.075) \\
0.098\end{array}$ & & $\begin{array}{c}(-0.990) \\
0.099\end{array}$ \\
\hline$F H C_{65}$ & & $(3.138)$ & & $(3.627)$ & & $(3.671)$ \\
\hline \multirow{2}{*}{$G I N I_{65}$} & & -0.040 & & -0.027 & & 0.002 \\
\hline & & $(-1.786)$ & & $(-1.874)$ & & $(0.139)$ \\
\hline$F_{E R T_{65-90} G I N I_{65}}$ & & $\begin{array}{c}0.010 \\
(1.729)\end{array}$ & & $\begin{array}{c}0.007 \\
(1.996)\end{array}$ & & $\begin{array}{l}-0.0001 \\
(-0.033)\end{array}$ \\
\hline \multirow[t]{2}{*}{$A S I A E$} & & & 0.012 & & 0.012 & \\
\hline & & & $(2.568)$ & & $(1.761)$ & \\
\hline \multirow[t]{2}{*}{$L A A M$} & & & -0.013 & & -0.015 & \\
\hline & & & $(-3.295)$ & & $(-3.660)$ & \\
\hline \multirow[t]{2}{*}{$S A F R I C A$} & & & -0.027 & & -0.029 & \\
\hline & & & $(-4.326)$ & & $(-4.590)$ & \\
\hline \multirow[t]{2}{*}{ constant } & 0.106 & 2,482 & 0.121 & 1.943 & 0.100 & 0.884 \\
\hline & $(3.365)$ & $(2.787)$ & $(4.425)$ & $(3.572)$ & $(2.482)$ & $(1.486)$ \\
\hline Number of observations & 57 & 57 & 57 & 57 & 57 & 57 \\
\hline$R^{2}$ & 0.3435 & 0.7762 & 0.6752 & 0.8345 & 0.6587 & 0.8564 \\
\hline
\end{tabular}

Column (8) in Table 5.7 shows that the results are fairly robust to the exclusion of regional dummies. The notable change here is that a price distortion variable turns statistically significant once regional dummies are excluded. ${ }^{19}$ It may be the case that the degree of price distortion is strongly correlated with regional dummies, and therefore it does not have any explanatory power in the first specification (Column (1)).

Regarding the inequality data, when values are expenditure based, we have added 6.6 to them as Deininger and Squire (1996) has suggested (see Section 5.3

\footnotetext{
${ }^{19}$ We observed a similar result when we compared Columns (2) and (3).
} 
for discussion). When we estimate our system without this correction (See Column (9)), we find no distinct differences between the results.

Column (10) shows the estimation results when no additional instruments are used to control for fertility in the system. We observe drastic changes. In particular, note that estimates of coefficients on fertility, inequality, and the interaction term of those two are not significant. This result may be suggesting that the instruments we have used could be appropriate. In fact, the Durbin-Wu-Hausman test reject the null hypothesis that both $F E R T_{65-90}$ and $F E R T_{65-90} G I N I_{65}$ are exogenous to the system at 10 per cent. ${ }^{20}$ Hence, our strong prior belief that fertility is endogenously determined with investment in human capital is statistically supported, although the level of significance is at 10 per cent.

Next, as we have discussed in Section 5.2, we now check if the use of aggregated education, instead of female education, will change the results. Column (11) in Table 5.8 shows that the results do not change much both in terms of magnitude of coefficients and the statistical significance, which is rather surprising given examples from existing studies.

When we look at the magnitude of the effects of inequality upon growth for each of the above specifications, we find little difference between them. Table 5.9 summarises the effects of a one standard deviation increase in the Gini coefficient upon the growth rate of real GDP per worker for a 57 country sample. The effects appear to be trivial in any case, the magnitude of the effects ranging between -0.02 and 0.06 percentage points.

Finally, we test the stability of coefficients across the OECD and the non-OECD subsamples. Column (12) and Column (13) present the estimation results for these two subsamples. ${ }^{21}$ As for the OECD subsample, signs of coefficients are estimated

${ }^{20} \mathrm{An} F$ statistic for this test is 2.75 and a $p$-value is 0.0738 . See Davidson and MacKinnon (1993, Chapter 7) for the Durbin-Wu-Hausman test.

${ }^{21}$ Note that regional dummies are dropped for the both columns. For Column (12) this is due to the fact that these dummies are all zero for the OECD countries. In order to make it consistent with Column (12), regional dummies are dropped in Column (13) as well. However, we keep using 
Table 5.8: Estimation results (continued)

\begin{tabular}{|c|c|c|c|c|c|c|}
\hline \multirow[b]{3}{*}{ Dependent variable } & \multirow{2}{*}{\multicolumn{2}{|c|}{$\begin{array}{c}\text { Aggregated education } \\
\text { (11) }\end{array}$}} & \multirow{2}{*}{\multicolumn{2}{|c|}{$\frac{\text { OECD only }}{(12)}$}} & \multirow{2}{*}{\multicolumn{2}{|c|}{$\frac{\text { Non-OECD only }}{\text { (13) }}$}} \\
\hline & & & & & & \\
\hline & $965-90$ & $E D U_{65-90}$ & $965-90$ & $F E D U_{65-90}$ & $965-90$ & $F E D U_{65-90}$ \\
\hline $\ln y 65$ & $\begin{array}{l}-0.011 \\
(-3.086)\end{array}$ & & $\begin{array}{l}-0.023 \\
(-5.903)\end{array}$ & & $\begin{array}{l}-0.015 \\
(-2.923)\end{array}$ & \\
\hline$P P P I_{65}$ & $\begin{array}{l}-0.004 \\
(-0.804)\end{array}$ & & $\begin{array}{l}-0.003 \\
(-0.204)\end{array}$ & & $\begin{array}{l}-0.012 \\
(-1.756)\end{array}$ & \\
\hline$F E D U_{65-90}$ & & & $\begin{array}{c}0.023 \\
(1.796)\end{array}$ & & $\begin{array}{c}0.072 \\
(2.433)\end{array}$ & \\
\hline$E D U_{65-90}$ & $\begin{array}{c}0.024 \\
(1.770)\end{array}$ & & & & & \\
\hline$F E R T_{65-90}$ & & $\begin{array}{l}-0.426 \\
(-3.456)\end{array}$ & & $\begin{array}{l}-0.696 \\
(-1.039)\end{array}$ & & $\begin{array}{c}0.488 \\
(1.265)\end{array}$ \\
\hline$F H C_{65}$ & & & & $\begin{array}{c}0.109 \\
(2.388)\end{array}$ & & $\begin{array}{l}-0.011 \\
(-0.065)\end{array}$ \\
\hline$H C_{65}$ & & $\begin{array}{c}0.074 \\
(2.801)\end{array}$ & & & & \\
\hline$G I N I_{65}$ & & $\begin{array}{l}-0.031 \\
(-2.462)\end{array}$ & & $\begin{array}{l}-0.030 \\
(-0.858)\end{array}$ & & $\begin{array}{c}0.078 \\
(1.624)\end{array}$ \\
\hline$F E R T_{65-90} G I N I_{65}$ & & $\begin{array}{c}0.007 \\
(2.407)\end{array}$ & & $\begin{array}{c}0.011 \\
(0.762)\end{array}$ & & $\begin{array}{l}-0.015 \\
(-1.579)\end{array}$ \\
\hline$A S I A E$ & $\begin{array}{c}0.013 \\
(2.784)\end{array}$ & & & & & \\
\hline LAAM & $\begin{array}{l}-0.012 \\
(-2.830)\end{array}$ & & & & & \\
\hline$S A F R I C A$ & $\begin{array}{l}-0.026 \\
(-4.051)\end{array}$ & & & & & \\
\hline constant & $\begin{array}{c}0.112 \\
(4.347)\end{array}$ & $\begin{array}{c}2.142 \\
(4.316)\end{array}$ & $\begin{array}{c}0.225 \\
(7.518)\end{array}$ & $\begin{array}{c}2.394 \\
(1.507)\end{array}$ & $\begin{array}{c}0.132 \\
(3.578)\end{array}$ & $\begin{array}{l}-2.258 \\
(1.200)\end{array}$ \\
\hline Number of observations & 58 & 58 & 19 & 19 & 38 & 38 \\
\hline$R^{2}$ & 0.6697 & 0.8250 & 0.7939 & 0.5850 & 0.3546 & 0.3490 \\
\hline $\begin{array}{l}\text { NB: Values in the paren } \\
\text { are heteroskedasticity-ro } \\
\text { secondary education and } \\
\text { with } F E R T_{60} \text { and } P O P_{6} \\
1960 \text {, and } E D U_{60} \text {, the } \\
\text { additional instruments fo }\end{array}$ & $\begin{array}{l}\text { eses are } \\
\text { 1st } t \text { stat } \\
\text { verage y } \\
H C_{60} \\
30 \text { value } \\
\text { Column }\end{array}$ & $\begin{array}{l}\text { statistics, b } \\
\text { stics. } E D U_{6} \\
\text { ars of second } \\
\text { erage years } \\
f \text { the total } 8 \\
\text { 1) estimatio }\end{array}$ & $\begin{array}{l}\text { t for thos } \\
-90 \text { and } \\
\text { ry schooli } \\
\text { f secondar } \\
\text { ss enrolm } \\
\text {, instead }\end{array}$ & $\begin{array}{l}\text { in the first e } \\
C_{65} \text { are the } \\
8 \text { in the total } \\
\text { schooling in } \\
\text { nt ratio for s } \\
F \mathrm{H}_{60} \text { and }\end{array}$ & $\begin{array}{l}\text { ation of } C \\
\text { tal gross } \\
\text { orking po } \\
\text { total wo } \\
\text { ondary scl } \\
\Xi D U_{60} \text {. }\end{array}$ & $\begin{array}{l}\operatorname{mn}(13), \text { whi } \\
\text { olment ratio f } \\
\text { lation. Togeth } \\
\text { ng population } \\
\text { ling are used }\end{array}$ \\
\hline
\end{tabular}

as anticipated, but most of the estimates including those of coefficients on GINI $I_{65}$ and FERT $T_{65-90}$ GIN $I_{65-90}$ are statistically insignificant. Regarding the non-OECD subsample, all of the estimates in the second equation turn out statistically insignificant and neither of them is in anticipated signs, the results which are difficult to interpret. The estimates of coefficients between the two subsamples appear to be quite different. In fact, the null hypothesis that all coefficients are stable across these subsamples is rejected at 1 per cent for each of the equations. ${ }^{22}$

regional dummies as instruments.

${ }^{22}$ Since we are using 2 SLS estimation, the Chow test using an ordinary $F$ statistic (also known as the Chow statistic) is invalid in this case. Therefore, we employ the analog of the ordinary $F$ 
Table 5.9: Effects of a one standard deviation increase in $G I N I_{65}$ upon $g_{65-90}$ for different specifications using a 57 country sample

\begin{tabular}{ccc}
\hline \hline Column in result tables & Change in FEDU $U_{65-90}$ & Change in $g_{65-90}$ \\
\hline$(1)$ & -0.007 & -0.0002 \\
$(8)$ & -0.014 & -0.0006 \\
$(9)$ & -0.008 & -0.0002 \\
$(10)$ & 0.015 & 0.0002 \\
$(11)$ & -0.022 & -0.0005 \\
\hline
\end{tabular}

NB: Values are evaluated at mean of a 57 country sample.

This result may be suggesting that the OECD subsample contains most of the economies that have already begun the demographic transition and that the non-OECD subsample contains most of the economies that have not begun the demographic transition. Recall that for the whole sample, the interaction term, FERT $T_{65-90} G I N I_{65}$, is included in estimation in order to capture (large) variation between economies across different demographic development stages. However, if each of the subsamples contains economies in the same stage of demographic development, variation between economies within each of the subsamples might not be so large. This may be the cause of this poor estimation result.

Not much of the empirical growth literature has, in fact, tested the stability of coefficients. Much of the growth literature has not reported anything on this matter (Alesina and Rodrik, 1994, Barro and Lee, 1994, Birdsall, 1995, Caselli et al., 1996, Perotti, 1994), or at most, it splits the sample according to some criteria but does not conduct any formal test to check the stability of coefficients across subsamples (Barro, 2000, Benhabib and Spiegel, 1994, Deininger and Squire, 1998, Galor and Zang, 1997, Mankiw et al., 1992, Perotti, 1996). ${ }^{23}$ This issue appears to require further investigation.

statistic, which is suggested by Davidson and MacKinnon (1993, Chapter 7). The statistics for the first and second equations are $29.31(3.72<F[4,46]<3.77)$ and $91.81(3.41<F[5,46]<3.46)$, respectively (relevant critical values at 1 per cent are in brackets).

${ }^{23}$ Forbes (2000) is the only inequality study that the author is aware of, which contains some formal testing for the stability of coefficients across subsamples. 


\subsection{Concluding Remarks}

This chapter has attempted to test a challenging conjecture from the previous chapter on a relationship between inequality and growth - inequality impedes growth for a country that has begun the demographic transition, but for a country that has not begun the demographic transition, it has no significant effects, and if any, the direction of the effect is ambiguous.

Using slightly different econometric specification from Perotti (1996), this chapter has shown that the effect of inequality upon growth is statistically significant and not negligible. Furthermore, the effects are shown to be dependent upon an economy's demographic stage of development - the non-monotonic nature of the effects of inequality upon growth is supported by the data.

We need to be cautious to state the above implication because of the following. First, this chapter particularly focussed upon human capital and fertility as economic factors that link inequality and economic growth. However, as a number of studies have shown, there are many other channels through which inequality might affect growth. This study does not encompass the effects of inequality upon growth through other possible channels (although we checked that the direct effect of inequality is not present in an ad hoc manner). Second, there may be a potential problem that coefficients are unstable across subsamples, where further research should be directed. 


\section{Chapter 6}

\section{Conclusion}

This chapter concludes the thesis. First, we summarise our findings emphasising our contribution to the literature. Then, we suggest some issues towards which further research should be directed.

\subsection{Summary of our findings}

\subsubsection{Inequality is important}

First, we have found that inequality is an important policy issue. Alongside of a number of studies we have reviewed in Chapter 2, this thesis has found that the effect of inequality upon growth is sizable.

\subsubsection{Challenging the common agreement}

Our thesis has confirmed that inequality is important, but in a different way from most of other studies. We have challenged the common agreement that the relationship between initial inequality and subsequent growth is negative, and have found the non-monotonic effect of inequality upon growth. In particular, whilst equality enhances growth in developed economies, inequality appears to enhance growth in less-developed economies. 


\subsubsection{Theoretical contribution}

In deriving this effect of inequality upon growth, we have particularly focussed upon investment in human capital and endogenous fertility as channels through which inequality affects growth. We have justified why we endogenise the fertility decision by individuals, emphasising a strong relationship between investment in human capital and fertility in Chapter 2. We have seen, in Chapter 2, that no theoretical study has attempted to deal simultaneously with inequality, fertility, investment in human capital, and growth. Our study has attempted to do this for the first time.

Our starting point (Chapter 3) was to incorporate endogenous fertility into the existing models that have dealt with inequality, human capital, and growth (Galor and Zeira, 1993, Galor and Zang, 1997). This extended theoretical model has turned out to produce negative growth in general, which is unrealistic. When we endogenise fertility and different individuals have different number of children, poor individuals who have many children eventually dominate the economy and per capita income is destined to decline. This chapter has made clear the limitations of the Galor and Zeira (1993) type of theoretical framework for growth analysis. We have also emphasised in Chapter 3 that inequality has been dealt with inappropriately. The definition of inequality in Chapter 3, as well as in Galor and Zeira (1993) and Galor and Zang (1997) is the share of unskilled individuals in the total population. We have pointed out that this definition is problematic.

Chapter 4 has overcome these problems. We have given a different interpretation to a model by Ehrlich and Lui (1991), which deals with human capital, fertility, and growth. Ehrlich and Lui (1991) look at an economy as a whole using a representative agent framework, but we have started with looking at heterogenous dynasties within an economy. Then, we have summed up these dynasties and focussed upon an economy as a whole. In this way, we incorporate inequality into their model, and it has enabled us to deal simultaneously with inequality, fertility, human capital, and growth. 
The model's new feature is endogenous growth. An economy could exhibit positive growth even in the long run, which is impossible in a framework as in Chapter 3. We have focussed upon economies under two regimes - before and after the productivity take-off. The former is characterised by zero per-capita output growth and positive population growth in the long run, whereas the latter is characterised by positive per-capita output growth and constant population in the long run. The former type of economy resembles an economy we have described in Chapter 3, but depending upon parameter values, the model can also produce positive long run growth, hence it overcomes one of the problems in Chapter 3 . We have also related these two regimes to demographic stages of development. More specifically, we have shown that the demographic transition is triggered by the productivity take-off.

The problem regarding the definition of inequality has been overcome by the use of the coefficient of variation in output, which is a typical measure of inequality in the literature. However, this has made further mathematical analysis too complex. We have used numerical simulations in analysing the effect of inequality upon growth. Since initial inequality is found to have no implication for growth in the long run, we have looked at growth during transition periods.

Our numerical simulations have conjectured the non-monotonic nature of the effect of inequality upon growth. The differences in (extremely) poor and (super) rich dynasties between countries are highlighted. Rich dynasties contribute positively to growth of output per worker but poor dynasties contribute negatively to it. We have conjectured that in a matured economy where income level is already high, the difference in rich dynasties does not matter that much but the difference in poor dynasties counts substantially, so more inequality leads to lower growth. In contrast, in an economy where income level is still not high enough, the difference in (super) rich dynasties also counts substantially so the overall effect is ambiguous. 


\subsubsection{Empirical findings and contribution}

Our analyses in Chapter 4 hinge critically upon parameter values we have assumed, so it is very important to test our conjecture against the real data. Chapter 5 has conducted the empirical analysis and has found some supportive evidence for our theoretical predictions.

Our prominent empirical contribution is that we estimated a structural econometric model based upon our theoretical model in Chapter 4. This has allowed us to interpret the result clearly, which has been impossible in studies that have estimated a reduced form growth equation.

Our system has taken into account that inequality affects growth through investment in human capital and fertility, and that fertility and investment in human capital are jointly determined, i.e., they are endogenous to the system. We have used the Durbin-Wu-Hausman test to check this endogeneity, and statistically shown that these variables are likely to be endogenous, which consolidates our prior belief through out this thesis.

The non-monotonic nature of the effect of inequality upon growth is supported by the data. We have used an interaction term between inequality and fertility to capture the different inequality effect according to different demographic stages of development. We have calculated the effect of a one standard deviation increase in inequality upon growth, as other studies have. When we evaluate this effect using the OECD subsample mean, it is a decrease in the growth rate by 0.28 percentage points, so inequality has a sizable negative impact upon growth for these economies. In contrast, when we evaluate this effect using the developing country subsample mean, it is an increase in the growth rate by 0.27 percentage points, so inequality has a sizable positive impact upon growth. 


\subsection{Further research directions}

We should be aware that there are some related issues this thesis does not encompass. In addition, some problems have been pointed out regarding our analyses in the previous chapters. Let us conclude this thesis by listing them where further research should be directed.

This study has consolidated the understanding that inequality is an important policy issue - the effect of inequality upon growth is non-trivial. We would like to ask then "what should the governments do in order to promote growth?" Unfortunately, the models we have dealt with do not have a government sector, so we cannot comment too much on this matter. We can only say that if an economy has not begun the demographic transition, policies that make it begin the demographic transition are in demand. We might be able to incorporate a government sector explicitly into the model, in which it collects tax and redistributes the revenue in terms of health expenditure or alternatives. As is pointed out in footnote 19 in Chapter 4, a significant increase in $\pi_{1}$, the probability of survival for children can make an economy begin the demographic transition. A government policy to improve health care could be modelled relating health expenditure and $\pi_{1}$, and its implementation might be justified on the grounds that it might enable an economy to begin the demographic transition.

Let us discuss another point regarding theoretical modelling. We have pointed out that the major problem in Chapter 4 is that there is no interaction between individuals. This nature of the model can be prone to a criticism that an economy does not mean anything. Incorporating externality in education might be a way to get round with this problem. If positive externality of education is present, we can define an economy as a set of people who can benefit from one another. Of course, this will make the model much more complicated, and the analytical solutions for the dynamics of an economy might not be obtained. Nevertheless, this is a very interesting issue to pursue as the long run implication will be much different under this situation. That is, poor dynasties will jump above the threshold level 
eventually, enjoying the externality effect from rich dynasties, so even in a regime we described as before the productivity take-off (Case I), an economy can begin the demographic transition and exhibit positive long run growth.

Let us now turn to discuss empirical aspects. In Chapter 5, we have conducted sensitivity analysis to check the robustness of our estimation results. Our results are found to be robust except when we divide our sample into OECD and non-OECD subsamples. We have statistically rejected the stability of coefficients across two subsamples at 1 per cent. We have pointed out the possibility that there might not be enough variation between countries within each of the subsamples, which could have lead to the poor estimation results. We also have pointed out that not much of the empirical growth literature has tested the stability of coefficients, but has tend to try to increase the number of observations instead. It appears we need to wait until further data become available so that enough variation between observations can be seen within each of the subsamples.

Another interesting empirical discussion stems from a study by Forbes (2000) that looks at the effect of inequality upon growth in the short run (5 years). The use of panel estimation enables Forbes (2000) to control for time-invariant countryspecific effects, which in turn, eliminates a potential source of omitted-variable bias. Our study has focussed upon long run growth since one period is 25 years in our theoretical model. There is no reason to assume that time-invariant country-specific effects do not exist, but again, due to limited data our estimation is restricted to cross-sectional, which cannot take country-specific effects into account. It requires us to wait until further data become available to conduct panel estimation to assess the long run relationship between inequality and growth.

Finally, we should emphasise that this study has focussed upon only one mechanism by which inequality affects growth. As we have reviewed in Chapter 2, there might be many other channels through which inequality affects growth. All the existing theoretical studies we have reviewed predict a negative relationship between inequality and long run growth, so in theory, we expect that overall effect 
of inequality upon growth is negative. However, empirical results have not been that convincing in supporting these theories, so in practice, we are still not quite sure about the overall effect. In addition, other channels that have not been proposed might exist. Inequality works through all these channels, including the one we looked at, and affects long run growth.

At present, the common agreement on the relationship between inequality and growth is that inequality harms growth in all cases. However, it appears the relationship is much more complicated. This study has clearly cast doubt upon the common agreement and induced needs for further investigation in this research area. 


\section{Bibliography}

Acemoglu, Daron (1995). "Reward Structures and the Allocation of Talent," European Economic Review, Vol. 39, pp. 17-33.

Aghion, Philippe and Patrick Bolton (1997). "A Theory of Trickle-Down Growth and Development," Review of Economic Studies, Vol. 64, pp. 151-72.

Alesina, Alberto and Dani Rodrik (1994). Distributive Politics and Economic Growth," Quarterly Journal of Economics, Vol. 109, pp. 465-90.

and Roberto Perotti (1996). "Income Distribution, Political Instability, and Investment," European Economic Review, Vol. 40, pp. 1203-28.

Anand, Sudhir and R.S.M. Kanbur (1993). "Inequality and Development: A Critique," Journal of Development Economics, Vol. 41, pp. 19-43.

Arellano, Manuel and Stephen Bond (1991). "Some Tests of Specification for Panel Data: Monte Carlo Evidence and an Application to Employment Equations," Review of Economic Studies, Vol. 58, pp. 277-97.

Banerjee, Abhijit V. and Andrew F. Newman (1993). "Occupational Choice and the Process of Development," Journal of Political Economy, Vol. 101, pp. 274-98.

Barro, Robert J. (1991). "Economic Growth in a Cross Section of Countries," Quarterly Journal of Economics, Vol. 106, pp. 407-43.

(2000). "Inequality and Growth in a Panel of Countries," Journal of Economic Growth, Vol. 5, pp. 5-32. 
and Gary S. Becker (1989). "Fertility Choice in a Model of Economic Growth," Econometrica, Vol. 57, pp. 481-501.

and Jong-Wha Lee (1993). "International Comparisons of Educational Attainment," Journal of Monetary Economics, Vol. 32, pp. 362-94.

and (1994). "Sources of Economic Growth," CarnegieRochester Conference Series on Public Policy, Vol. 40, pp. 1-46.

and Xavier Sala-i-Martin (1995). Economic Growth. Singapore: McGraw-Hill.

Becker, Gary S. (1960). "An Economic Analysis of Fertility," in A. J. Coale (ed.), Demographic and Economic Change in Developed Countries. Princeton: Princeton University Press.

and Robert J. Barro (1988). "A Reformulation of the Economic Theory of Fertility," Quarterly Journal of Economics, Vol. 103, pp. 1-25.

, Kevin M. Murphy and Robert Tamura (1990). "Human Capital, Fertility, and Economic Growth," Journal of Political Economy, Vol. 98, pp. S1237.

Bénabou, Roland (1993). "Working of a City: Location, Education, and Production," Quarterly Journal of Economics, Vol. 108, pp. 619-52.

(1996a). "Equity and Efficiency in Human Capital Investment: The Local Connection," Review of Economic Studies, Vol. 63, pp. 237-64.

(1996b). "Heterogeneity, Stratification, and Growth: Macroeconomic Implication of Community Structure and School Finance," American Economic Review, Vol. 86, pp. 584-609.

(1996c). "Inequality and Growth," NBER Macroeconomics Annual, pp. $11-74$. 
Benhabib, Jess and Aldo Rustichini (1996). "Social Conflict and Growth," Journal of Economic Growth, Vol. 1, pp. 125-42.

and Mark M. Spiegel (1994). "The Role of Human Capital in Economic Development: Evidence from Aggregate Cross-Country Data," Journal of Monetary Economics, Vol. 34, pp. 143-73.

Bertola, Giuseppe (1993). "Factor Shares and Savings in Endogenous Growth," American Economic Review, Vol. 83, pp. 1184-98.

Birdsall, Nancy, David Ross and Richard Sabot (1995). "Inequality and Growth Reconsidered: Lessons from East Asia," World Bank Economic Review, Vol. 9, pp. $477-508$.

Blanchard, Olivier Jean and Stanley Fischer (1989). Lectures on Macroeconomics. Cambridge: MIT Press.

Bourguignon, François (1981). "Pareto Superiority of Unegalitarian Equilibria in Stiglitz" Model of Wealth Distribution with Convex Saving Function," Econometrica, Vol. 49, pp. 1469-75.

Brander, James A. and Steve Dowrick (1994). "The Role of Fertility and Population in Economic Growth," Journal of Population Economics, Vol. 7, pp. 1-25.

Caselli, Francesco, Gerardo Esquivel and Fernando Lefort (1996). "Reopening the Convergence Debate: A New Look at Cross-Country Growth Empirics," Journal of Economic Growth, Vol. 1, pp. 363-89.

Clarke, George R.G. (1995). "More Evidence on Income Distribution and Growth," Journal of Development Economics, Vol. 47, pp. 403-27.

Davidson, Russell and James G. MacKinnon (1993). Estimation and Inference in Econometrics. New York: Oxford University Press.

Deininger, Klaus and Lyn Squire (1996). "A New Data Set Measuring Income Inequality," The World Bank Economic Review, Vol. 10, pp. 565-91. 
and (1998). "New Ways of Looking at Old Issues: Inequality and Growth," Journal of Development Economics, Vol. 57, pp. 259-87. Dowrick, Steve and John Quiggin (1994) "Convergence in Living Standards: A Non-parametric Approach," Centre for Economic Policy Research Discussion Paper, no. 309, The Australian National University. and (1997). "True Measures of GDP and Convergence," American Economic Review, Vol. 87, pp. 41-64. and Guy Bruten (2000). "True International Comparisons of GDP: Correcting for Substitution Bias in Standard Measures of 'Real' GDP," Mimeograph.

Durlauf, Steven N. (1994). "Spillovers, Stratification, and Inequality," European Economic Review, Vol. 38, pp. 836-45.

Easterly, William and Ross Levine (1997). "Africa's Growth Tragedy: Policies and Ethnic Divisions," Quarterly Journal of Economics, Vol. 112, pp. 1203-50.

Ehrlich, Isaac and Francis T. Lui (1991). "Intergenerational Trade, Longevity, and Economic Growth," Journal of Political Economy, Vol. 99, pp. 1029-59.

Fernandez, Raquel and Richard Rogerson (1996). "Income Distribution, Communities, and the Quality of Public Education," Quarterly Journal of Economics, Vol. 111, pp. 135-64.

Forbes, Kristin J. (2000). "A Reassessment of the Relationship Between Inequality and Growth," American Economic Review, Vol. 90, pp. 869-87.

Galor, Oded and Hyoungsoo Zang (1997). "Fertility, Income Distribution, and Economic Growth: Theory and Cross-country Evidence," Japan and the World Economy, Vol. 9, pp. 197-229. and Joseph Zeira (1993). "Income Distribution and Macroeconomics," Review of Economic Studies, Vol. 60, pp. 35-52. 
Grossman, Herschel I. (1991). "A General Equilibrium Model of Insurrections," American Economic Review, Vol. 81, pp. 912-21.

(1994). "Production, Appropriation, and Land Reform," American Economic Review, Vol. 84, pp. 705-12.

and Minseong Kim (1996). "Predation and Accumulation," Journal of Economic Growth, Vol. 1, pp. 333-50.

Jodice, D. and D. L. Taylor (1988). World Handbook of Social and Political Indicators. New Haven: Yale University Press.

Kaldor, Nicholas (1961). "Capital Accumulation and Economic Growth," in D. C. Hague (ed.), The Theory of Capital. London: Macmillan.

Kelley, Allen C. (1988). "Economic Consequences of Population Change in the Third World," Journal of Economic Literature, Vol. 26, pp. 1685-728.

Kuznets, Simon (1955). "Economic Growth and Income Inequality," American Economic Review, Vol. 45, pp. 1-25.

Li, Hongyi and Heng-fu Zou (1998). "Income Inequality is not Harmful for Growth: Theory and Evidence," Review of Development Economics, Vol. 2, pp. 318-34.

Mankiw, Gregory N., David Romer and David N. Weil (1992). "A Contribution to the Empirics of Economic Growth," Quarterly Journal of Economics, Vol. 107, pp. $407-37$.

Murphy, Kevin M. Andrei Shleifer and Rovert W. Vishny (1993). "Why is RentSeeking So Costly to Growth?," American Economic Review, Vol. 83, pp. 409-13.

North, Douglass C. (1981). Structure and Change in Economic History. New York: Norton.

Perotti, Robert (1993). "Political Equilibrium, Income Distribution, and Growth," Review of Economic Studies, Vol. 60, pp. 755-76. 
(1994). "Income Distribution and Investment," European Economic Review, Vol. 38, pp. 827-35.

(1996). "Growth, Income Distribution, and Democracy: What the Data Say," Journal of Economic Growth, Vol. 1, pp. 149-87.

Persson, Torsten and Guido Tabellini (1992a). "Growth, Distribution and Politics," in Alex Cukierman, Zvi Hercowitz, and Leonardo Leiderman (eds.), Political Economy, Growth, and Business Cycles. Cambridge: MIT Press. and (1992b). "Growth, Distribution and Politics," European Economic Review, Vol. 36, pp. 593-602. and (1994). "Is Inequality Harmful for Growth?," American Economic Review, Vol. 84, pp. 600-21.

Piketty, Thomas (1997). "The Dynamics of the Wealth Distribution and the Interest Rate with Credit Rationing," Review of Economic Studies, Vol. 64, pp. 173189.

Ray, Debraj (1998). Development Economics. Princeton: Princeton University Press.

Saint-Paul, Gilles and Thierry Verdier (1997). "Power, Distributive Conflicts, and Multiple Growth Paths," Journal of Economic Growth, Vol. 2, pp. 155-68.

Stiglitz, J. E. (1969). "Distribution of Income and Wealth among Individuals," Econometrica, Vol. 37, pp. 382-97.

Summers, Robert and Alan Heston (1995). "Penn World Table (Mark 5.6a)," Electronic Data Set.

Temple, Jonathan (1999) "The New Growth Evidence," Journal of Economic Literature, Vol. 37, pp. 112-56. 
Tornell, Aaron and Andrés Velasco (1992). "The Tragedy of the Commons and Economic Growth: Why Does Capital Flow from Poor to Rich Countries?," Journal of Political Economy, Vol. 100, pp. 1208-31. 